\title{
UPPER MANTLE SHEAR WAVE VELOCITY STRUCTURE OF THE EAST ANATOLIAN-CAUCASUS REGION
}

A Dissertation Presented to

The Faculty of Graduate School

University of Missouri-Columbia

In Partial Fulfillment

Of the Requirements for the Degree of

Doctor of Philosophy

\begin{abstract}
by
GLEB ANATOLYEVICH SKOBELTSYN
\end{abstract}

Dr. Eric Sandvol, Dissertation Supervisor

May, 2014 
Then undersigned, appointed by the Dean of the Graduate School, have examined the

dissertation entitled

\title{
UPPER MANTLE SHEAR WAVE VELOCITY STRUCTURE OF THE EAST ANATOLIAN-CAUCASUS REGION
}

\author{
Presented by Gleb Anatolyevich Skobeltsyn, \\ a candidate for the degree of Doctor of Philosophy of Geological Sciences,
}

and hereby certify that, in their opinion, it is worthy of acceptance.

\begin{tabular}{c}
\hline Professor Eric Sandvol \\
\hline Professor Robert Bauer \\
\hline Professor Francisco Gomez \\
\hline Professor Mian Liu
\end{tabular}

Professor Brent Rosenblad 


\section{ACKNOWLEDGEMENTS}

I would like to thank all the people without whose support this $\mathrm{PhD}$ dissertation would not be possible.

First, I would like to express my gratitude to my parents Larisa Skobeltsyna and Anatoliy Puzyrev. Their love and moral support gave me the necessary strength to overcome the difficulties, which I encountered during my $\mathrm{PhD}$ program.

Second, I would like to thank my PhD advisor Eric Sandvol for his immense help and participation in my project. The amount of the student-advisor interaction was simply astronomical. It allowed me to learn many new and useful skills necessary for the development of my future career. I appreciate all your advices that you have given to me during the period of my PhD study.

I would also like to thank my committee members Dr. Robert Bauer, Dr. Francisco Gomez, Dr. Mian Liu, and Dr. Brent Rosenblad for the time they allowed in their busy schedule in order to provide critical and helpful comments that led to major improvements of this dissertation.

I am also very grateful to Alan Wittington and Peter I. Nabelek for their help and advice related to geochemistry of igneous rocks.

In addition, I would like to thank the current and already graduated students and employees of the Department of Geological Sciences of the University of MissouriColumbia Qie Zhang, Xueyang Bao, Savas Ceylan, Xiaofeng Liang, Frank Calixto, Geneviève Robert, and Ashraf Gafeer for their advice and help in the preparation of some of the material for this dissertation. 


\section{TABLE OF CONTENTS}

ACKNOWLEDGEMENTS ii

TABLE OF CONTENTS iii

LIST OF FIGURES AND TABLES................................................................... vi

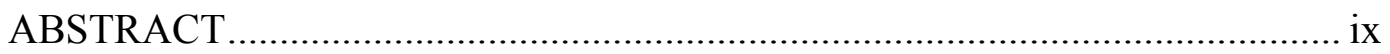

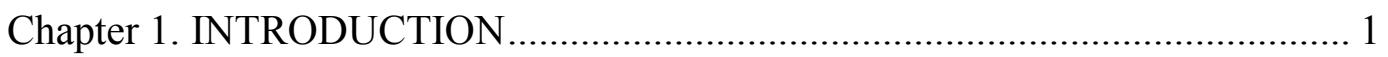

1.1. Neotectonics and the key geophysical observations in the Eastern

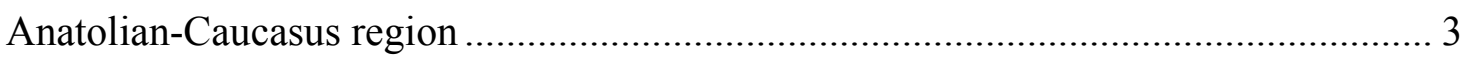

1.1.1. Geophysical observations and volcanism in the Eastern Anatolia ........ 6

1.1.2. Geodynamic models of the late Cenozoic tectonic evolution of the

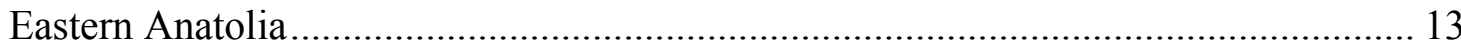

1.1.3. Uplift, volcanism, and geophysical observations in the Greater Caucasus

1.2. Methods applied in the research of the regional upper mantle $S$ wave

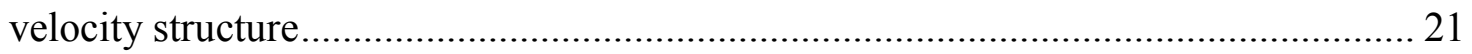

1.2.1. Two-plane Rayleigh wave tomography ………..................................... 23

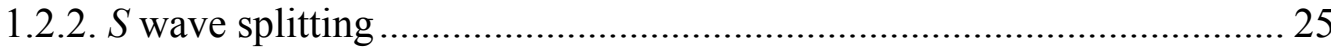

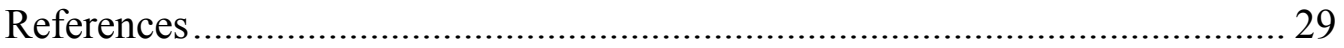

Chapter 2. UPPER MANTLE $S$ WAVE VELOCITY STRUCTURE OF THE EASTERN ANATOLIAN-CAUCASUS REGION ${ }^{1}$ 
Abstract

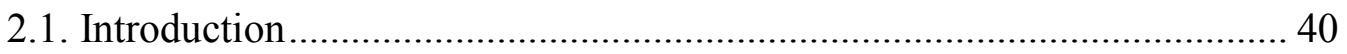

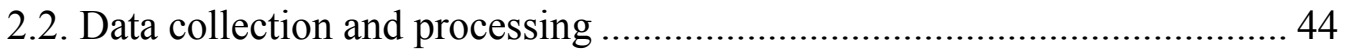

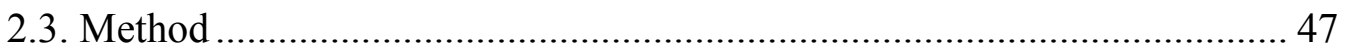

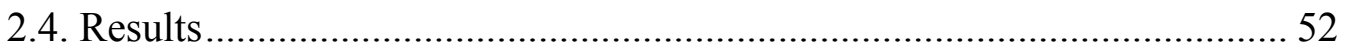

2.4.1. 1-D Rayleigh wave phase and $S$ wave velocity models...................... 52

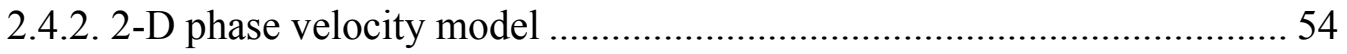

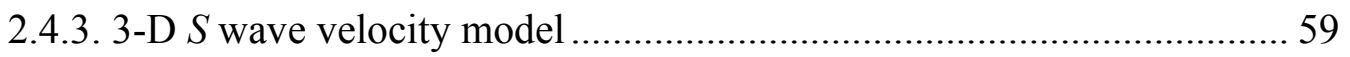

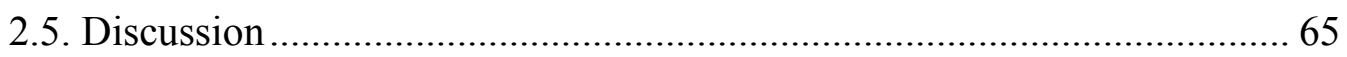

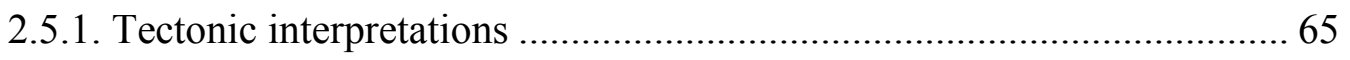

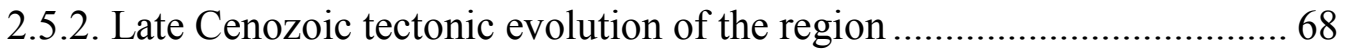

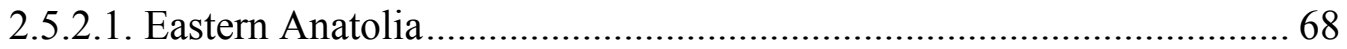

2.5.2.2. Lesser and Greater Caucasus/Kura basin.................................... 72

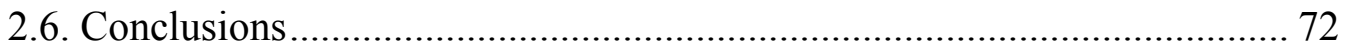

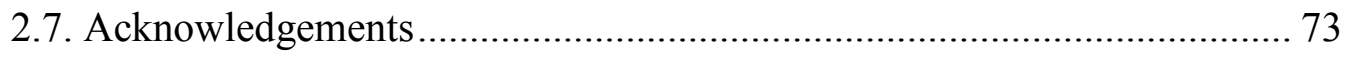

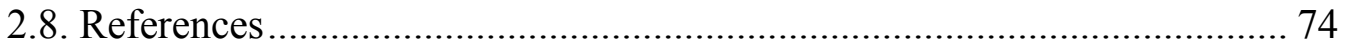

2.9. Appendix 2A1: Non-uniqueness in inversion of Rayleigh wave phase velocities as a function of period to $S$ wave velocities as a function of depth............ 80

Chapter 3. SHEAR WAVE SPLITTING IN THE EASTERN ANATOLIAN-

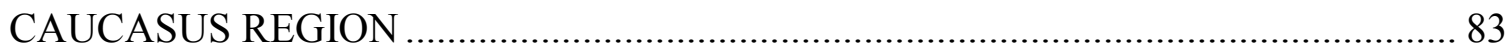


Abstract 83

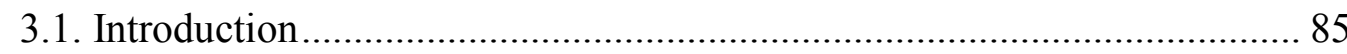

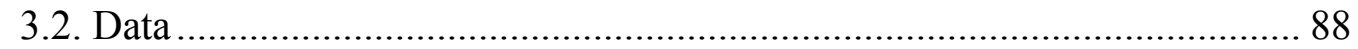

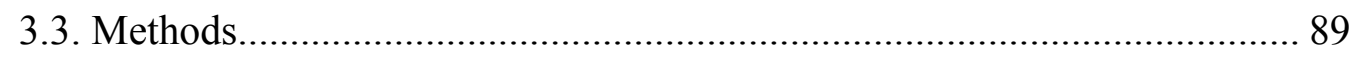

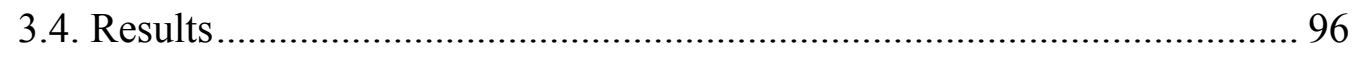

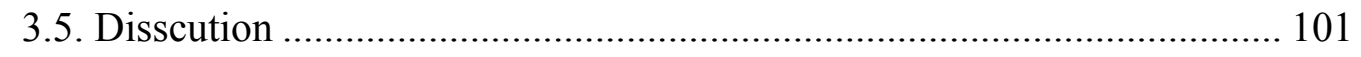

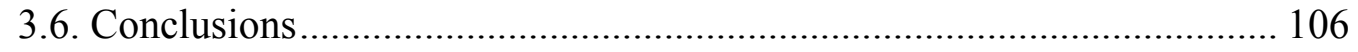

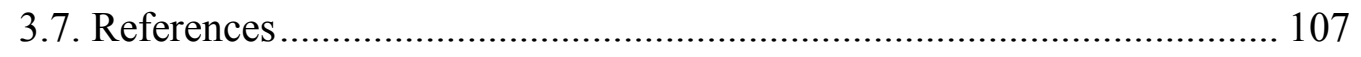

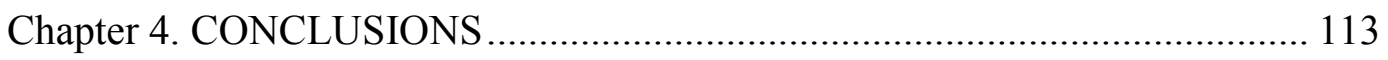

4.1. Eastern Anatolian, north Iranian Plateaus, and Lesser Caucasus ............ 114

4.2. The Greater Caucasus region ................................................................ 116

4.3. Possible future work ..................................................................... 118

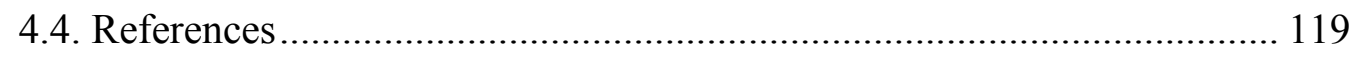

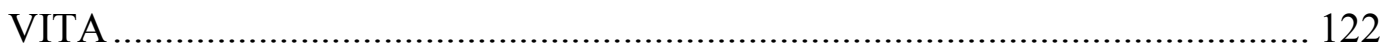




\section{LIST OF FIGURES AND TABLES}

Figure

Figure 1.1. Map showing shaded topography and the major tectonic boundaries in

Arabia-Eurasia collision zone.................................................4

Figure 1.2. Topographic map showing the locations of the broadband seismometers used

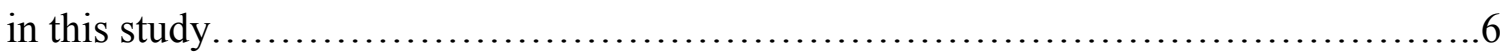

Figure 1.3. A map of Moho depths in the Eastern Anatolian-Caucasus region.............8

Figure 1.4. Map showing Sn efficiency tomography results........................10

Figure 1.5. A map showing inverted tomographic image of Pn velocity of the Middle

East..........................................................................

Figure 1.6. Map of shaded topography showing the regional locations of subcrustal earthquakes.................................................................. 11

Figure 1.7. Map showing the relationship between $S$ wave splitting results of Sandvol et al., [2003b] and GPS vectors [Reilinger et al., 2006] of the absolute plate motions.....12

Figure 2.1. Map showing the major tectonic boundaries in eastern Turkey and the

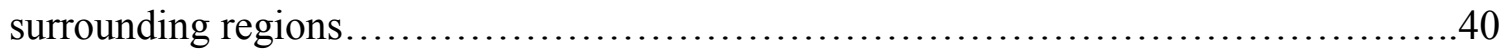

Figure 2.2. Topographic map showing the locations of the broadband seismometers used

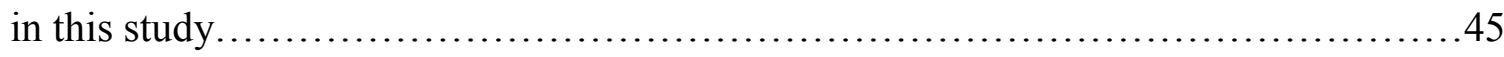

Figure 2.3. World map showing the epicenters of selected teleseismic earthquakes.....47

Figure 2.4. Average dispersion curve in the study area...........................49

Figure 2.5. One-dimensional shear wave velocity model of the region...............52 
Figure 2.6. Average dispersion curve in the Eastern Anatolia

Figure 2.7. Average dispersion curve in the eastern Caucasus region.................54

Figure 2.8. Checkerboard test results of Rayleigh wave phase velocity resolution......57

Figure 2.9. Maps of fundamental mode Rayleigh wave phase velocity for different

periods............................................................... 58

Figure 2.10. Average Rayleigh wave azimuthal anisotropy in the region...............59

Figure 2.11. Maps of shear wave velocity perturbations that are calculated relative to the average shear wave velocity at the depth...................................61

Figure 2.12. Vertical N-S cross sections showing shear wave velocities, and their perturbations relative to the average shear wave velocity at the depth............... 62

Figure 2.13. Three-dimentional views of iso surfaces...........................63

Figure 2.14. Schematic cross sections showing tectonic evolution of the Anatolian plateau in eastern Turkey from the Eocene to the present...........................71

Figure 2A1. Non-uniqueness in the inversion of the theoretical Rayleigh wave phase

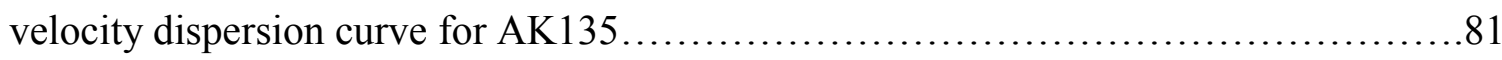

Figure 2A2. Non-uniqueness in the inversion of the regional phase velocity dispersion

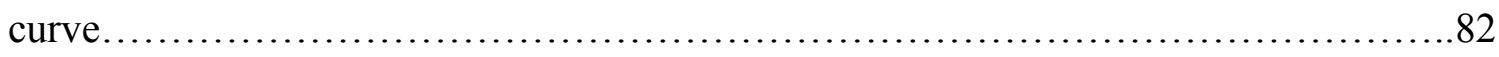

Figure 3.1. World map showing the epicenters of selected teleseismic earthquakes.......89

Figure 3.2. Illustration of the visual data quality control.........................92

Figure 3.3. Dependence of synthetic splitting observations from two-layer anisotropic structure on the characteristic period and noise level...........................93 
Figure 3.4. The fit of the $S$ wave splitting synthetic results derived using method of $A b t$ and Fisher [2008] (green) to the synthetic results generated by the grid search approach.

Figure 3.5. Teleseismic $S$ wave splitting results of the method of Silver and Chan [1991]. .97

Figure 3.6. Teleseismic $S$ wave splitting results of the method of Wolfe and Silver [1998].

Figure 3.7. The fit of the $S$ wave splitting results for station GAN to the synthetic results. 100

Figure 3.8. Two layer splitting results. 100

Figure 3.9. Local $S$ wave splitting parameters in comparison with the top layer anisotropy.

Figure 3.10. Average Rayleigh wave azimuthal anisotropy in the Eastern Anatolian

Plateau .102

Figure 3.11. Average Rayleigh wave azimuthal anisotropy in Azerbaijan .103

Figure 4.1. The differences between the geodynamic model proposed by Barazangi et al. [2006] and the model proposed in the present dissertation.... 115

Table

Table 1.1. Relationship between the fabrics of olivine, the dominant slip systems, and the fast polarization direction of a vertically traveling $S$ wave. 


\title{
UPPER MANTLE S WAVE VELOCITY STRUCTURE OF THE EASTERN ANATOLIAN-CAUCASUS REGION
}

\author{
Gleb Skobeltsyn
}

Dr. Eric Sandvol, Dissertation Supervisor

\begin{abstract}
The Eastern Anatolian-Caucasus region is a relatively young part of the AlpineHimalayan orogenic belt and has been formed as the result of the ongoing continental collision of Arabia and Eurasia. In spite of a number of geological studies that have been conducted in this area, there is still no consensus within the geoscience community about the regional tectonic settings and a model for the late Cenozoic tectonic evolution of the Anatolian Plateau. Knowledge of the upper mantle velocity structure in this region can provide the geological community with important constraints that are crucial for developing an understanding of the regional geology and the processes associated with early stages of mountain building.

In the present dissertation, I describe two studies of the regional upper mantle $S$ wave velocity structure. In order to derive the absolute velocity structure of the upper mantle, I have applied surface wave tomography to model Rayleigh wave phase velocities as a function of period. Then I inverted the Rayleigh phase velocities to obtain $S$ wave velocities as a function of depth. The resulted high-resolution 3-D $S$ wave velocity model of the regional upper mantle is characterized by a better depth resolution than any preexisting tomographic models. I also conducted an $S$ wave splitting analysis using traditional methods and developed a two-layer grid search algorithm in order to ix
\end{abstract}


infer the upper mantle anisotropic structure. The results of the $S$ wave splitting analysis for the stations located in Azerbaijan are the first in the region.

The $S$ wave tomographic model demonstrates a thin to absent mantle lid beneath the Eastern Anatolian Plateau, north Iranian Plateau, and most of the Lesser Caucasus. My model shows the depth extent of the asthenospheric layer beneath the Turkish and Iranian Plateaus, which does not exceed $200 \mathrm{~km}$ and therefore rejects any suggestions of the existence of deep mantle plums in the area. I interpret the deep high velocity bodies identified beneath the Black Sea and northern Iranian Plateau as the remnant slabs of the northern and southern braches of the Neo-Tethys lithosphere, which serve as an important new evidence of the existence of the double subduction zone prior to the initiation of the continental collision. Furthermore, the similar depths of these remnant slabs suggest that the detachment of both of them happened at approximately the same time. As a result, I propose a new geodynamic model for Eastern Anatolian Plateau, which explains the widespread collision-related volcanism and the uplift within the plateau by a gradual steepening of the subducting slab of the southern branch of NeoTethys. Furthermore, my model shows a well-developed north dipping lithospheric structure beneath the eastern Greater Caucasus and Kura Basin that serves as an evidence for the ongoing subduction of the Kura Basin lithosphere under the Scythian Platform. The results of the $S$ wave splitting analysis show evidence of the two-layer anisotropic structure beneath the eastern Caucasus region with the fast polarization directions parallel to the strike of the mountain range in the top layer. The orogen-parallel fast directions are consistent with the olivine fabrics developed as the results of the compressional stress caused by the subduction the Kura Basin lithosphere beneath Scythian Platform. 


\section{Chapter 1}

\section{INTRODUCTION}

Orogenic belts occupy at least 20 percent of the area of the continents. The collisional orogenic belts are perhaps the most geologically complicated as their structures involve the terrains, which were accreted during both the subduction, and the closure of oceanic basins. Furthermore, the complex collage of accreted terrains can undergo quite significant changes through volcanism and deformation, which are related to the upper mantle geodynamic processes that have occurred since the initiation of the continental collision. Understanding and identifying the processes that occur at the early stages of continental collision are crucial to the understanding of the tectonic history of these regions.

The Eastern Anatolian-Caucasus region is a relatively young part of the AlpineHimalayan orogenic belt, which, in the author's opinion, is the most prominent example of the active continental tectonics. Because of the relatively short time that has passed since the initiation of the continental collision, the Eastern Anatolian-Caucasus region is a perfect candidate for studying the early stages of mountain building; however, in spite of a number of geological studies that have been done in this area, its neotectonic upper mantle geodynamic processes are still poorly understood and there is no consensus within the scientific community about a single viable model of the late Cenozoic tectonic evolution of this region.

The results of the geochemical, structural, stratigraphic, and geophysical studies of the crust of the Eastern Anatolian-Caucasus region allow us to infer recent tectonic 
evolution of this area. Yet, understanding of the crustal geological structure alone without the knowledge of the upper mantle structure would not provide a complete understanding of the regional upper mantle structure and therefore the late Cenozoic regional tectonic history. Knowledge of the velocity structure of the upper mantle in the Eastern Anatolian-Caucasus region can provide the geological scientific community with important constraints that cannot be obtained elsewhere. Furthermore, the upper mantle regional velocity structure can play an important role in determining the necessary constraints for geodynamic modeling of the tectonic evolution of this region.

This research focuses on two major characteristics of the upper mantle velocity structure of the Eastern Anatolian-Caucasus region: a 3-D $S$ wave velocity model derived from Rayleigh wave tomography, and $S$ wave polarization anisotropy. While the upper mantle 3-D $S$ wave velocity model can give us an estimate of the spatial distribution of the lithosphere and asthenosphere in this region, the azimuthal $S$ wave velocity anisotropy can allow us infer the regional upper mantle flow - a very important clue into the role the asthenospheric flow has had on the formation of this young plateau (e.g Eastern Anatolian Plateau and Lesser Caucasus).

This dissertation is structured as follows: in Chapter 1 (this chapter), I describe the key geological and geophysical observations in the study region, as well as the competing models for its neotectonic evolution. Next, I provide a brief theoretical background for the surface wave tomography and $S$ wave splitting methods, which I applied in this research and compare their benefits with those of the other seismic techniques used in the study area. In Chapter 2, I present the results of the Rayleigh wave tomography in the Eastern Anatolian-Caucasus region and discuss a possible model of 
the late Cenozoic regional tectonic evolution based on these results. Finally, in Chapter 3, I present the results of the $S$ wave splitting analysis combined with the results of the previous $S$ wave splitting study conducted in the research area and discuss the possible mechanisms of the upper mantle deformation.

\subsection{Neotectonics and the key geophysical observations in the Eastern Anatolian- Caucasus region}

The Eastern Anatolian-Caucasus region (Figure 1.1) is a part of a relatively young ongoing continent-continent collision of the Arabian and Eurasian Plates, which is often compared to the early stage of evolution of another part of the Alpine-Himalayan orogenic belt, the collision zone between India and Eurasia [e.g., Şengör and Kidd, 1979; Dewey et al., 1986]. The main topographic features of the study region include the Eastern Anatolian and north Iranian Plateaus, Talesh (Talysh) and Alborz Mountains, the Kura Basin, and the Greater and Lesser Caucasus mountain belts, as well as parts of the Black Sea and south Caspian Basin. The regional high topography is believed to be a direct result of the stresses that affected the crust and were produced by the processes associated with the continental collision [e.g., Barazangi et al., 2006].

Prior to the initiation of the continental collision between Arabia and Eurasia, throughout the Mesozoic and most of the Cenozoic, two converging supercontinents, Gondwana in the south and Eurasia in the north, were separated first by the Paleo-Tethys Ocean and, subsequently, by two branches of the Neo-Tethys Ocean [Şengör and Yilmaz, 1981]. The northern oceanic branch of the Neo-Tethys lithosphere was subducted beneath 
the southern margin of Eurasia, i.e., the Pontides, producing arc and back-arc volcanism, and was completely closed in the late Eocene [Şengör and Yilmaz, 1981; Dewey et al., 1986] creating a vast region of accreted material called East Anatolian Accretionary Complex (EAAC) [e.g., Şengör et al., 2003], similar to the contemporary Makran accretionary complex in southwestern Iran [e.g., Smith et al., 2013]. The southern oceanic branch of the Neo-Tethys Ocean, an oceanic portion of the Arabian lithosphere, continued subducting northward beneath the Bitlis microcontinent [e.g., Pearce et al., 1990] until the middle Miocene and did not produce any associated arc volcanism since the late Eocene during the last stages of subduction probably due to a shallow subduction angle [Yllmaz, 1993].

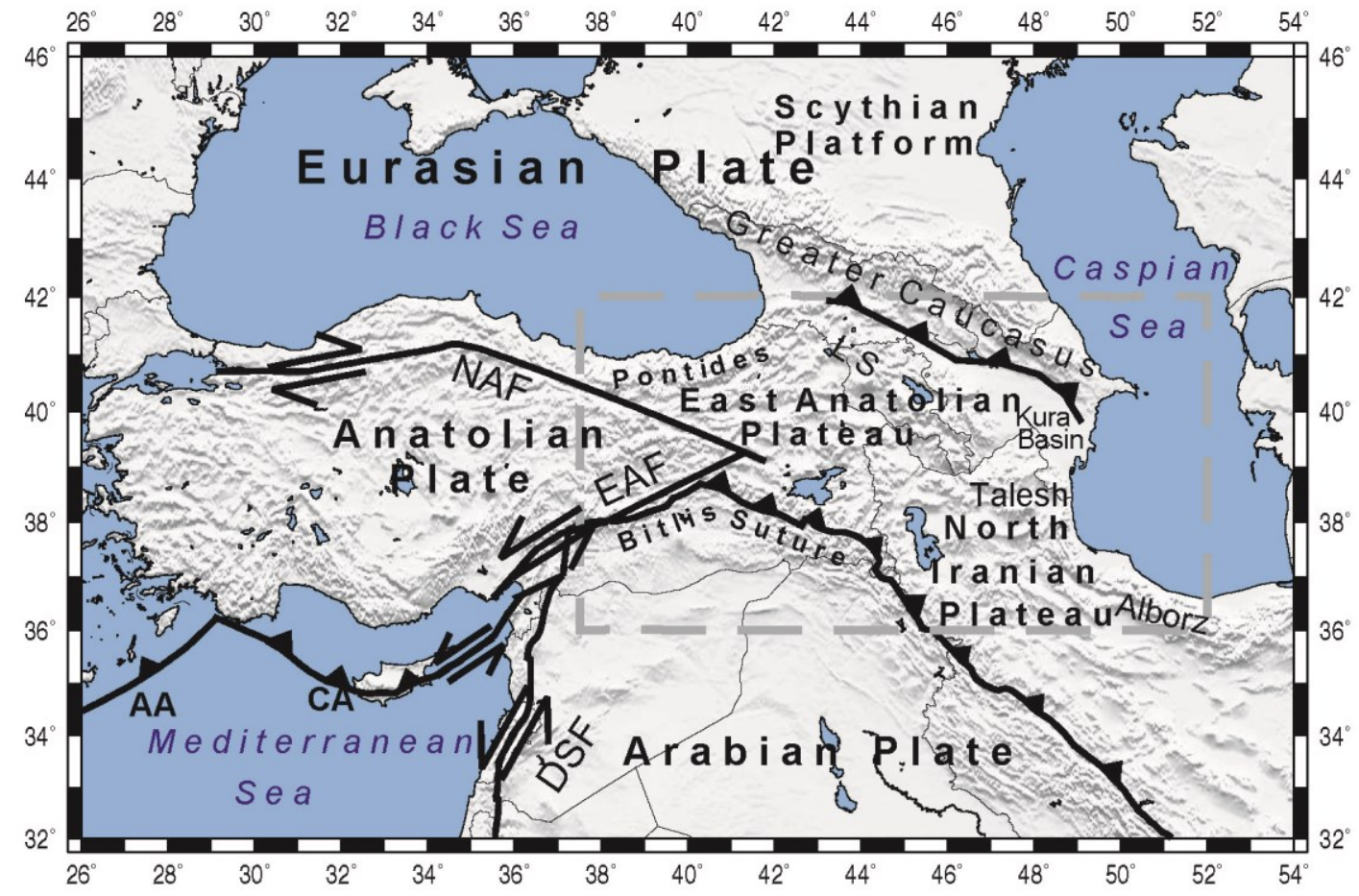

Figure 1.1. Map showing shaded topography and the major tectonic boundaries in Arabia-Eurasia collision zone. The dashed grey frame shows the region of study. LS Lesser Caucasus, NAF North Anatolian Fault, EAF Eastern Anatolian Fault, DSF Dead 
Sea Fault, AA Aegean Arc, and CA Cyprian Arc. Large arrows indicate directions of plate motion relative to Eurasia.

The timing of the initiation of the collision between Arabia and Eurasia is not well constrained, perhaps because it did not begin simultaneously along the entire plate boundary which resulted in different time of cessation of the subduction-related volcanism and marine sedimentation [e.g., Pearce et al., 1990]. The oldest estimate of the age of the collision is late Eocene [Robertson and Aktas, 1984; Michard et al., 1984], which is marked by the youngest subduction-related volcanic rocks in Eastern Anatolia. The youngest estimate is middle Miocene, the age of the last marine deposits discovered on the Eastern Anatolian Plateau [e.g., Keskin, 2007], which signaled the beginning of the formation of the East Anatolian plateau [e.g., Şengör and Kidd, 1979; Şengör and Yilmaz, 1981; Barazangi et al., 2006; Keskin, 2007]. The age of the collision structures in the central part of the EAAC is possibly younger than the age of the initiation of the continental collision at its flanks. Furthermore, the compressional stresses, generated by the continued convergence of the Arabian Plate with Eurasia initiated the last stage of the tectonic uplift in the Greater Caucasus in early Pliocene [e.g., Saintot and Amgelier, 2002; Reilinger et al., 2006; Avdeev and Niemi, 2011].

The timing of the initiation of the uplifts of the Eastern Anatolian Plateau and the Greater Caucasus is not the only difference between these two regional high topographic features; their crustal deformation styles since the onset of their uplift are also unalike. The Eastern Anatolian Plateau is predominately dissected by zones associated with strike slip fault deformation, while the Greater Caucasus consists mostly of belt-parallel fold and thrust fault structures with less significant strike-slip component. The deformation 
style discrepancies between the plateau and the mountain belt are probably related to the particular qualities of their lithospheric structure, which can be only investigated by means of geophysical methods.

\subsubsection{Geophysical observations and volcanism in the Eastern Anatolia}

A number of seismological techniques have been applied in studies of this part of the orogenic belt to image the crustal and mantle structure. The data recorded by the temporary array of 29 PASSCAL broadband instruments during the Eastern Turkey Seismic Experiment (ETSE) [Sandvol et al., 2003a] were used to create the first detailed subsurface images of the Eastern Anatolia. The consecutive expansion and development of the national seismic networks of Turkey, Azerbaijan, and Georgia led to improved regional data coverage in both the Eastern Anatolia and the Caucasus region (Figure 1.2).

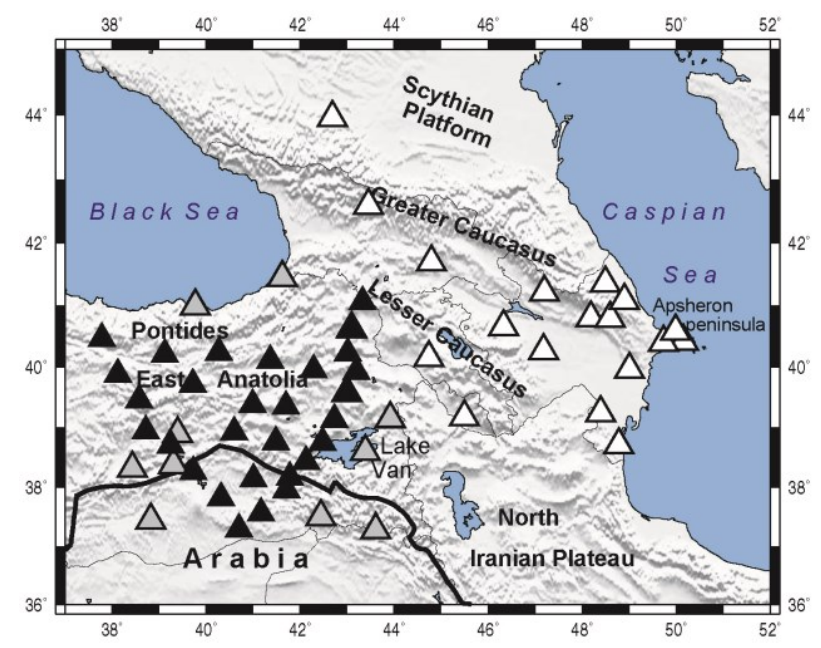

Figure 1.2. Topographic map showing the locations of the broadband seismometers used in this study. Black triangles - Eastern Turkey Seismic Experiment (ETSE) temporary array, white triangles - stations of National Seismic Network of Azerbaijan, Georgia, Armenia, and Russia, grey triangles - instruments of Bogazici University and Kandilli Observatory and the Earthquake Research Institute (KOERI), thick black line shows the northern plate boundary of Arabia. 
Results of teleseismic $P$ wave [e.g., Zor et al., 2003] and $S$ wave [Angus et al., 2006] receiver functions studies as well as a combined analysis of the $P$ wave receiver functions and surface waves [Gök et al., 2011] show that the regional crustal thickness is on average less than $45 \mathrm{~km}$. The regional Moho depth varies from the deepest ( $\sim 50 \mathrm{~km})$ in the central Greater Caucasus and western Lesser Caucasus to the shallowest $(<28 \mathrm{~km})$ in the Black Sea (Figure 1.3). The crustal thickness in the Eastern Anatolian and northIranian Plateaus is rarely above the average and usually does not exceed $43 \mathrm{~km}$. Therefore, the Eastern Anatolian and north Iranian Plateaus require $\sim 10 \mathrm{~km}$ of additional crustal thickness [e.g., SSengör et al., 2003] in order to support their average topography of $2 \mathrm{~km}$ above the sea level by means of Airy isostatic compensation, assuming normal mantle and crustal densities [e.g., Dewey et al., 1986]; however, the density of the regional upper mantle can be lowered by partially molten material (i.e. a layer of asthenosphere that underlies the plateaus). In this case, the high topography of Eastern Anatolian and the northern Iranian Plateaus would be supported by this more buoyant asthenosphere, which is in a good agreement with observations of a long wavelength negative Bouguer gravity anomalies [Seber et al., 2001] and long-wavelength free-air positive gravity anomaly in these regions [Maggi and Priestley, 2005].

There are several important geophysical observations that suggest that a layer of asthenosphere underlies the Eastern Anatolian Plateau with little to no mantle lid. Sn waves are blocked at very short distances across the Anatolian Plateau (Figure 1.4) [e.g., Gök et al., 2003]. Regional tomographic Pn velocity models [e.g., Al-Lazki et al., $2003,2004]$ show the presence of a broad low-velocity $(7.6-7.8 \mathrm{~km} / \mathrm{s})$ zone in the upper 


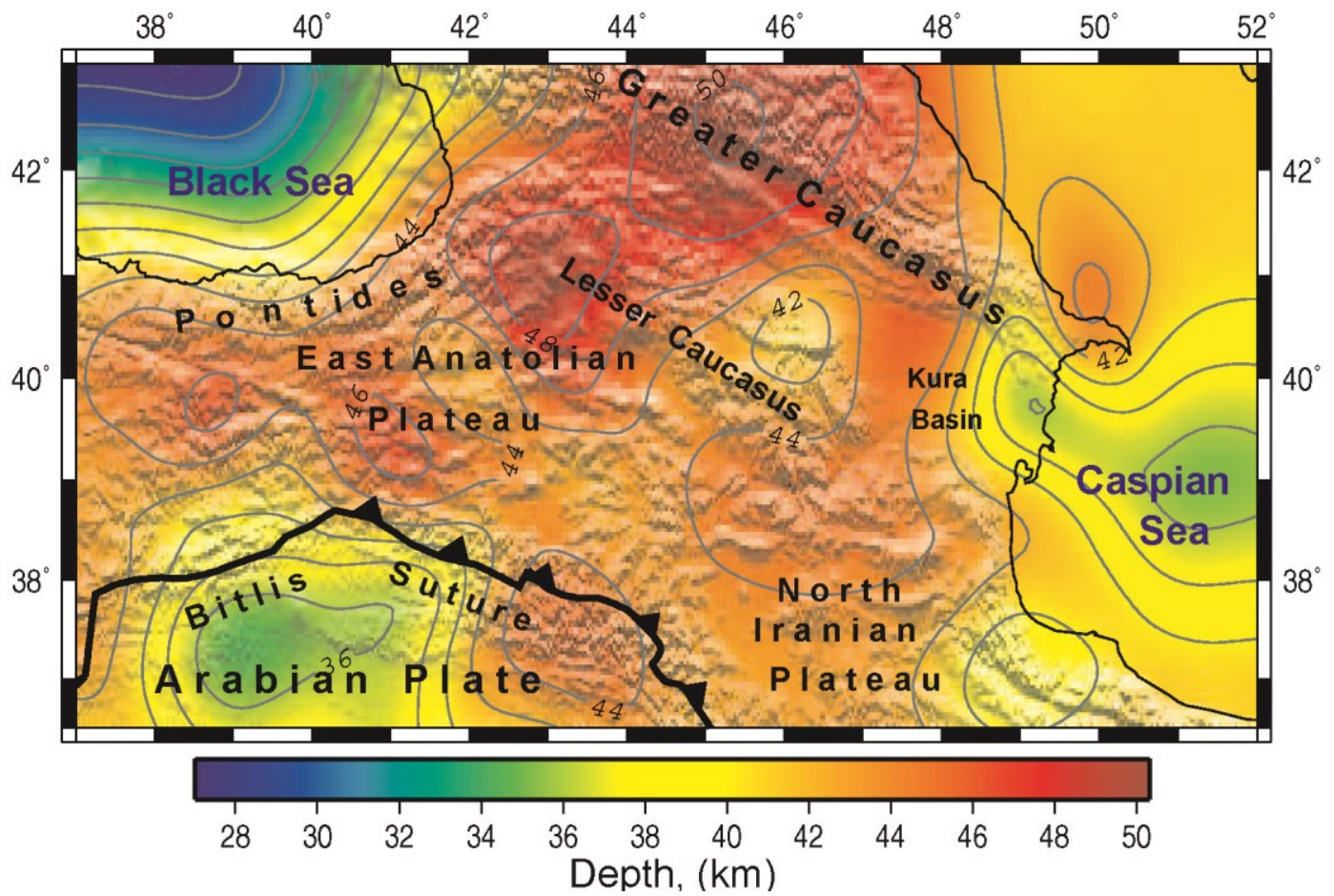

Figure 1.3. A map of Moho depths in the Eastern Anatolian-Caucasus region derived from the model of Gök et al [2011], complemented by CRUST2.0 [Bassin et al., 2000]. The contour interval is $2 \mathrm{~km}$.

mantle below the Eastern Anatolian Plateau (Figure 1.5), which correlates reasonably well with the Sn attenuation observations. Absence of any deep earthquakes [e.g., Türkelli et al., 2003] in the eastern Anatolia (Figure 1.6) in spite of existence of very seismically-active plate boundary faults such as the North Anatolian and the Eastern Anatolian strike slip faults and the thrust of the Bitlis Suture, serves as the evidence of no brittle deformation of the lower crust and lithospheric mantle. Regional magnetotelluric studies [e.g., Türkoğlu et al., 2008] show that the upper mantle beneath Eastern Anatolia is characterized by a very low resistivity, which is consistent with the presence of shallow asthenosphere beneath the region. Finally, the results of teleseismic $S$ wave receiver functions [Angus et al., 2006] demonstrate a very thin lithospheric thickness below the Eastern Anatolian Plateau with the lithosphere-asthenosphere boundary having depths 
ranging between 60 and $85 \mathrm{~km}$. This study also shows that the lithosphere of the northern Iran ranges in thickness between 90 and $120 \mathrm{~km}$ while the northern Arabian lithosphere has a thickness of 100-125 km. $S$ wave splitting analysis [Sandvol et al., 2003b] for the ETSE array shows that the fast polarization directions in the eastern Anatolia are significantly deviated from the present day absolute plate motions or the estimated finite strain across any of the major plate boundaries in this region (Figure 1.7). These fast directions are probably associated with deeper mantle fabric as the plate motions in the region do not create enough basal drag in the shallow, less viscous asthenosphere and thus a measureable anisotropic pattern.

Perhaps the most striking geological evidence that supports the geophysical observations of shallow asthenosphere below the Eastern Anatolian Plateau is the widespread, middle Miocene to present, collision-related alkaline volcanism [Pearce et al., 1990; Keskin, 2003, 2007]. The composition of the volcanic units, covering over a half of the region and exceeding in some locations $1 \mathrm{~km}$ in thickness, varies from basaltic to rhyolitic [Keskin, 2003]; however, the volume of the extrusive materials $\left(>15000 \mathrm{~km}^{3}\right)$ could only represent a small fraction of the melt generated in the region as the greater portion of the melt could have intruded deep in the crust [Keskin, 2007]. The primitive lavas across the region have trace element and isotopic signatures, which are very different from those of the crust and suggest an enriched mantle origin [Pearce et al., 1990; Keskin, 2003, 2007]. 


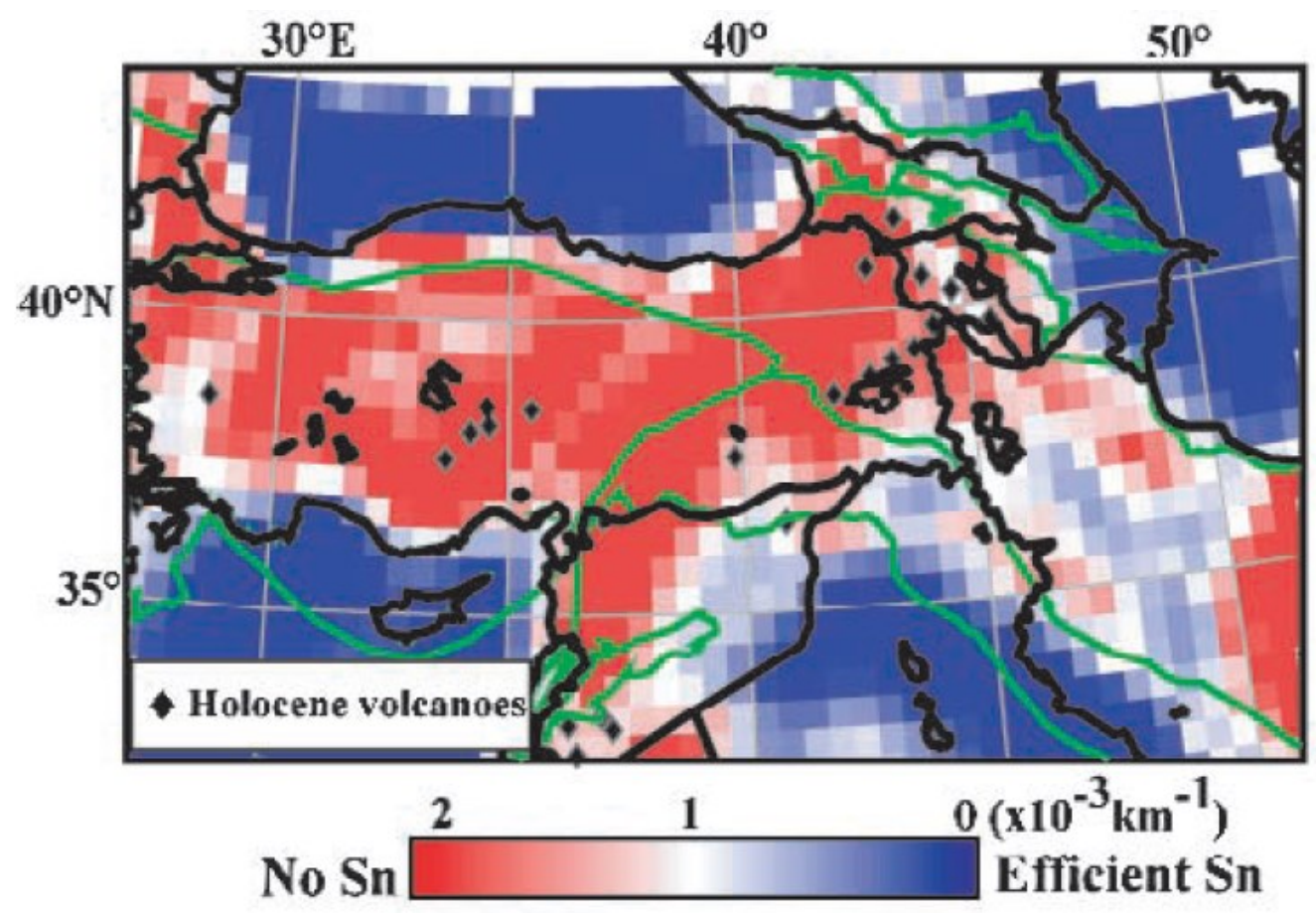

Figure 1.4. Map showing Sn efficiency tomography results (from Gök et al. [2003]). Green lines are major tectonic boundaries, black lines are national boundaries and coast lines.

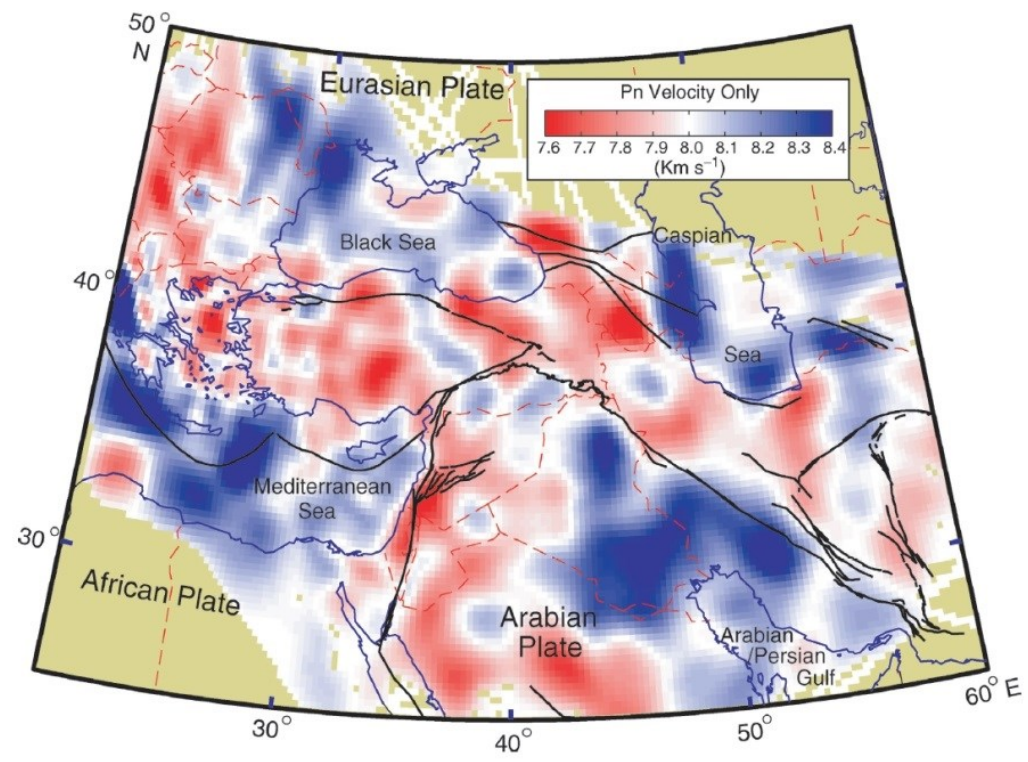

Figure 1.5. A map showing inverted tomographic image of Pn velocity of the Middle East (from Al-Lazki et al. [2004]). Black lines are major tectonic boundaries, Blue lines represent coast lines, dashed red lines are national boundaries. 


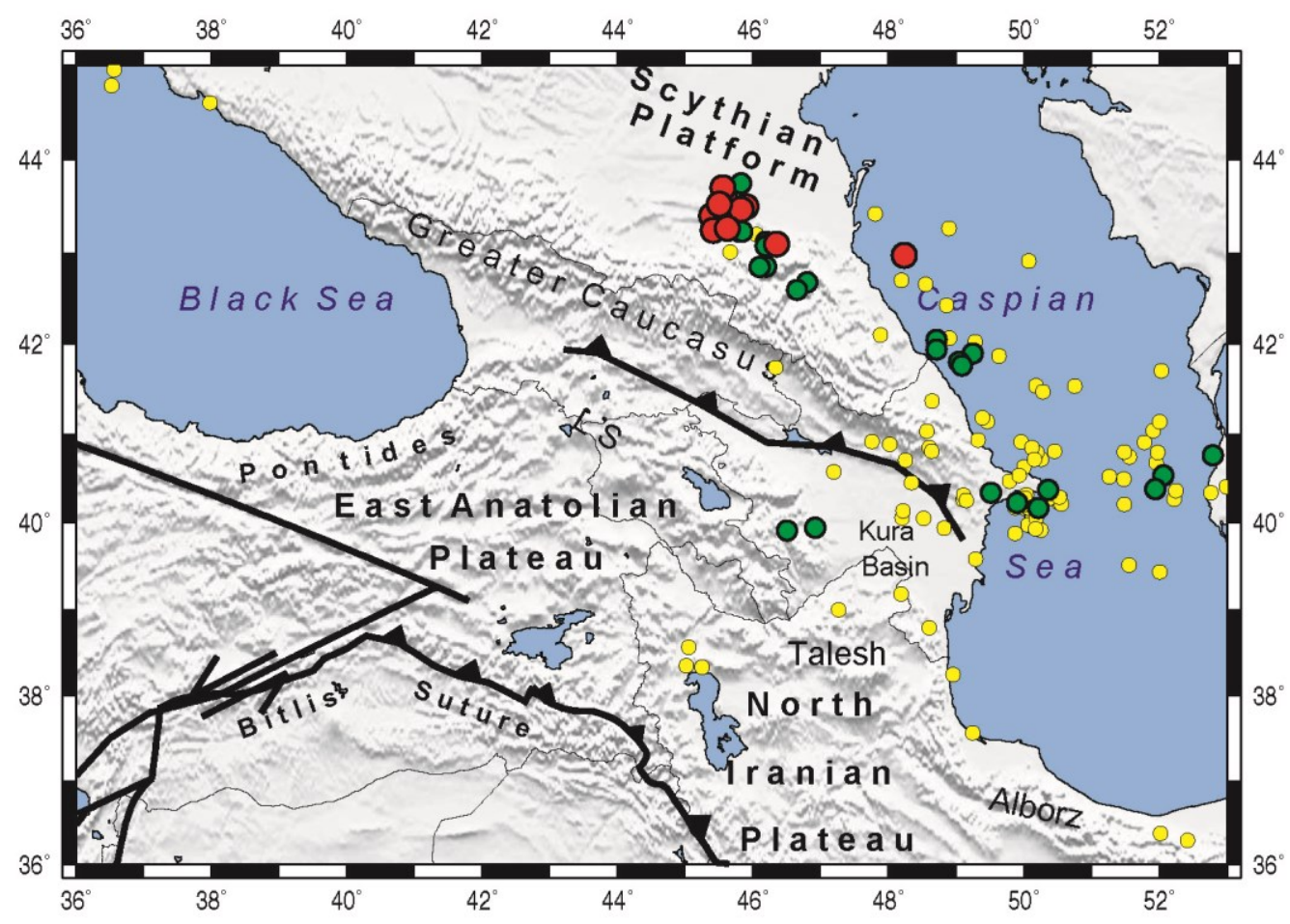

Figure 1.6. Map of shaded topography showing the regional locations of subcrustal earthquakes of $\mathrm{Mb}>3$ and hypocenter depths $>50 \mathrm{~km}$, recorded in the ISC (International Seismic Centre) catalog since January 1, 2000. Yellow circles - hypocenters with depths 50-79 km, green circles - hypocenters with depths 80-99 km, red circles - hypocenters with depths $>100 \mathrm{~km}$.

Some geochemical and petrological properties of the extrusive rocks in the eastern Anatolia show trends of gradual change in the southeast direction. First, the ages of the initiation of the volcanic activity since late Miocene gradually change from the oldest in the northern part of the eastern Anatolia to the youngest in the southeastern part of the region [e.g., Keskin, 2003]. Second, the crystallization assemblages change from hydrous and anhydrous minerals in the north to predominately-anhydrous mineral assemblages in the south. This indicates that the melts generated in the northern part of the plateau have been richer in water than those in the south. The geochemical characteristics of the rocks are also consistent with the petrologic observations: the 


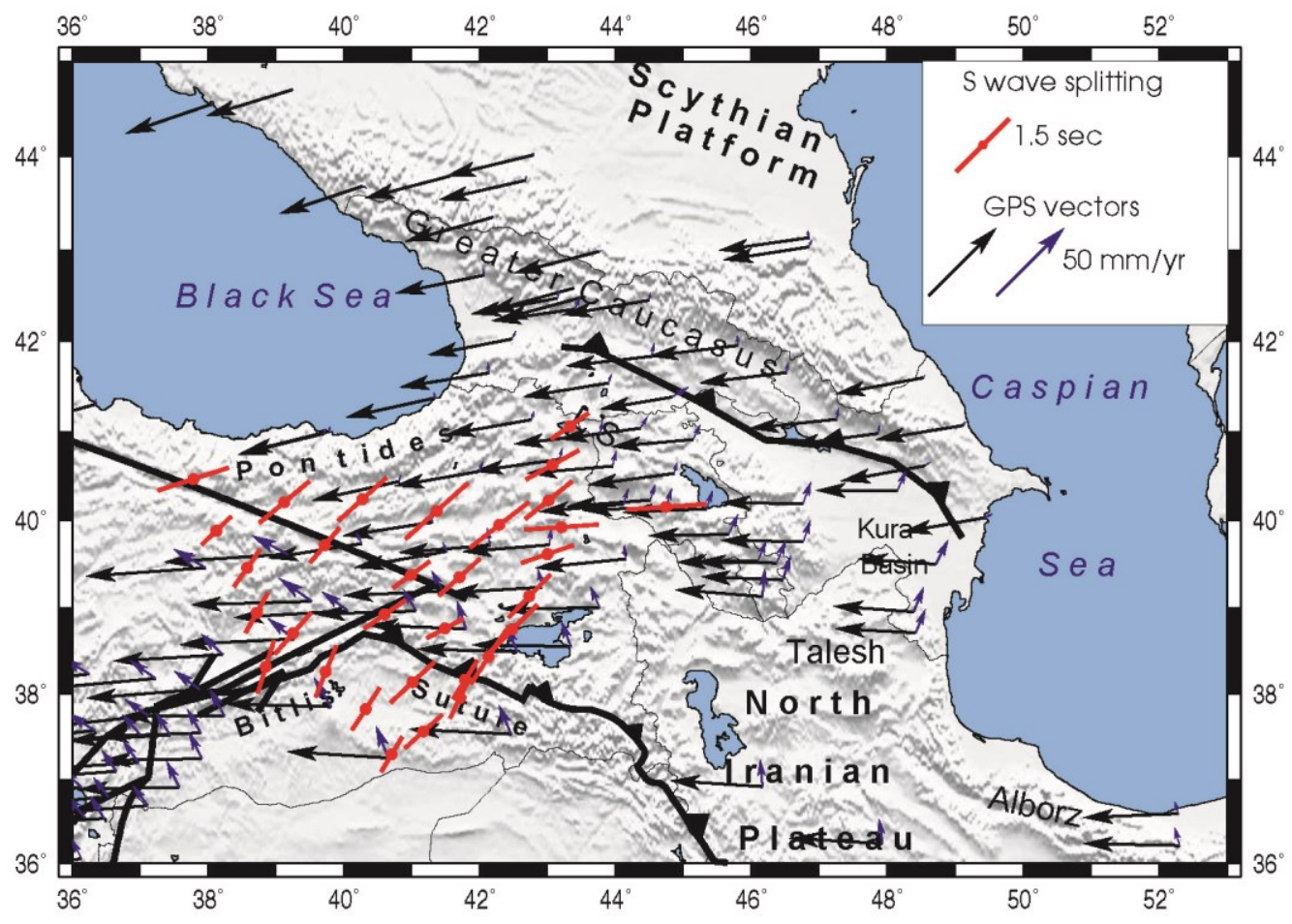

Figure 1.7. Map showing the relationship between $S$ wave splitting results of Sandvol et al., [2003b] and GPS vectors [Reilinger et al., 2006] of the absolute plate motions relative the hot spot reference (black arrows) and plate motions relative to "stable" Eurasian Plate (blue arrows).

northern volcanic rocks that contain hydrous minerals, such as amphiboles, are calcalkaline and show significant depletion in $\mathrm{Ta}$ and $\mathrm{Nb}$ and increased concentrations of $\mathrm{Rb}$ on MORB-normalized spider diagrams, thus demonstrating a pronounced subduction signature. On the other hand, the southern volcanic rocks with predominately-anhydrous minerals are alkaline, significantly less depleted in $\mathrm{Ta}$ and $\mathrm{Nb}$ and show lower concentrations of $\mathrm{Rb}$ [Pearce et al., 1990; Keskin, 2007]. Therefore, the subduction signature in the northern volcanic units is partially to completely replaced by an intraplate signature in the southern extrusive rocks [Keskin, 2007]. 


\subsubsection{Geodynamic models of the late Cenozoic tectonic evolution of the Eastern}

\section{Anatolia}

A viable geodynamic model for the collision of the Arabian and Eurasian Plates must explain the uplift, crustal deformation variations, and the temporal, spatial, and geochemical evolution in the widespread volcanism. Over ten different geodynamic models of the evolution of this part of the collisional orogenic belt have been proposed during more than four decades of previous regional geological studies [Keskin, 2007]. Any geodynamic model proposed for the regional tectonic evolution should be compatible with the geophysical observations in the region; however, the authors of the geodynamic models proposed before the detailed geophysical studies did not have the crucial information about the regional crustal and lithospheric structure. Therefore, the model explaining the uplift of the plateaus by the crustal and lithospheric thickening due to the continental collision between the Arabian and Eurasian Plates [Dewey et al., 1986] was finally rejected by the scientific geological community as such information became available. Some early regional geodynamic models, such as the slip-line escape of microplates to the west and east [McKenzie, 1972], did not explain the generation of huge volumes of magmas in the region. Furthermore, the escape model of McKenzie, [1972], rifting of east-west oriented late Miocene-Pliocene basins and decompression melting of asthenosphere due to extension [McKenzie and Bickle, 1988] did not account for uplift of the high plateaus. The Neogene-Quaternary regional deformation was dominated by compressional regimes and all of the associated basins are related to pull-apart structures [Keskin, 2007]. Although, the localized extension of the lithosphere related to these pullapart basins in strike-slip systems [Dewey et al., 1986; Pearce et al., 1990; Keskin et al., 
1998] could have facilitated the volcanic eruptions, the volcanic products are not confined to these basins and cover a much greater area [Keskin, 2007]. Ongoing continental subduction of the Arabian lithosphere [Rostein and Kafca, 1982] is also not evident as there are no deep sub-crustal seismicity in this the region. Moreover, models of teleseismic $P$ wave tomography [Zor, 2008; Lei and Zhao, 2007] and teleseismic body wave tomography [Koulakov et al., 2012] do not show any subducting Arabian lithosphere beneath the region. Perhaps the least convincing model among the remaining competing geodynamic models, in my opinion, is the model of the passive deep mantle plume, which is the result of the northward spreading of the African superplume along a lithospheric channel beneath the Red Sea and Dead Sea Fault [Ershov and Nikishin, 2004]; however, Lei and Zhao [2007] observed a low-velocity anomaly beneath the active volcanic centers in the Eastern Anatolian Plateau, which extended down to $400 \mathrm{~km}$ depth in their teleseismic $P$ wave tomography model and suggested that this low-velocity anomaly could be associated with a small-scale mantle plume. While the topographic profile of the Eastern Anatolian Plateau is very similar to that of the Ethiopian High Plateau and both plateaus represent domal structures [Şengör et al., 2003], the deep mantle plume model does not explain the southeastern trends in petrology, geochemistry, and the ages of the volcanic products [Keskin, 2007].

Only a few of the proposed geodynamic models of the tectonic evolution of the Eastern Anatolia do not seem to strongly contradict the aforementioned regional geophysical and geological observations. Although, some of the competing geodynamic models might have minor discrepancies with the geological and geophysical data, they still can be considered as reasonable. Delamination of the lithosphere beneath the Eastern 
Anatolia [Pearce et al., 1990; Keskin, 1998] can explain the regional uplift, volcanism and thin to absent mantle lid; however, accretionary complexes are devoid of their own lithospheric roots and instead are supported by subduction oceanic slabs [Keskin, 2007]. Therefore, the existence of the vast EAAC contradicts this idea unless the geological interpretation of the north dipping slices of late Cretaceous ophiolitic mélange and the Paleocene to late Oligocene flysch, which becomes progressively younger from north to south as a subduction accretionary complex for the whole area of the EAAC [Şengör et al., 2003] is incorrect. The rest of the competing geodynamic models involve the detachment of an oceanic slab beneath the Eastern Anatolian Plateau.

The pioneering model of the detachment and northward sinking of the Arabian oceanic lithosphere beneath the Eastern Anatolian Plateau [Innocenti et al., 1982] explained the initiation of the late Cenozoic regional magmatism by the rising asthenosphere where the subducted slab was detached. However, this early model suggested the northward migration of the volcanic centers from Lake Van through time based on the available dating of the volcanic samples. Although, the recent radiometric dating of the volcanic products just north of Lake Van [Lebedev et al., 2010a] suggests that the collision-related volcanism initiated first in that location in the middle Miocene $(\sim 15 \mathrm{Ma})$, thus disrupting the southeast age trend beginning in the late Miocene ( 11 Ma) and lasting until the resent [e.g., Pearce et al., 1990; Keskin, 2007]; however, this early initiation of the volcanism is likely associated not with the Arabian (Bitlis) slab breakoff but rather with an episode of steepening of the subducting slab, that produced the asthenospheric upwelling and decompression melting. 
The last two competing geodynamic models both involve detachment of one of the branches of Neo Tethys oceanic lithosphere. Both models explain the initiation of the uplift and wide spread magmatism in the region by the decompression melting of the asthenosphere. The first model explains the uplift and volcanism in the Eastern Anatolia by steepening and detachment of the northern branch of the Neo Tethys oceanic lithosphere [Şengör et al., 2003; Keskin, 2007]. This model is based on the existence of the vast EAAC that was underlain by the shallow angle oceanic lithosphere instead of a continental one. The difference between this model and the model of Inoicenti et al. [1982] is that by including the steepening of the slab, it can better explain the southeastern trends in geochemistry and the ages of the volcanic rocks, which makes it the most convincing. Barazangi et al. [2006], however, proposed an alternative model blaming the detachment and subsequent sinking of the southern Neo Tethys lithosphere for the initiation of the volcanism and uplift in the region. According to this model, the detachment of the northern Neo Tethys lithosphere happened beneath the Pontides by early Miocene, while the subduction of the Arabian lithosphere beneath the Bitlis arc lasted until the middle Miocene; the slab had a shallow subduction angle [Yllmaz, 1993] because no subduction-related volcanic rocks of ages younger than late Eocene have been identified in the Bitlis Suture zone. Both models do not have any strong discrepancies with the preceding this study geophysical observations and tomographic models. 


\subsubsection{Uplift, volcanism, and geophysical observations in the Greater Caucasus}

The Greater Caucasus is the result of the tectonic inversion of the deep-water post-rifting basin existing from the late Jurassic to the late Eocene following the middle late Jurassic rifting episodes [e.g., Saintot et al., 2006]. There have been two stages of the tectonic inversion of the Greater Caucasus basin that have been proposed. The earlielst proposed onset of the orogenesis of the Greater Caucasus did not involve a significant rate of uplift of rocks at the surface and has continued since late Eocene or early Oligocene, which is documented by olistostromes and a regional angular unconformity at the base of the Oligocene-early Miocene Maikop formation [e.g., Vincent et al., 2007, Vincent et al., 2010]. The other view on the timing of uplift is that it began in the late Miocene which is supported by the widespread occurrence of coeval conglomerates in the surrounding the mountain belt basins [e.g., Philip et al., 1998]. Recent thermochronometric study of the samples, which were collected in the central part of the mountain belt [Avdeev and Niemi, 2011], showed identical rates of uplift to the western Greater Caucasus since early Oligocene to late Miocene [Vincent et al., 2010] with a significant acceleration of the exhumation of the central Greater Caucasus in early Pliocene which resulted in more than tripling the rate of uplift. Based on the thermochronometric studies conducted in the eastern Greater Caucasus by Bochud et al. [2011], the uplift rates of the eastern Greater Caucasus appear to accelerate in the Pliocene, which is coeval to a similar change of rate observed in the central part of the mountain range. Although, the uplift rates in the eastern Greater Caucasus have been less than those of the central part of the mountain range since early Pliocene, their uplift history can be considered distinct from that of the western Greater Caucasus during the 
last $5 \mathrm{Myr}$ as no acceleration of uplift has been documented in that area during that time. According to the estimates of the uplift derived from these thermochronometric data, the latest stage of the uplift of the mountain belt, which began in early Pliocene, signifies the time when the Greater Caucasus finally became a high-standing orogenic structure [Avdeev and Niemi, 2011].

Collision-related volcanism also exists in the central Greater Caucasus (e.g., Mount Elbrus and Mount Kazbek areas), which is, coincidently, the fastest uplifting part of the Greater Caucasus [e.g., Koulakov et al., 2012]. However, the volumes of the collision-related extrusive materials located in the Greater Caucasus are small in comparison with those in the Eastern Anatolian Plateau. The ages of the volcanic products vary from late Miocene to Holocene [e.g., Lebedev et al., 2011]. Their compositions are represented by calc-alkaline and subalkaline basalts, andesite-basalts, andesite-dacites and rhyolites; their parental melts were likely the products of interaction between contrasting mantle melts and crustal material [e.g., Lebedev et. al., 2010b]. The role of the mantle materials sequentially increases with the age of the magmatic activity, which is reflected in systematic change of isotope-geochemical characteristics such as decrease in ${ }^{87} \mathrm{Sr} /{ }^{86} \mathrm{Sr}$, increase in ${ }^{143} \mathrm{Nd} /{ }^{144} \mathrm{Nd}$ and decrease of $\mathrm{K}_{2} \mathrm{O}$ and $\mathrm{Rb}$ content in the extrusive products [e.g., Lebedev et. al., 2010b]. There is a suggestion that part of the magma could be generated in the lower mantle implying a combination of hot spot activity with continental activity in the area [e.g., Lebedev et. al., 2010b]. On the other hand, most of the young pyroclastic rocks in the central Greater Caucasus are geochemically similar to island arc and syncollisional rocks [Chernyshev et al., 2014]. Contrary to the known existence of the arc volcanism in the Eastern Anatolian and 
northern Iranian Plateaus, there is no obvious record of any subduction zone along the Greater Caucasus during Mesozoic and Cenozoic times: there is no volcanic arc or blueschist and high-grade metamorphic rocks of those ages, and no accretionary complexes are present [Saintot et al., 2006].

Whatever the mantle sources of the melts are, some geophysical models such as those of surface wavefield tomography [Maggi and Priestly, 2005], the teleseismic body wave tomography [Koulakov et al., 2012; Zor, 2008], Sn attenuation [e.g., Gök et al., 2003] and Pn tomography [e.g., Al-Lazki et al., 2003] support the idea of the mantle magma generation by imaging a very thin to absent lithospheric mantle below the recent volcanic centers within the Greater Caucasus. The thinning might have resulted from delamination of the dense lithosphere that initiated the volcanism and uplift in this part of the mountain belt [Koulakov et al., 2012]. Mitchell and Westaway [1999] suggested a different mechanism that initiated the uplift and volcanism in the the Greater Caucasus by inflow of lower ductile crust, which is driven by the isostatic response to erosion, transportation, and sedimentation of the eroded material in the basins located in the surrounding areas (e.g., Black Sea, Caspian Sea), which in turn produces subsidence in those basins. Although, the uplift of the mountain belt probably has some component due to the denudation-driven isostatic response, the model itself does not consider the compressional tectonics in the region and does not explain the shortening in the Greater Caucasus by means of folding and thrust faulting. Furthermore, this model does not account for the absence of the lithospheric mantle bellow the central part of the Greater Caucasus. The most scientifically accepted explanation of the uplift in the Greater Caucasus mountain range is the lateral extension of compressive stress field generated by 
the convergence between the Arabian and Eurasian Plates. According to geodetic data, the total rate of this convergence is $20-30 \mathrm{~mm} / \mathrm{yr}$. [e.g., Reilinger et al., 2006; DeMets et al., 2010]. A detailed analysis of regional deformations reviles that about $40 \%$ of this convergence rate is accommodated in crustal shortening in the Greater Caucasus [Allen et al., 2003].

The study region does not cover the western segment of the Greater Caucasus, which is the northern shore of the Black Sea, and only includes the eastern Greater Caucasus and a large portion of the central part of the mountain range (Figure 1.1). Therefore, I will only concentrate on these areas in the dissertation. Several geological and geophysical characteristics make these parts of the mountain range different from each other. First, the Neogene-Quaternary collision-related volcanic products, as discussed earlier, only exist in the central part of the mountain range. There is no evidence of existence of neither extrusive nor intrusive rocks younger than late Jurassic [e.g., Saintot et al., 2006] in the eastern Greater Caucasus. Second, the geophysical models [e.g., Al-Lazki et al., 2003; Gök et al., 2003; Maggi and Priestly, 2005; Koulakov et al., 2012; Zor, 2008] show some evidence of thick to normal lithosphere beneath these two parts of the belt: the central part of the mountain range seems to lack much of lithospheric mantle while the eastern part has an apparent lithospheric root [e.g., the model of Koulakov et al., 2012]. Thirdly, the exhumation rates during the latest phase of the uplift (early Pliocene-Present) are greater in the central part of the mountain range than in the eastern one. Finally, while shallow seismicity is prevalent throughout the mountain range, the deep, subcrustal (roughly defined as $>50 \mathrm{~km}$ ) events (Figure 1.6) only occur in eastern Greater Caucasus [e.g., Mellors et al., 2012]. In fact, all the 
subcrustal earthquake hypocenters in the region (Figure 1.6) are concentrated in the eastern Greater Caucasus, under the mid-Caspian, and at the edges of the south Caspian under the Kura Basin [e.g., Ulomov et al., 2007; Triep et al., 1995; Godzikovskaya and Reysner, 1989; Myers et al., 2011]. The deep seismicity beneath the eastern Greater Caucasus may be caused by underthrusting or subduction of the Kura Basin lithosphere [e.g., Mellors et al., 2012], which is consistent with the plate motions vectors measured by GPS [Reilinger et al., 2006]. All of these geological and geophysical differences are

probably associated with changes in the lithospheric structure along the mountain range; therefore, a robust model of the regional upper mantle velocity structure with a more reliable depth resolution than the existing models would help to understand these variations better.

\subsection{Methods applied in the research of the regional upper mantle $S$ wave velocity structure}

Previous geophysical studies of the Eastern Anatolian-Caucasus region employed various seismic techniques to study the upper mantle velocity structure. The results of these studies have provided geoscientists with crucial information about the regional lithospheric structure. For example, the existing regional body wave tomography models [e.g., Al-Lazki et al., 2003; Gök et al., 2003; Lei and Zhao, 2007; Zor, 2008; Biryol et al,. 2011; Koulakov et al., 2012], while having excellent lateral resolution, lack robust vertical resolution due to limited numbers of crossing ray paths and large distances between the seismic stations. 
The regional models of Sn attenuation [e.g., Gök et al., 2003; Al-Damegh et al., 2004] and Pn tomography [e.g., Al-Lazki et al., 2003; Amini et al., 2012] only image the shallow part of the upper mantle. They are consistent with a shallow asthenosphere beneath Eastern Ananolia and Lesser Caucasus and the central Greater Caucasus. Barazangi et al. [2006] suggested that the layer of asthenosphere is very thin $(<30 \mathrm{~km})$ based on calculated low gravity residuals form the regional Bouguer gravity model [Seber et al., 2001] using the crustal thickness model of Zor et al. [2003]; however, he emphasized that his model could have lost the resolution with depth. Therefore, the depth extent of the low-density asthenosphere remains unclear, which could result in controversial interpretations of the low velocity anomaly (e.g., the plume in the teleseismic $P$ wave tomography model of Lei and Zhao [2007]).

$S$ wave splitting results have a good coverage in the eastern Anatolia [e.g., Sandvol et al., 2003b], but only a handful of stations have been analyzed in the rest of the study region [Vinnik et al., 1992; Kaviani et al., 2009; Helffrich et al., 1994; Paul et al., 2014] leaving the eastern Greater Caucasus devoid of any splitting measurments. However, upper mantle seismicity indicates the lithospheric mantle deformation in this region and new knowledge of the regional $S$ wave splitting parameters could elucidate the causes of such deep seismic activity in this region, which could lead to a better understanding of the local tectonic setting. In order to address the issues related to the vertical resolution of the regional upper mantle velocity structure and the gap of the azimuthal anisotropy results in the Greater Caucasus, I employ an event-based Rayleigh wave tomography and $\mathrm{S}$ wave splitting techniques, which are briefly described in the following sections of this chapter. 


\subsubsection{Two-plane Rayleigh wave tomography}

Surface waves travel parallel to the surface of the Earth along great circle paths. Rayleigh waves are a kind of surface waves, which have the particle motion appearing in the vertical plane oriented along the wave propagation direction. The retrograde elliptical particle motion of Rayleigh waves involves a mix of $P$ and $S V$ (vertically polarized shear wave) wave motions [e.g., Lay and Wallace, 1995]. Long-period Rayleigh waves depend stronger on $S V$ wave velocity than on $P$ wave velocity or density in the upper mantle. On the other hand, the wavelength of surface waves determines the thickness of the medium that they sample, which produces dispersion of surface waves when they propagate in a vertically inhomogeneous earth interior. As a result, it is possible to invert for upper mantle absolute $S V$ wave velocity structure using long-period Rayleigh wave phase velocity dispersion curves achieving a better depth resolution than that of body wave tomography. The ability to model the absolute $S$ wave velocity structure of the upper mantle is an additional advantage of surface wave tomography in comparison with body wave tomography techniques, which can only resolve relative body wave velocity structure(i.e. percent of velocity perturbation) .

In this research, I use the teleseismic two-plane wave tomography method of Yang and Forsyth [2006a, 2006b] in order to model the Rayleigh wave phase velocity structure of the region. The two-plane wave approach for surface wave tomography has a few significant advantages in comparison with the traditional teleseismic surface wave tomography techniques previously applied at a global scale [e.g., Nishida et al., 2009]. While the traditional surface wave methods simplify the wavefield of the Rayleigh waves 
at a teleseismic distance from the sources as a single plane wave traveling along the great circle raypath, in the two-plane wave approach, each incoming fundamental mode of Rayleigh waves is modelled as the interference of two plane waves [Forsyth et al., 1998]. The two-plane wave representation of the wavefield is a better approximation of the actual complex wavefield affected by the scattering produced when the Rayleigh waves propagate through regional structures. Therefore, this method is better suitable for developing of regional scale velocity models then the traditional teleseismic surface wave techniques [e.g., Forsyth and Li, 2005]. Furthermore, while traditional methods only use phase data, which is gathered at each seismic station, the two-plane wave technique utilizes both the phase and amplitude data in the inversion to better recover the magnitudes of the phase velocity anomalies [Forsyth and $L i$, 2005]. Finally, this technique employs 2-D single scattering (Born) approximation kernels [Zhou et al., 2004] to take into account finite frequency effects and describe the sensitivity of phase and amplitude of each of the two incoming plane waves to the local structure [Yang and Forsyth, 2006a, 2006b]. The use of the 2-D single scattering (Born) approximation kernels instead of the commonly used oversimplified Gaussian kernels helps in recovering the phase velocity anomalies whose dimensions are small enough to approach the wavelength of the dominant period Rayleigh wave [e.g., Forsyth and Li, 2005; Yang and Forsyth, 2006a, 2006b; Li, 2011]. By applying the two-plane wave method of surface wave tomography I intend to improve the recovery of the phase velocity values and the lateral resolution in my model over those in the existing global and regional [e.g., Maggi and Priestly, 2005] surface wave tomography models. 


\subsection{2. $S$ wave splitting}

Plate tectonic processes such as subduction cause the upper mantle plastic deformation (i.e. mantle convection or mantle flow). The lattice preferred orientation (LPO) (or crystal preferred orientation (CPO)) of anisotropic upper mantle minerals such as olivine and pyroxenes is formed in response to the mantle flow and usually has a systematic relationship with the direction of the maximum finite strain in the mantle [Ribe, 1989]. LPO (CPO) is the major cause of our observations of seismic anisotropy in the upper mantle [e.g., Karato, 1987]; therefore, knowledge of the direction and strength of regional upper mantle seismic anisotropy provides a powerful tool for analysis of the upper mantle strain fabrics and particularly the direction of the upper mantle flow, which may be a very important factor affecting the geodynamic processes in that region. Moreover, the seismic anisotropy caused by the strain-induced lattice preferred orientation not only shows the characteristics of the present day mantle deformation (e.g., asthenospheric flow), but can also serve as the records of the past regional upper mantle deformational patterns (e.g., preserved lithospheric fabric) which could shed lite on some aspects of the regional deformation history [e.g., Mainprice et al., 2000].

Diffusion creep and dislocation creep are the main types of deformation, which exist within the upper mantle [e.g., Karato, 1987]. Low stresses and small grain sizes are the required conditions for diffusion creep to occur [Lee et al., 2002]. However, during diffusion creep no LPO is developed because the process of migration of ions through crystal lattice and between the grain boundaries does not produce any coherent rotation of the mineral lattice [Karato, 1987]. Therefore, if the diffusion creep is the dominant type 
of the mantle deformation, the resulting mantle fabric will be isotropic. On the other hand, dislocation creep is associated with larger grain sizes and often facilitated by planar defects or other imperfections in the crystal lattice [e.g., Lee et al., 2002]. Dislocation creep is represented by simple shear, resulting in LPO where mineral grains tend to orient toward the direction in which microscopic shear due to dislocation creep agrees with the imposed macroscopic shear [Karato et al., 2008]. For example, simple shear can develop during a horizontal mantle flow with a vertical gradient in flow velocity. This type of deformation is the dominant mechanism in high strain asthenospheric flows such as those created by basal drags bellow the moving oceanic plates and in the mantle wedge of the subduction zones [e.g., Babuska and Cara, 1991].

Olivine is known as the primary mineral of the upper mantle composing $50-70 \%$ of its volume. The mineral possesses strong $(\sim 18 \%)$ intrinsic single-crystal $S$ wave velocity anisotropy [e.g., Long 2013]. The anisotropy of a single olivine crystal increases slightly with crowing temperature and reduces slightly with increasing pressure. Therefore one would expect the single crystal anisotropy to be nearly constant along a geotherm [Mainprice et al., 2000].

Orthopyroxene and clinopyroxene are the other common anisotropic minerals found in the upper mantle and have 13 and $21 \%$ of intrinsic $S$ wave velocity anisotropy, respectively [e.g., Mainprice et al., 2000]; however, based on the fact of the dominant presence of olivine in the upper mantle, the role of the olivine LPO is considered the most significant in the observed upper mantle anisotropy [e.g., Long, 2013]. A peridotite aggregate that contains 70 percent of olivine LPO is estimated to have $3-6 \%$ of average anisotropy for $S$ waves [Russo and Silver, 1994]. Several factors such as water, stress, 
temperature, pressure, as well as partial melt can significantly influence the development of LPO and therefore the relationship between the observed upper mantle anisotropy and the mantle flow [Karato et al., 2008]. As a result, depending on the combination of these factors, there have been distinguished five types of olivine fabrics (Table 1.1.), which have specific relationships of the orientations of their dominant slip systems (i.e. slip directions and slip planes) with the direction of the maximum finite strain in the upper mantle [e.g., Karato et al., 2008; Long, 2013].

\begin{tabular}{|c|c|c|c|c|c|}
\hline Fabric & A-type & B-type & C-type & D-type & E-type \\
\hline Slip system & {$[100](010)$} & {$[001](010)$} & {$[001](100)$} & {$[100](0 \mathrm{kl})$} & {$[100](001)$} \\
\hline $\begin{array}{c}\text { Direction of } \\
\text { fast } \\
\text { polarization }\end{array}$ & $\begin{array}{c}\text { Parallel to } \\
\text { flow }\end{array}$ & $\begin{array}{c}\text { Normal to } \\
\text { flow }\end{array}$ & $\begin{array}{c}\text { Parallel to } \\
\text { flow }\end{array}$ & $\begin{array}{c}\text { Parallel to } \\
\text { flow }\end{array}$ & $\begin{array}{c}\text { Parallel to } \\
\text { flow }\end{array}$ \\
\hline
\end{tabular}

Table 1.1. Relationship between the fabrics of olivine, the dominant slip systems, and the fast polarization direction of a vertically traveling $S$ wave (from Karato, et al., [2008]). The values in brackets represent the slip directions, and the values in parentheses correspond to the slip plane orientations.

The dehydration of subducting oceanic lithosphere can produce serpentinization of the mantle wedge above the slab [e.g., Long 2013]. Serpentine minerals can have single-crystal intrinsic $S$ wave anisotropy as strong as $68 \%$ [Mainprice and Ildefonse, 2009]. Therefore, the effect of a layer of these minerals, on the seismic anisotropy when this layer is deformed by simple shear during subduction, can be very significant and comparable to olivine LPO.

When a vertically incident $S$ wave such as SKS starts to propagate through an anisotropic mantle layer, the $S$ wave will split into two mutually perpendicular polarization directions if the initial polarization of the $\mathrm{S}$ wave is neither parallel or perpendicular to the direction of the layer anisotropy. The $S$ wave splits in such a way 
that one of the components is polarized parallel to [100] axis of olivine LPO and travels faster than the other component, which is polarized perpendicular to the fast axis. As both components travel with different velocities after they split, a seismic station will record a lag time between their arrivals. This lag time, $\delta t$ between the fast and slow components is proportional to the thickness of the anisotropic layer and to the strength of anisotropy. Depending on the type of olivine fabric, the fast polarization direction, $\phi$ (originally measured with respect to the back azimuth of the event) can be parallel (i.e. A-type) or perpendicular (i.e. B-type) to the direction of the mantle flow.

Shear wave splitting is the traditional, unambiguous technique used to measure the bulk average seismic anisotropy of the upper mantle beneath a seismic station. It can be applied to both the teleseismic core phases (i.e. PKS, SKS, SKKS) that have a known initial polarization and local direct $S$ wave arrivals, with unknown initial polarization direction. Traditional $S$ wave splitting methods work best to determine the splitting parameters of the horizontal component of mantle flow and in most cases will not work if the direction of the maximum finite strain is vertical. The disadvantages of the traditional $S$ wave splitting techniques also include inability to determine the depth of anisotropy as it can measure the bulk average anisotropy over the entire length of the ray path. In this research, in order to calculate the optimal $S$ wave splitting parameters ( $\phi$ and $\delta t)$ for the region of study, I apply the method of Silver and Chan [1991] for analysis of the SKS and SKKS phases. This method has been used in many regional $S$ wave splitting studies of the core phases and utilizes a grid search over all reasonable combinations of splitting parameters, $\phi$ and $\delta t$ in order to minimize the energy of the corrected tangential component for a single event [Silver and Chan, 1991]. In addition to this method, I apply the method, 
which applies the aforementioned technique to the stacked corrected tangential energy from all of the events [Wolfe and Silver, 1998] to determine the average splitting parameters for each station. Finally, I perform an analysis of deep local events by means of minimizing of the second eigenvalue in the covariance matrix formed by the horizontal components [Bowman and Ando, 1987].

Although, seismic anisotropy can be reliably detected in the crust and the upper mantle by application of the appropriate $S$ wave splitting techniques, the time lags between the fast and slow polarizations of $S$ waves associated with crustal anisotropy are usually insignificant in comparison with those related to the upper mantle. Therefore, we will not account for the regional crustal anisotropy, as the effect of the short delay times on SKS and SKKS splitting is usually not detectable because of their relatively long periods.

\section{References}

Al-Damegh, K., E. Sandvol, A. Al-Lazki, and M. Barazangi (2004), Regional seismic wave propagation ( $\mathrm{Lg}$ and $\mathrm{Sn}$ ) and Pn attenuation in the Arabian Plate and surrounding regions, Geophysical Journal International, 157(2), 775-795, doi: 10.1111/j.1365-246X.2004.02246.x.

Al-Lazki, A., D. Seber, E. Sandvol, N. Türkelli, R. Mohamad, and M. Barazangi (2003), Tomographic Pn velocity and anisotropy structure beneath the Anatolian plateau (eastern Turkey) and the surrounding regions, Geophys. Res. Lett., 30(24), 8043, doi:10.1029/2003GL017391.

Al-Lazki, A. I., E. Sandvol, D. Seber, M. Barazangi, N. Turkelli, and R. Mohamad (2004), Pn tomographic imaging of mantle lid velocity and anisotropy at the 
junction of the Arabian, Eurasian and African plates, Geophysical Journal International, 158(3), 1024-1040, doi: 10.1111/j.1365-246X.2004.02355.x.

Allen, M. B., S. J. Vincent, G. I. Alsop, A. Ismail-zadeh, and R. Flecker (2003), Late Cenozoic deformation in the South Caspian region: Effects of a rigid basement block within a collision zone, Tectonophysics, 366(3-4), 223-239, doi:10.1016/S0040-1951(03)00098-2.

Amini, S., Z. H. Shomali, H. Koyi, and R. G. Roberts (2012), Tomographic upper-mantle velocity structure beneath the Iranian Plateau, Tectonophysics, 554-557(0), 42-49, doi: dx.doi.org/10.1016/j.tecto.2012.06.009.

Angus, D. A., D. C. Wilson, E. Sandvol, and J. F. Ni (2006), Lithospheric structure of the Arabian and Eurasian collision zone in eastern Turkey from S-wave receiver functions, Geophys. J. Int., 166(3), 1335-1346, doi:10.1111/j.1365246X.2006.03070.x.

Avdeev, B., and N. A. Niemi (2011), Rapid Pliocene exhumation of the central Greater Caucasus constrained by low-temperature thermochronometry, Tectonics, 30 , TC2009, doi:10.1029/2010TC002808.

Babuska, V., and Cara, M., (1991), Seismic Anisotropy in the Earth: Kluwer Academic Publishers, $217 \mathrm{p}$.

Barazangi, M., E. Sandvol, and D. Seber (2006), Structure and tectonic evolution of the Anatolian plateau in eastern Turkey, Geol. Soc. Am. Spec. Pap., 409, 463-473, doi:10.1130/2006.2409(22).

Bassin, C., G. Laske, and G. Masters (2000), The current limits of resolution for surface wave tomography in North America, Eos Trans. AGU, 81, F987.

Biryol, B. C., S. L. Beck, G. Zandt, and A. A. Özacar (2011), Segmented African lithosphere beneath the Anatolian region inferred from teleseismic P-wave tomography, Geophys. J. Int., 184(3), 1037-1057, doi:10.1111/j.1365246X.2010.04910.x.

Bochud, M., (2011), Tectonics of the Eastern Greater Caucasus in Azerbaijan, PhD dissertation, Department of Geosciences, University of Fribourg, Switzerland, $207 \mathrm{p}$. 
Bowman, J.R., and Ando, M., (1987), Shear-wave splitting in the upper-mantle wedge above the Tonga subduction zone: Geophysical Journal of the Royal Astronomical Society, v. 88, p. 25-41.

Chernyshev, I. V., S. N. Bubnov, V. A. Lebedev, Y. V. Gol'tsman, E. D. Bairova, and A. I. Yakushev (2014), Two stages of explosive volcanism of the Elbrus area: Geochronology, petrochemical and isotopic-geochemical characteristics of volcanic rocks, and their role in the neogene-quaternary evolution of the Greater Caucasus, Stratigr. Geol. Correl., 22(1), 96-121, doi: 10.1134/S086959381401002X.

DeMets, C., R. G. Gordon, D. F. Argus, and S. Stein (1990), Current plate motions, Geophysical Journal International, 101(2), 425-478, doi: 10.1111/j.1365246X.1990.tb06579.x.

Dewey, J. F., M. R. Hempton, W. S. F. Kidd, F. Saroglu, and A. M. C. Şengör (1986), Shortening of continental lithosphere: The neotectonics of Eastern Anatolia-A young collision zone, Geol. Soc. Lond. Spec. Publ., 19(1), 1-36, doi:10.1144/gsl.sp.1986.019.01.01.

Ershov, A.V. and Nikishin, A.M. (2004). Recent Geodynamics of the Caucasus-ArabiaEast Africa Region, Geotectonics, 38(2), 123-136.

Forsyth, D. W., S. C. Webb, L. M. Dorman, and Y. Shen (1998), Phase velocities of Rayleigh waves in the MELT experiment on the East Pacific Rise, Science, 280(5367), 1235-1238, doi:10.1126/science.280.5367.1235.

Forsyth, D. W., and A. Li (2005), Array analysis of two-dimensional variations in surface wave phase velocity and azimuthal anisotropy in the presence of multipathing interference, in Seismic Earth: Array Analysis of Broadband Seismograms, edited by A. Levander, and G. Nolet, pp. 81-97, AGU, Washington, D. C.

Godzikovskaya, A., and G. I. Reysner (1989), Endogenic position of deep earthquakes in the Caucasus, Geotectonics, 3, 205-213. Gök, R., E. Sandvol, N. Türkelli, D. Seber, and M. Barazangi (2003), Sn attenuation in the Anatolian and Iranian plateau and surrounding regions, Geophys. Res. Lett., 30(24), 8042, doi:10.1029/2003GL018020. 
Gök, R., E. Sandvol, N. Türkelli, D. Seber, and M. Barazangi (2003), Sn attenuation in the Anatolian and Iranian plateau and surrounding regions, Geophys. Res. Lett., 30(24), 8042, doi:10.1029/2003GL018020.

Gök, R., et al. (2011), Lithospheric velocity structure of the Anatolian plateau-CaucasusCaspian region, J. Geophys. Res., 116, B05303, doi:10.1029/2009JB000837.

Helffrich, G., P. Silver, and H. Given (1994), Shear-wave splitting variation over short spatial scales on continents, Geophysical Journal International, 119(2), 561-573, doi: 10.1111/j.1365-246X.1994.tb00142.x.

Innocenti, F., R. Mazzuoli, G. Pasquarè, F. Radicati Di Brozolo, and L. Villari (1982), Tertiary and quaternary volcanism of the Erzurumkars area (Eastern Turkey): Geochronological data and geodynamic evolution, Journal of Volcanology and Geothermal Research, 13(3-4), 223-240, doi: 10.1016/0377-0273(82)90052-X.

Karato, S.-I. (1987), Seismic Anisotropy Due to Lattice Preferred Orientation of Minerals: Kinematic or Dynamic?, in High-Pressure Research in Mineral Physics: A Volume in Honor of Syun-iti Akimoto, edited, pp. 455-471, American Geophysical Union.

Karato, S.-i., H. Jung, I. Katayama, and P. Skemer (2008), Geodynamic Significance of Seismic Anisotropy of the Upper Mantle: New Insights from Laboratory Studies, Annual Review of Earth and Planetary Sciences, 36(1), 59-95, doi: doi:10.1146/annurev.earth.36.031207.124120.

Kaviani, A., D. Hatzfeld, A. Paul, M. Tatar, and K. Priestley (2009), Shear-wave splitting, lithospheric anisotropy, and mantle deformation beneath the ArabiaEurasia collision zone in Iran, Earth and Planetary Science Letters, 286(3-4), 371-378, doi: 10.1016/j.eps1.2009.07.003.

Keskin, M. (2003), Magma generation by slab steepening and breakoff beneath a subduction-accretion complex: An alternative model for collision-related volcanism in Eastern Anatolia, Turkey, Geophys. Res. Lett., 30(24), 8046, doi:10.1029/2003GL018019.

Keskin, M. (2007), Eastern Anatolia: A hotspot in a collision zone without a mantle plume, Geol. Soc. Am. Spec. Pap., 430, 693-722, doi:10.1130/2007.2430(32). 
Koulakov, I., I. Zabelina, I. Amanatashvili, and V. Meskhia (2012), Nature of orogenesis and volcanism in the Caucasus region based on results of regional tomography, Solid Earth, 3(2), 327-337, doi:10.5194/se-3-327-2012.

Lay, T., and T. C. Wallace (1995). Modern Global Seismology, Academic Press, San Diego, 521p.

Lebedev, V. A., I. V. Chernyshev, and E. V. Sharkov (2011), Geochronological scale and evolution of late Cenozoic magmatism within the Caucasian segment of the alpine belt, Doklady Earth Sciences, 441(2), 1656-1660, doi: 10.1134/S1028334X11120051.

Lebedev, V. A., E. V. Sharkov, M. Keskin, and V. Oyan (2010a), Erratum: Geochronology of Late Cenozoic volcanism in the area of Lake Van, Turkey: An example of developmental dynamics for magmatic processes [Doklady earth sciences, 433(2), pp. 1031-1037], Doklady Earth Sciences, 435(1), 1548-1554, doi: 10.1134/S1028334X10110309.

Lebedev, V. A., I. V. Chernyshev, A. V. Chugaev, Y. V. Gol'tsman, and E. D. Bairova (2010b), Geochronology of eruptions and parental magma sources of Elbrus volcano, the Greater Caucasus: $\mathrm{K}-\mathrm{Ar}$ and $\mathrm{Sr}-\mathrm{Nd}-\mathrm{Pb}$ isotope data, Geochem. Int., 48(1), 41-67, doi: 10.1134/S0016702910010039.

Lee, K.-H., Z. Jiang, and S.-i. Karato (2002), A scanning electron microscope study of the effects of dynamic recrystallization on lattice preferred orientation in olivine, Tectonophysics, 351(4), 331-341, doi: 10.1016/S0040-1951(02)00250-0.

Lei, J., and D. Zhao (2007), Teleseismic evidence for a break-off subducting slab under Eastern Turkey, Earth Planet. Sci. Lett., 257(1-2), 14-28, doi:10.1016/j.eps1.2007.02.011.

Li, A. (2011), Shear wave model of southern Africa from regional Rayleigh wave tomography with 2-D sensitivity kernels, Geophys. J. Int., 185(2), 832-844, doi:10.1111/j.1365-246X.2011.04971.x.

Long, M. D. (2013), CONSTRAINTS ON SUBDUCTION GEODYNAMICS FROM SEISMIC ANISOTROPY, Reviews of Geophysics, 51(1), 76-112, doi: 10.1002/rog.20008. 
Maggi, A., and K. Priestley (2005), Surface waveform tomography of the Turkish-Iranian plateau, Geophys. J. Int., 160(3), 1068-1080, doi:10.1111/j.1365246X.2005.02505.x.

Mellors, R. J., J. Jackson, S. Myers, R. Gök, K. Priestley, G. Yetirmishli, N. Türkelli, and T. Godoladze (2012), Deep earthquakes beneath the northern Caucasus: Evidence of active or recent Subduction in western Asia, Bull. Seismol. Soc. Am., 102(2), 862-866, doi:10.1785/0120110184.

Mainprice, D., and B. Ildefonse (2009), Seismic Anisotropy of Subduction Zone Minerals-Contribution of Hydrous Phases, in Subduction Zone Geodynamics, edited by S. Lallemand and F. Funiciello, pp. 63-84, Springer Berlin Heidelberg.

Mainprice, D., G. Barruol, and W. B. IsmaïL (2000), The Seismic Anisotropy of the Earth's Mantle: from Single Crystal to Polycrystal, in Earth's Deep Interior: Mineral Physics and Tomography From the Atomic to the Global Scale, edited, pp. 237-264, American Geophysical Union.

McKenzie, D. (1972), Active Tectonics of the Mediterranean Region, Geophysical Journal of the Royal Astronomical Society, 30(2), 109-185, doi: 10.1111/j.1365246X.1972.tb02351.x.

McKenzie, D., and M. J. Bickle (1988), The Volume and Composition of Melt Generated by Extension of the Lithosphere, Journal of Petrology, 29(3), 625-679, doi: 10.1093/petrology/29.3.625.

Michard, A., H. Whitechurch, L. E. Ricou, R. Montigny, and E. Yazgan (1984), Tauric subduction (Malatya-Elazığ provinces) and its bearing on tectonics of the Tethyan realm in Turkey, Geological Society, London, Special Publications, 17(1), 361373, doi: 10.1144/gsl.sp.1984.017.01.26.

Mitchell, J., and R. Westaway (1999), Chronology of Neogene and Quaternary uplift and magmatism in the Caucasus: constraints from $\mathrm{K}-\mathrm{Ar}$ dating of volcanism in Armenia, Tectonophysics, 304(3), 157-186, doi: 10.1016/S0040-1951(99)00027$\mathrm{X}$.

Myers, S. C., G. Johannesson, and N. A. Simmons (2011), Global-scale P wave tomography optimized for prediction of teleseismic and regional travel times for Middle East events: 1. Data set development, J. Geophys. Res., 116, B04304, doi:10.1029/2010jb007967. 
Nishida, K., J.-P. Montagner, and H. Kawakatsu (2009), Global Surface Wave Tomography Using Seismic Hum, Science, 326(5949), 112, doi: 10.1126/science. 1176389 .

Parsons, T., G. A. Thompson, and N. H. Sleep (1994), Mantle plume influence on the Neogene uplift and extension of the U.S. western Cordillera?, Geology, 22(1), 83-86, doi:10.1130/0091-7613(1994)022<0083:mpiotn>2.3.co;2.

Paul, A., H. Karabulut, A. K. Mutlu, and G. Salaün (2014), A comprehensive and densely sampled map of shear-wave azimuthal anisotropy in the Aegean-Anatolia region, Earth and Planetary Science Letters, 389(0), 14-22, doi: 10.1016/j.epsl.2013.12.019.

Pearce, J. A., J. F. Bender, S. E. De Long, W. S. F. Kidd, P. J. Low, Y. Güner, F. Saroglu, Y. Yilmaz, S. Moorbath, and J. G. Mitchell (1990), Genesis of collision volcanism in Eastern Anatolia, Turkey, J. Volcanol. Geotherm. Res., 44(1-2), 189-229.

Philip, H., A. Cisternas, A. Gvishiani, and A. Gorshkov (1989), The Caucasus: An actual example of the initial stages of continental collision, Tectonophysics, 161(1-2), $1-21$.

Ribe, N. M. (1989), Seismic anisotropy and mantle flow, Journal of Geophysical Research: Solid Earth, 94(B4), 4213-4223, doi: 10.1029/JB094iB04p04213.

Reilinger, R., et al. (2006), GPS constraints on continental deformation in the AfricaArabia-Eurasia continental collision zone and implications for the dynamics of plate interactions, J. Geophys. Res., 111, B05411, doi:10.1029/2005JB004051.

Robertson, A. H. F., and G. Aktaş (1984), The Maden Complex, SE Turkey: evolution of a Neotethyan active margin, Geological Society, London, Special Publications, 17(1), 375-402, doi: 10.1144/gsl.sp.1984.017.01.27.

Rotstein, Y., and A. L. Kafka (1982), Seismotectonics of the southern boundary of Anatolia, eastern Mediterranean region: Subduction, collision, and arc jumping, Journal of Geophysical Research: Solid Earth, 87(B9), 7694-7706, doi: 10.1029/JB087iB09p07694. 
Russo, R. M., and P. G. Silver (1994), Trench-Parallel Flow Beneath the Nazca Plate from Seismic Anisotropy, Science, 263(5150), 1105-1111, doi:

10.1126/science.263.5150.1105.

Saintot, A., and J. Angelier (2002), Tectonic paleostress fields and structural evolution of the NW-Caucasus fold-and-thrust belt from Late Cretaceous to Quaternary, Tectonophysics, 357(1-4), 1-31, doi:10.1016/s0040-1951(02)00360-8.

Saintot, A., M. F. Brunet, F. Yakovlev, M. Sebrier, R. Stephenson, A. Ershov, F. ChalotPrat, and T. McCann (2006), The Mesozoic-Cenozoic tectonic evolution of the Greater Caucasus, Geol. Soc. Lond. Mem., 32(1), 277-289, doi:10.1144/gsl.mem.2006.032.01.16.

Sandvol, E., N. Türkelli, and M. Barazangi (2003a), The Eastern Turkey Seismic Experiment: The study of a young continent-continent collision, Geophys. Res. Lett., 30(24), 8038, doi:10.1029/2003GL018912.

Sandvol, E., N. Türkelli, E. Zor, R. Gök, T. Bekler, C. Gurbuz, D. Seber, and M. Barazangi (2003b), Shear wave splitting in a young continent-continent collision: An example from Eastern Turkey, Geophys. Res. Lett., 30(24), 8041, doi:10.1029/2003GL017390.

Seber, D., E. Sandvol, C. Sandvol, C. Brindisi, and M. Barazangi (2008), Crustal model for the Middle East and North Africa region: implications for the isostatic compensation mechanism, Geophys J, 147(3), 630-638, doi: 10.1046/j.0956540x.2001.01572.x.

Şengör, A. M. C., and W. S. F. Kidd (1979), Post-collisional tectonics of the TurkishIranian plateau and a comparison with Tibet, Tectonophysics, 55(3-4), 361-376.

Sengör, A. M. C., and Y. Yilmaz (1981), Tethyan evolution of Turkey: A plate tectonic approach, Tectonophysics, 75(3-4), 181-190. Şengör, A. M. C., S. Özeren, T. Genç, and E. Zor (2003), East Anatolian high plateau as a mantle-supported, north-south shortened domal structure, Geophys. Res. Lett., 30(24), 8045, doi:10.1029/2003GL017858.

Silver, P. G., and W. W. Chan (1991), Shear wave splitting and subcontinental mantle deformation, Journal of Geophysical Research: Solid Earth, 96(B10), 1642916454, doi: 10.1029/91JB00899. 
Smith, G. L., L. C. McNeill, K. Wang, J. He, and T. J. Henstock (2013), Thermal structure and megathrust seismogenic potential of the Makran subduction zone, Geophysical Research Letters, 40(8), 1528-1533, doi: 10.1002/grl.50374.

Triep, E. G., G. A. Abers, A. L. Lerner-Lam, V. Mishatkin, N. Zakharchenko, and O. Starovoit (1995), Active thrust front of the Greater Caucasus: The April 29, 1991, Racha earthquake sequence and its tectonic implications, J. Geophys. Res., 100(B3), 4011-4033, doi:10.1029/94JB02597.

Türkelli, N., et al. (2003), Seismogenic zones in eastern Turkey, Geophys. Res. Lett., 30(24), 8039, doi:10.1029/2003GL018023.

Türkoğlu, E., M. Unsworth, İ. Çağlar, V. Tuncer, and Ü. Avşar (2008), Lithospheric structure of the Arabia-Eurasia collision zone in eastern Anatolia: Magnetotelluric evidence for widespread weakening by fluids?, Geology, 36(8), 619-622, doi:10.1130/g24683a.1.

Ulomov, V. I., T. I. Danilova, N. S. Medvedeva, T. P. Polyakova, and L. S. Shumilina (2007), Assessment of seismic hazard in the North Caucasus, Izvestiya Phys Solid Earth, 43(7), 559-572, doi:10.1134/S1069351307070051.

Vincent, S. J., A. C. Morton, A. Carter, S. Gibbs, and T. G. Barabadze (2007), Oligocene uplift of the Western Greater Caucasus: an effect of initial Arabia-Eurasia collision, Terra Nova, 19(2), 160-166, doi: 10.1111/j.1365-3121.2007.00731.x.

Vincent, S. J., A. Carter, V. A. Lavrishchev, S. P. Rice, T. G. Barabadze, and N. Hovius (2010), The exhumation of the western Greater Caucasus: a thermochronometric study, doi: $10.1017 / \mathrm{S} 0016756810000257$.

Vinnik, L. P., L. I. Makeyeva, A. Milev, and A. Y. Usenko (1992), Global patterns of azimuthal anisotropy and deformations in the continental mantle, Geophysical Journal International, 111(3), 433-447, doi: 10.1111/j.1365246X.1992.tb02102.x.

Wolfe, C. J., and P. G. Silver (1998), Seismic anisotropy of oceanic upper mantle: Shear wave splitting methodologies and observations, Journal of Geophysical Research: Solid Earth, 103(B1), 749-771, doi: 10.1029/97JB02023. 
Yang, Y., and D. W. Forsyth (2006a), Regional tomographic inversion of the amplitude and phase of Rayleigh waves with 2-D sensitivity kernels, Geophys. J. Int., 166(3), 1148-1160, doi:10.1111/j.1365-246X.2006.02972.x.

Yang, Y., and D. W. Forsyth (2006b), Rayleigh wave phase velocities, small-scale convection, and azimuthal anisotropy beneath southern California, J. Geophys. Res., 111, B07306, doi:10.1029/2005JB004180.

Yilmaz, Y. (1993), New evidence and model on the evolution of the southeast Anatolian orogen, Geol. Soc. Am. Bull., 105(2), 251-271, doi:10.1130/00167606(1993)105<0251:neamot>2.3.co;2.

Zhou, Y., F. A. Dahlen, and G. Nolet (2004), Three-dimensional sensitivity kernels for surface wave observables, Geophys. J. Int., 158(1), 142-168, doi:10.1111/j.1365246X.2004.02324.x.

Zor, E. (2008), Tomographic evidence of slab detachment beneath eastern Turkey and the Caucasus, Geophys. J. Int., 175(3), 1273-1282, doi:10.1111/j.1365246X.2008.03946.x.

Zor, E., E. Sandvol, C. Gürbüz, N. Türkelli, D. Seber, and M. Barazangi (2003), The crustal structure of the East Anatolian plateau (Turkey) from receiver functions, Geophys. Res. Lett., 30(24), 8044, doi:10.1029/2003GL018192. 


\title{
Chapter 2
}

\section{UPPER MANTLE $S$ WAVE VELOCITY STRUCTURE OF THE EASTERN ANATOLIAN-CAUCASUS REGION ${ }^{1}$}

\begin{abstract}
Geodynamic processes occurring in the upper mantle such as slab break off and lithosphere delamination often result in high rates of lithospheric deformation and rapid tectonic uplift of large areas. The continent-continent collision zone between Arabia and Eurasia has been widely studied in this context but several different viable geodynamic models exist to explain the uplift and deformation of the Anatolian Plateau and the Caucasus Mountains. I have imaged the uppermost mantle shear wave velocity structure of the East Anatolian-Caucasus region using surface wave tomography to better understand the regional tectonic activity since the onset of the collision between the Arabian and Eurasian Plates. Furthermore, I used my tomographic models to better understand the processes, which are responsible for the formation of the $2 \mathrm{~km}$ high plateau and the widespread volcanism in eastern Turkey, as well as reactivation of deformation and deep seismicity in the eastern Greater Caucasus. Our model of regional upper mantle shear wave velocity structure supports subduction of the northern and southern branches of Neo-Tethys lithosphere between Eurasia and Gondwana and suggests a possible underthrusting of the Kura Basin lithosphere beneath the Greater Caucasus.

${ }^{1}$ Original article: Skobeltsyn, G., R. Mellors, R. Gök, N. Türkelli, G. Yetirmishli, and E. Sandvol (2014), Upper mantle $S$ wave velocity structure of the East Anatolian-Caucasus region, Tectonics, 33, doi:10.1002/2013TC003334.
\end{abstract}




\subsection{Introduction}

The East Anatolian-Caucasus region (Figure 2.1) is a part of an ongoing continentcontinent collision of the Arabian and Eurasian Plates, which is often compared to the collision zone between India and Eurasia during its early stage of evolution [e.g., Şengör and Kidd, 1979; Dewey et al., 1986]. The northward convergence of the Arabian Plate relative to Eurasia has produced predominately strike slip fault deformation within the

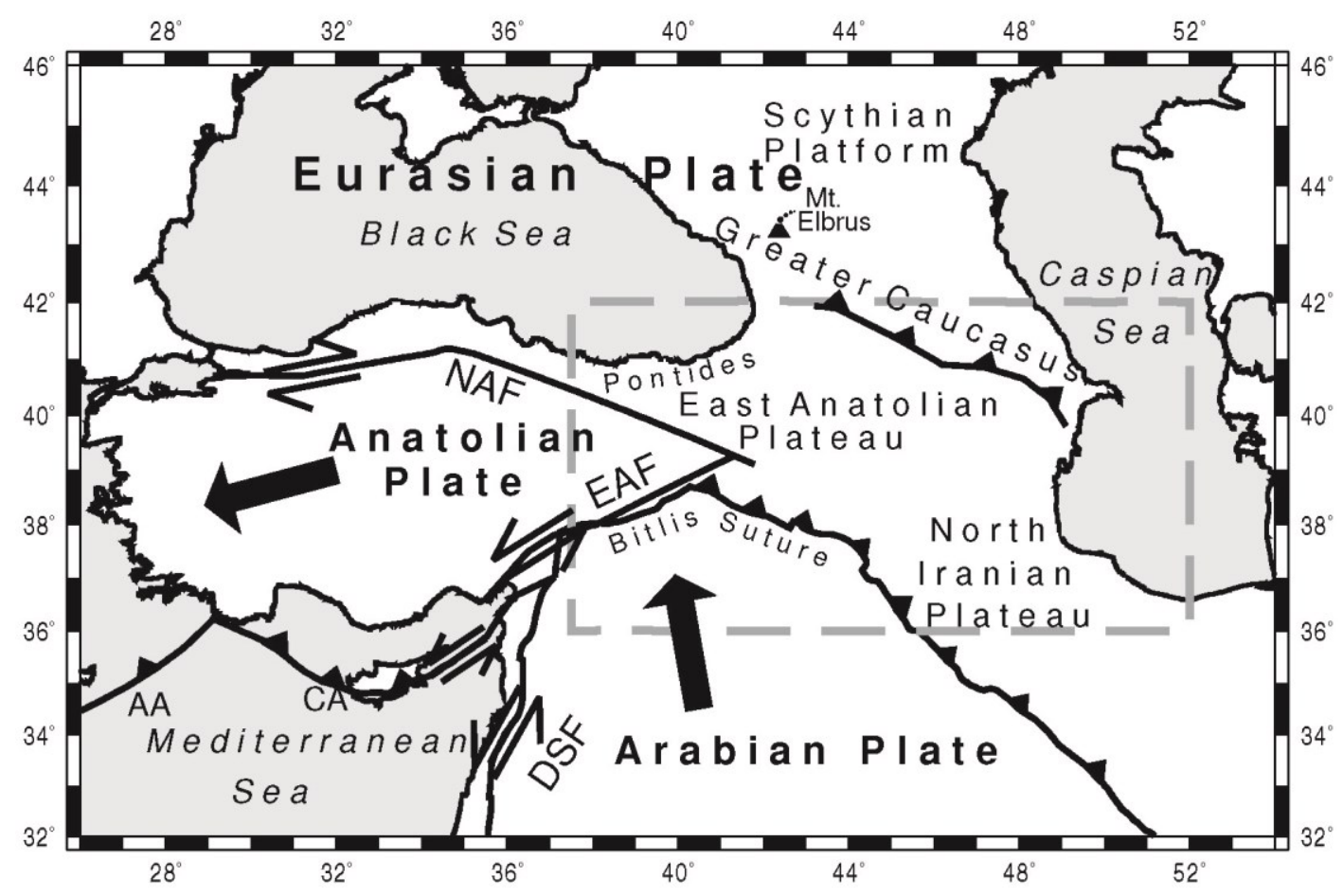

Figure 2.1. Map showing the major tectonic boundaries in eastern Turkey and the surrounding regions. The dashed frame shows the region of study. NAF North Anatolian Fault, EAF East Anatolian Fault, DSF Dead Sea Fault, AA Aegean Arc, and CA Cyprian Arc. Large arrows indicate directions of plate motion relative to Eurasia.

East Anatolian Plateau and was a major driving force that caused the Anatolian Plate to escape westward along the North and Eastern Anatolian fault zones. In comparison, the deformation style in the Greater Caucasus appears distinct from that in the East Anatolian 
Plateau and is mostly characterized by folds and thrust faults, which are parallel to the strike of the mountain belt.

A viable geodynamic model for the collision of the Arabian and Eurasian Plates must explain the temporal and spatial evolution in widespread volcanism and the crustal deformation. The East Anatolian Plateau is characterized by widespread collision-related (middle Miocene to present) alkaline volcanism decreasing in age from west to east [Keskin, 2007]. The composition varies from basaltic to rhyolitic, and the magmas appear to be derived from enriched mantle sources. Furthermore, the subduction component decreases from north to south [Pearce et al., 1990; Keskin, 2003, 2007]. Volcanism exists in the western Greater Caucasus (e.g., Mount Elbrus) [e.g., Koulakov et al., 2012] but not in the eastern Greater Caucasus. Shallow seismicity is prevalent throughout the region but clearly subcrustal (roughly defined as $>50 \mathrm{~km}$ ) events only occur in eastern Greater Caucasus, under the mid-Caspian, and at the edges of the south Caspian under the Kura Basin [e.g., Ulomov et al., 2007; Triep et al., 1995; Godzikovskaya and Reysner, 1989; Myers et al., 2011]. A striking cluster of deep (> $80 \mathrm{~km}$ ) events (Figure 2.2) also appears in the eastern Greater Caucasus [e.g., Godzikovskaya and Reysner, 1989], which may be caused by underthrusting or subduction of the Kura Basin lithosphere northward [e.g., Mellors et al., 2012], an idea that is consistent with plate motions vectors measured by GPS [Reilinger et al., 2006].

The Cenozoic geological structure of the East Anatolian-Caucasus region is the result of the closure of the Neo-Tethys, consequent collision, and suturing of the Arabian Plate with the Anatolian terrains and Eurasian Plate. Throughout the Mesozoic and most of the Cenozoic, two converging supercontinents, Gondwana in the south and Eurasia in 
the north, were separated first by the Paleo-Tethys and, subsequently, by two branches of the Neo-Tethys [Şengör and Yilmaz, 1981]. The northern oceanic branch of the NeoTethys was subducted beneath the southern margin of Eurasia, i.e., the Pontides, producing arc and back-arc volcanism, and was completely closed in the late Eocene [Şengör and Yilmaz, 1981; Dewey et al., 1986]. However, the southern oceanic branch of the Neo-Tethys ocean, an oceanic portion of the Arabian plate, continued subducting northward beneath the Bitlis arc until the middle Miocene and did not produce any associated arc volcanism during the last stages of subduction probably due to a shallow subduction angle [Yllmaz, 1993]. One proposed scenario for the evolution of the plate boundary is the subsequent gradual steepening and final breaking off of either of the branches of Neo Tethys lithosphere. That process enabled the hot asthenosphere to rise, which resulted in thermal weakening of the lithosphere beneath the East Anatolia, decompression melting of the asthenospheric material, and initiation of the widespread collision-related volcanism around $11 \mathrm{Ma}$ [e.g., Şengör et al., 2003; Keskin, 2007; Barazangi et al., 2006; Zor 2008]. The continued convergence of the Arabian Plate with Eurasia generated a compressive stress field that reactivated the deformation and uplift of the Greater Caucasus in the Pliocene [e.g., Saintot and Amgelier, 2002; Reilinger et al., 2006].

A number of studies have attempted to image the crustal and mantle structure of this enigmatic region. Teleseismic receiver functions indicate that the crustal thickness in East Anatolia ranges between 42 and $50 \mathrm{~km}$ [Zor et al., 2003]. Results of regional Sn attenuation studies [ e.g., Gök et al., 2003], together with the absence of subcrustal earthquakes across East Anatolia [Turkelli et al., 2003], combined with results of 
teleseismic $S$ wave receiver functions [Angus et al., 2006] suggest a very thin to absent mantle lid. Regional Pn tomography studies [Al-Lazki et al., 2003] show a vast lowvelocity zone in the East Anatolian and northern Iranian Plateaus and two high-velocity anomalies in the eastern Greater Caucasus and Talesh. These observations indicate that the plateau, which averages $2 \mathrm{~km}$ in elevation, is not isostatically compensated [Şengör et al., 2003]. These observations also correlate with a long-wavelength free-air positive gravity anomaly in the region, which is probably caused by low-density asthenosphere, which could support the high plateaus [Maggi and Priestley, 2005].

The spatial extent of the low-density asthenosphere is unclear. Teleseismic $P$ wave tomography [Zor, 2008] demonstrated that the low velocity beneath East Anatolian Plateau was quite shallow (e.g., 50-200 km) and underlain by a slab-like high-velocity body. Beneath the eastern part of Lesser Caucasus and the Kura Basin, however, the tomographic images show a high-velocity body down to depths of nearly $200 \mathrm{~km}$, which was interpreted as a lithospheric root. Lei and Zhao [2007], on the basis of a different method of teleseismic $P$ wave tomography but similar data set to Zor [2008], proposed that the observed low-velocity anomaly beneath the active volcanoes in the East Anatolian Plateau extends down to $400 \mathrm{~km}$ depth and could be associated with a smallscale mantle plume. A regional magnetotelluric study [Türkoğlu et al., 2008] shows that the upper mantle beneath Eastern Anatolia has a very low resistivity, which is consistent with the presence of shallow partially molten material beneath the region. Maggi and Priestly [2005] used surface waveform tomography to show that the Turkish-Iranian Plateau is underlain by asthenosphere in the depth range of 50-200 km; their model also 
images a high-velocity body beneath the eastern Greater Caucasus and the south Caspian Sea.

In this study, I employ event-based Rayleigh wave tomography to measure the spatial extent of the asthenospheric material and possible remnants of the Neo-Tethys slabs beneath East Anatolia, as well as the lithospheric structure beneath the Kura Basin and the eastern Greater Caucasus. The objective is to image the shear wave velocity structure of the upper mantle structure in the East Anatolian-Caucasus region, which is necessary to understand the Neogene-Quaternary tectonic evolution of the area. The results will also aid understanding of the early stages of continent-continent collision. This study differs from previous studies in two ways: first, I use an improved algorithm that includes finite-frequency effects and second, the study benefits from new permanent stations installed in Turkey and in Azerbaijan, which provide much better coverage in the Caucasus and Kura Basin region.

\subsection{Data collection and processing}

I collected seismic data from 29 temporary and 28 permanent broadband stations that have operated in the region of investigation (Figure 2.2). The main data set was obtained by a deployment of temporary Program for Array Seismic Studies of the Continental Lithosphere (PASSCAL) broadband stations, which recorded continuous data during the Eastern Turkey Seismic Experiment (late October 1999 to August 2001). This dataset was supplemented by continuous data from 13 permanent stations of Bogazici University and Kandilli Observatory and the Earthquake Research Institute 
(KOERI) and 15 permanent instruments of the National Seismic Network of Azerbaijan recording from January 2006 to July 2008.

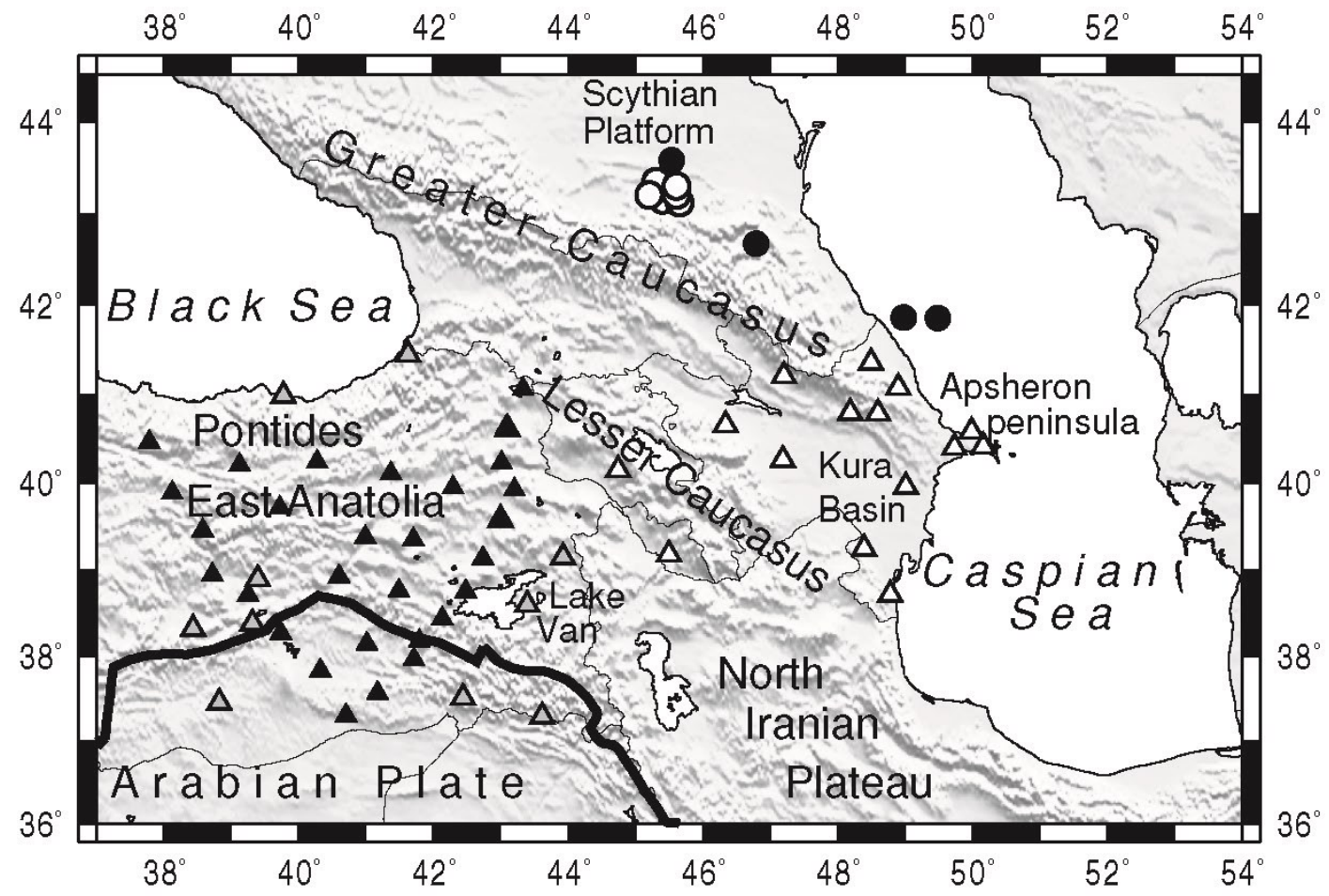

Figure 2.2. Topographic map showing the locations of the broadband seismometers used in this study. Black triangles - Eastern Turkey Seismic Experiment (ETSE) temporary array, white triangles - National Seismic Network of Azerbaijan, grey triangles instruments of Bogazici University and Kandilli Observatory and the Earthquake Research Institute (KOERI), white circles - locations of deep ( $>80 \mathrm{~km}$ depth) earthquakes in the Greater Caucasus from Godzikovskaya and Reysner [1989], and black circles - epicenters of subcrustal events in the Greater Caucasus from Myers et al. [2011].

I chose events with epicentral distances between 30 and $120^{\circ}$ from the center of our region and surface wave magnitudes greater than 5.8 in order to minimize the differences in source radiation patterns across the array and still get reasonable phase and amplitude data of fundamental mode Rayleigh waves. I used vertical component seismograms to avoid interference of Rayleigh waves with Love waves as well as horizontal tilt at the temporary stations. I normalized the selected data to the instrument 
response of the Streckeisen STS-2 sensor and corrected for the gain differences produced by different digitizers. The waveforms were filtered with a series of 13 band pass, zerophase shift, four-pole Butterworth windows centered at frequencies ranging from 0.007 to $0.05 \mathrm{~Hz}$ (centered periods: $143-20 \mathrm{~s}$ ). I used the filter window bandwidth of $3 \mathrm{mHz}$ for the centered periods ranging from 143 to $80 \mathrm{~s}$ in order to mitigate leakage of shorterperiod energy and produce the correct dominant periods in the filtered data. I used the bandwidth of $3 \mathrm{mHz}$ [e.g., Yang and Forsyth, 2006a, 2006b] to produce the shorter centered period (67-20 s) seismograms. I visually inspected the filtered seismograms for each event and discarded the stations with unreasonably high noise levels (SNR (signalto-noise ratio) $<3$ ). If the period corresponding to an event had fewer than 10 and 7 stations for the main and complementary datasets, respectively, it was removed from the subsequent data analysis; the minimum number of stations required for the wave front parameters inversion, which is discussed in the next section, is 4 [Weeraratne et al., 2003]. I were able to process the complementary data set for only 8 periods (143-40 s.) due to high noise levels at the shorter periods. As a result, I selected a total of 60 teleseismic events (38, main data set; 22, complementary data set), which provided us with a sufficient azimuthal coverage of the region (Figure 2.3). The remaining filtered seismograms were cut using a boxcar time window with a half cosine taper at each end and the same width for each event-period pair, in order to isolate the fundamental modes of Rayleigh waves from other seismic phases. The amplitudes of the isolated phases were corrected for geometrical spreading on a spherical Earth. 


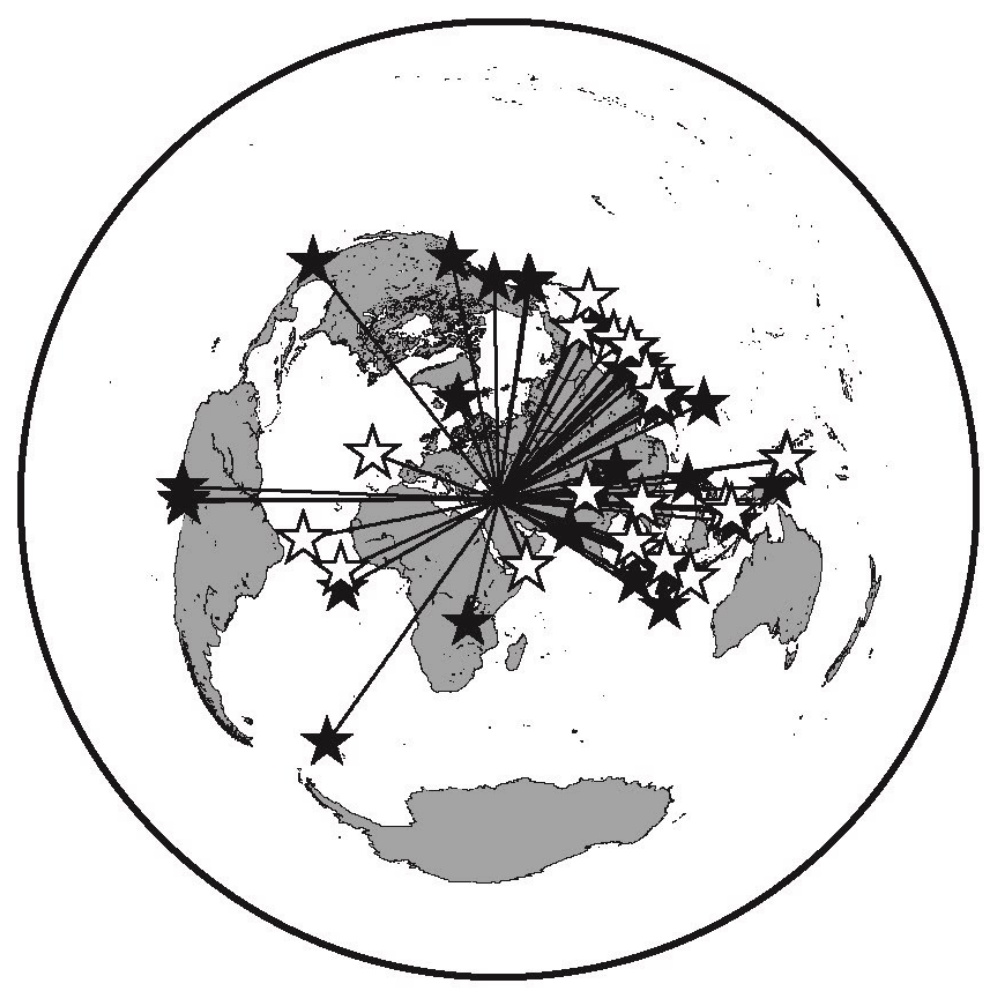

Figure 2.3. World map showing the epicenters of selected teleseismic earthquakes. Black stars - events representing the main data set, and white stars - complimentary data set.

\subsection{Method}

Long-period Rayleigh waves depend more strongly on $S V$ wave velocities than on $P$ wave velocity and density in the upper mantle. On the other hand, the wavelength of surface waves determines the thickness of the medium that they sample, which produces dispersion of surface waves when they propagate in a vertically inhomogeneous Earth interior. As a result, we can invert Rayleigh wave phase velocity dispersion curves for $S V$ wave velocity structure with a better depth resolution than that of body wave tomography. 
In order to model the Rayleigh wave phase velocity structure of the region, I use the two-plane wave tomography method of Yang and Forsyth [2006a, 2006b] that has three main advantages with respect to traditional surface wave tomography techniques that assume that surface waves propagate as single plane waves along a great circle raypaths. First, in the two-plane wave approach, each incoming fundamental mode of Rayleigh waves is represented as an interference of two plane waves to better approximate the effect of the structure on the complex wavefield [Forsyth et al., 1998]. Second, both the phase and amplitude data are used in the inversion to better recover the magnitudes of the phase velocity anomalies [Forsyth and $L i$, 2005]. Finally, this technique employs 2-D single scattering (Born) approximation kernels [Zhou et al., 2004] to take into account finite frequency effects and describe the sensitivity of phase and amplitude of Rayleigh waves to the local structure [Yang and Forsyth, 2006a, 2006b], which helps in recovering phase velocity anomalies whose dimensions are close to the wavelength. The two-plane wave method has been described in detail by its authors [e.g., Forsyth and Li, 2005; Yang and Forsyth, 2006a, 2006b; Li, 2011].

Two-stage inversion is applied to resolve for 6 wavefield parameters (the amplitude, reference phase, and direction for each of the two waves) as well as 1 isotropic and 2 anisotropic phase velocity coefficients at each grid node for a given frequency based on the phase and amplitude information gathered at the stations [Forsyth and Li, 2005; Yang and Forsyth, 2006a, 2006b]. During the first stage of inversion, the velocity structure is fixed and I only solve for the wavefield parameters by means of a simulated annealing inversion schema. During the last stage of inversion, I solve for the remaining model parameters including isotropic and anisotropic phase velocity 
coefficients at each grid node, as well as for changes to the wavefield parameters by applying a standard, iterative, linearized inversion method [Tarantola and Valette, 1982].

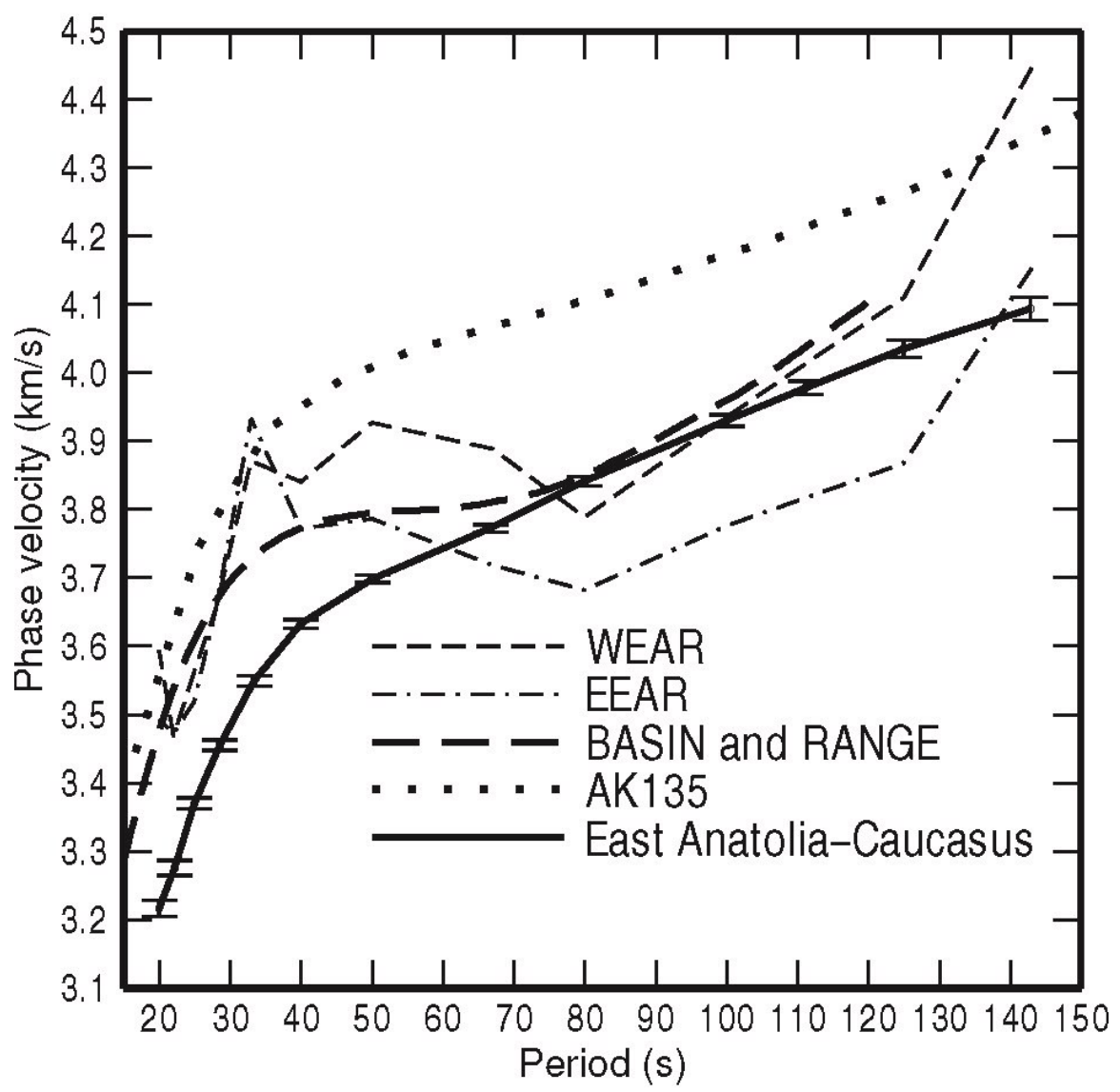

Figure 2.4. Average dispersion curve in the study area (solid line). WEAR - the western branch of East African Rift [Weeraratne et al., 2003], EEAR - the eastern branch of East African Rift [Weeraratne et al., 2003], Basin and Range dispersion curve is from Priestley and Brune [1978], and AK135 - theoretical dispersion curve for the average Earth model.

I begin with calculating a 1-D Rayleigh wave isotropic phase velocity model (Figure 2.4) by assuming a uniform phase velocity for each period and using a theoretically computed fundamental mode Rayleigh wave dispersion curve of AK135 $S$ wave velocity model [Kennett et al., 1995] as the starting model in the inversion. I calculate phase velocities at 372 grid nodes at regularly spaced intervals of $0.5^{\circ}$ to 
accommodate for the average distance between the stations in the study area. I use the resulting average regional phase velocity dispersion curve for calculating the 2-D sensitivity kernels and as the starting model for 2-D Rayleigh wave phase velocity inversion. In this inversion, I add 2 outer rows and columns of grid nodes to the existing grid and assign higher a priori errors for them in order to absorb the irregularities in the incoming wavefield that are caused by the velocity variations outside of the array and cannot be reliably determined by the two-plane wave approximation [e.g., Yang and Forsyth, 2006a, 2006b]. I chose $80 \mathrm{~km}$ as the length for the Gaussian weighted function to smooth both the 2-D sensitivity kernels in the inversion and the phase velocities from the grid nodes to produce the phase velocity maps with a grid spacing of 0.1 degrees. The use of this length produced the most consistent phase maps of the neighboring periods without adding false small-scale anomalies, which appeared when I used shorter lengths. Longer smoothing lengths resulted in decreasing amplitudes of velocity perturbations. As the 2-D sensitivity kernels account for finite frequency effects, there is no need to change the smoothing length for different periods unlike in the earlier versions of the two-plane wave method [e.g., Weeraratne et al. 2003] where a Gaussian sensitivity function with a period-dependent smoothing length was used instead.

I use the DISPER80 algorithm [Saito, 1988] to invert Rayleigh wave phase velocities for $S V$ wave velocities as a function of depth. The method calculates the partial derivatives of phase velocities with respect to model parameters such as density, $P$ and $S$ wave velocities, and the synthetic phase velocities that best fit the real phase data while keeping constant $\mathrm{Vp} / \mathrm{Vs}$ ratio and densities at depths to reduce the number of model parameters. 
I use the AK135 $S$ wave velocities (Figure 2.5) with an average regional Moho depth of $44 \mathrm{~km}$ calculated from the crustal thickness model of Gök et al. [2011] combined with CRUST2.0 [Bassin et al., 2000] as a starting model in the inversion. After I ran numerous tests of DISPER80 using different numbers of layers and layer thicknesses, I decided to use a 25-layer structure in our inversion for the optimal 1-D $S$ wave velocity model. In order to determine the three dimensional $S$ wave velocity model, I computed 1-D inversion at each node in our model using our 1-D $S$ wave velocity model with a heavily smoothed regional crustal thickness model as a starting model. Since I processed the data at 13 and 8 periods for the main data set (Eastern Turkey Seismic Experiment (ETSE)) and complementary data set, respectively, I divided our study area into two regions where I used a different number of periods in the inversion. I used the phase velocity results of all 13 periods in the inversion west of $44^{\circ} \mathrm{E}$, where the ETSE temporary array was deployed, and 8 periods (143-40 s) in the rest of our model area. I ran numerous tests where I used a uniform number of frequencies across our model region and found that the use of shorter period data $(\mathrm{T}<40 \mathrm{~s})$ in the inversion greatly affects the crustal $S$ wave velocity results and causes only minor changes to the upper mantle structure. 


\subsection{Results}

\subsubsection{1-D Rayleigh wave phase and $S$ wave velocity models}

The uniform Rayleigh wave phase velocity model of the East Anatolian-Caucasus region demonstrates significantly lower values of fundamental mode phase velocities in comparison with the theoretical dispersion curve of the average Earth model at all of the periods (Figure 2.4), which suggests an upper mantle with significant amounts of partial melt. However, due to high noise levels in the data recorded by the stations located in Azerbaijan, the dispersion curve describes the whole region only at the period range of 143 to $40 \mathrm{~s}$. At the shorter periods, the phase velocity model describes East Anatolia. The distinct characteristics of the dispersion curves, which were modeled separately for the East Anatolian Plateau (Figure 2.6) and the eastern Caucasus region (i.e. eastern Greater Caucasus, Kura Basin, and northeastern Lesser Caucasus) (Figure 2.7) suggest different lithospheric thicknesses in those areas. The Eastern Anatolia is responsible for the contribution to low phase velocities in the study region while the dispersion curve of the Caucasus region is closer to the theoretical dispersion curve of AK135.

The 1-D $S$ wave velocity model for our region (Figure 2.5 ) has lower values in comparison with the AK135 model as expected from the regional dispersion curve; however, I can observe an ultralow-velocity upper mantle zone (nearly 10\% lower than AK135) at a depth range between 70 and $150 \mathrm{~km}$. Our 1-D $S$ wave velocity model agrees 


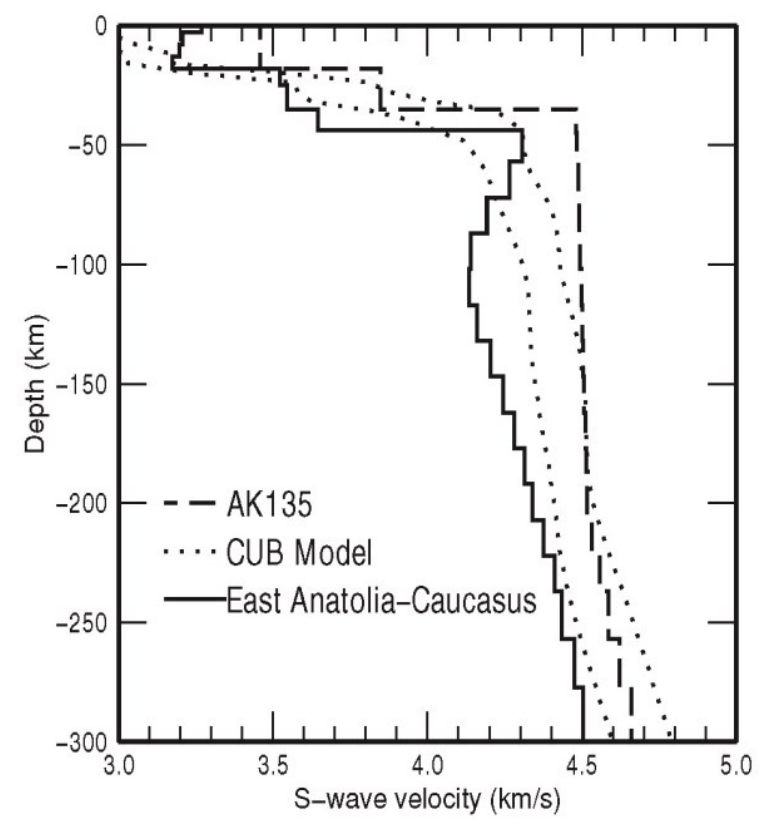

Figure 2.5. One-dimensional shear wave velocity model of the region (solid line). AK135 shear wave velocity model of the Earth [Kennett et al., 1995], CUB model average corridor of vertically polarized $S$ wave velocities of the region [Ritzwoller et al., 2002].

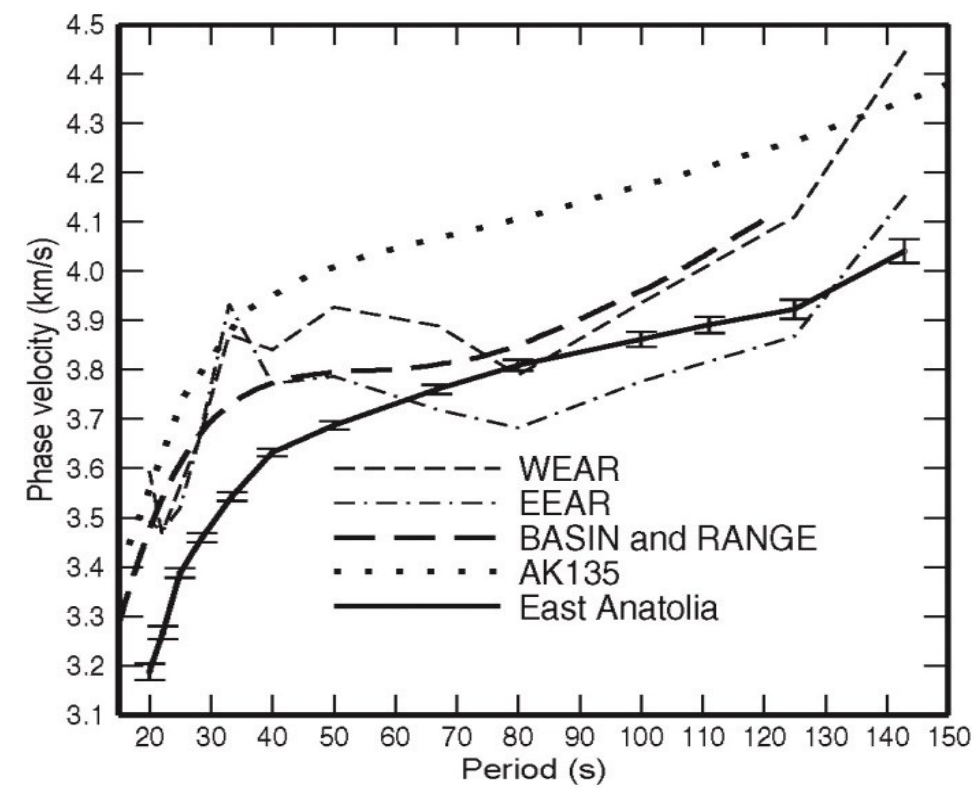

Figure 2.6. Average dispersion curve in the Eastern Anatolia (solid line). WEAR - the western branch of East African Rift [Weeraratne et al., 2003], EEAR - the eastern branch of East African Rift [Weeraratne et al., 2003], Basin and Range dispersion curve is from Priestley and Brune [1978], and AK135 - theoretical dispersion curve for the average Earth model. 


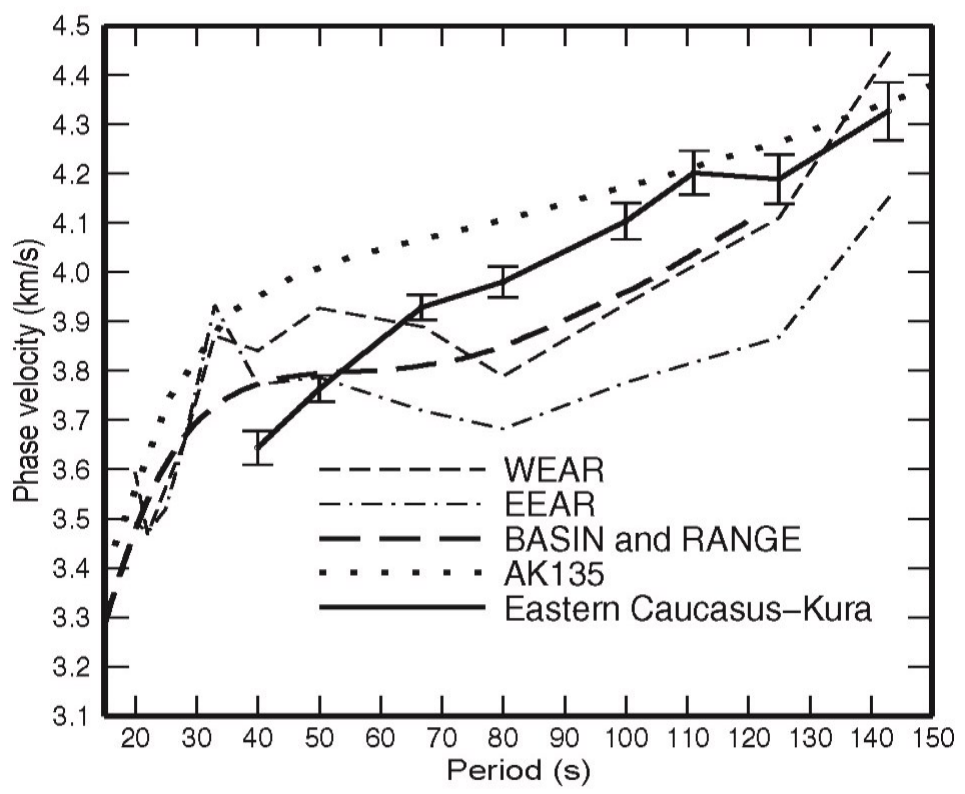

Figure 2.7. Average dispersion curve in the eastern Caucasus region (solid line). WEAR - the western branch of East African Rift [Weeraratne et al., 2003], EEAR - the eastern branch of East African Rift [Weeraratne et al., 2003], Basin and Range dispersion curve is from Priestley and Brune [1978], and AK135 - theoretical dispersion curve for the average Earth model.

well with the top (depth $<70 \mathrm{~km}$ ) and the bottom (depth $>200 \mathrm{~km}$ ) parts of the CUB (Colorado University at Boulder) model for East Anatolia, which was derived from independent group velocity results of global diffraction tomography [Ritzwoller et al., 2002]. The velocities of both models are slower than those of AK135 in the crust and uppermost mantle. However, the limits of the velocity corridor of the CUB model do not show the low upper mantle velocity zone, observed in our model, probably due to larger $\left(2^{\circ}\right)$ node spacing and a less ray path density in the region for the global model.

\subsubsection{2-D phase velocity model}

The station array distribution and ray coverage of a study region play a major role in affecting the reliability of the results of a 2-D Rayleigh wave phase velocity 
inversion. In other words, the phase velocity structure that is located inside of the station array, providing good ray coverage, is more reliable than that outside of the array. A checkerboard resolution test, although it does not account for finite frequency effects, provides a relatively good test of our ray coverage. Our checkerboard Rayleigh wave phase velocity test results (Figure 2.8) show that I can resolve the general structure of the input model for a $2^{\circ}$ by $2^{\circ}$ cell size of velocity anomaly for East Anatolia without a great deal of smearing at most of the periods. Due to high noise levels in the data set from the Azerbaijan's network, I were unable to use it for the periods shorter than $40 \mathrm{~s}$ and therefore excluded it from the inversion which resulted in smearing of the anomalies in the Caucasus Mountains and northern Iranian Plateau at those periods. However, the phase velocities of the periods of 33 to $20 \mathrm{~s}$ are more sensitive to the crustal structure than to the upper mantle. Therefore, in theory, our phase velocity model should reliably describe the upper mantle velocity structure of the whole study region. Although, as expected, the test results demonstrate that I underestimate the magnitudes of velocity anomalies in the region of investigation.

Reliability of the regional Rayleigh wave velocity structures observed in our model can be judged upon both our checkerboard test results and consistency of the phase velocity maps of adjacent periods (Figure 2.9). Longer period phase velocity structures such as the high-velocity anomalies beneath the Black Sea and Pontides and beneath northern Iran lie in the zone of good ray coverage and can be consistently seen at the period range of $143-80 \mathrm{~s}$. The peak sensitivity depth of phase velocities to the $S V$ velocity structure is roughly equal to $1 / 3$ of the wavelength. The approximate peak sensitivity depth range of the observed velocity anomalies is $100-200 \mathrm{~km}$. Therefore, they represent 
real upper mantle velocity structures of the region. The same can be said about the highvelocity bodies beneath the north-east Arabia (80-50 s), the Black Sea (50-40 s), and the eastern Greater Caucasus and Kura Basin (111-50 s) as well as the low-velocity anomaly, which can be observed through most of the periods in the East Anatolia and at intermediate periods (80-40 s) in northern Iran. On the contrary, the high-velocity anomaly in the south Caspian Basin is outside of our array and represents eastward smearing of the eastern Greater Caucasus and Kura Basin anomaly.

The 2-D phase velocity model was inverted including anisotropic coefficients of phase velocity, which allowed us to compute Rayleigh wave phase velocity anisotropy in the region. First, I calculated uniform phase velocity anisotropy for the whole region (Figure 2.10). The fast directions for the periods of 143, 125, 100, 80, 67, 40, and $33 \mathrm{~s}$ were consistent with the interpretation of Sandvol et al., [2003a, 2003b]. The magnitude of the observed anisotropy suggests that the uppermost mantle (the upper $\sim 150 \mathrm{~km}$ of the mantle) is only weakly anisotropic and confirms the suggestion of Sandvol et al. [2003b] that most of the SKS and SKKS delay times ( $\delta \mathrm{t}>1 \mathrm{~s})$ are associated with anisotropy in the deeper part of the upper mantle. The other periods showed a null anisotropy in our region possibly due to high errors caused by noise in the data. In addition, I tested the hypothesis that small subregions located in our study area had different fast directions that canceled each other and produced low overall anisotropy values for the region as a whole. I parameterized our inversion for anisotropic phase velocities by dividing it into six, eight, and 16 subregions. However, in all of the three cases, the phase velocity anisotropy for nearly all of the sub-regions had errors that were larger than the anisotropy values. In our opinion, the high noise in the data could be a possible reason for the high 
anisotropic errors, but it appears that the uppermost mantle beneath eastern Anatolia is only weakly anisotropic and possibly isotropic.

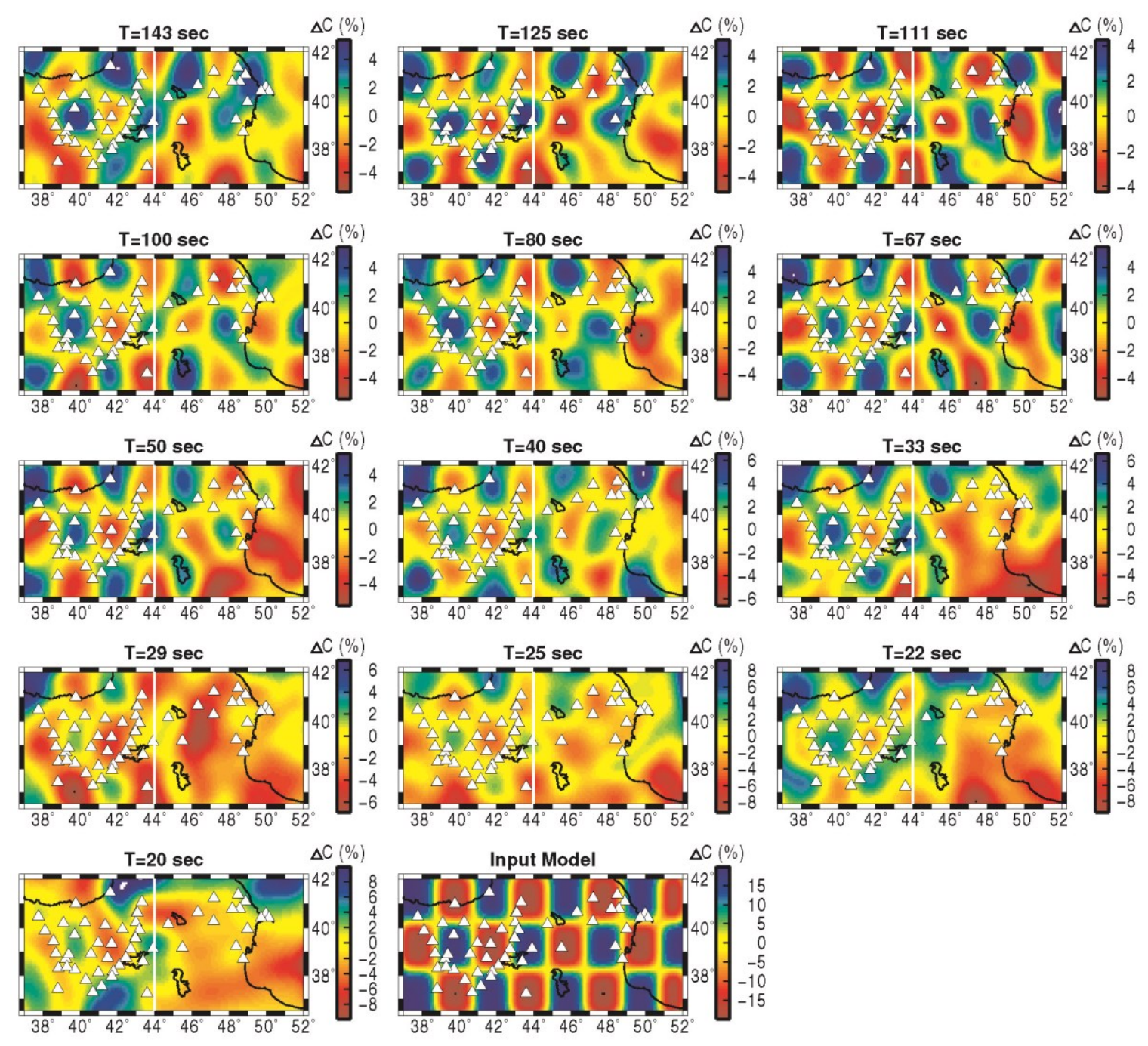

Figure 2.8. Checkerboard test results of Rayleigh wave phase velocity resolution. Dashed white line - the boundary between the regions where different numbers of frequencies were used in the $S$ wave velocity inversion, and white triangles - seismic stations. 


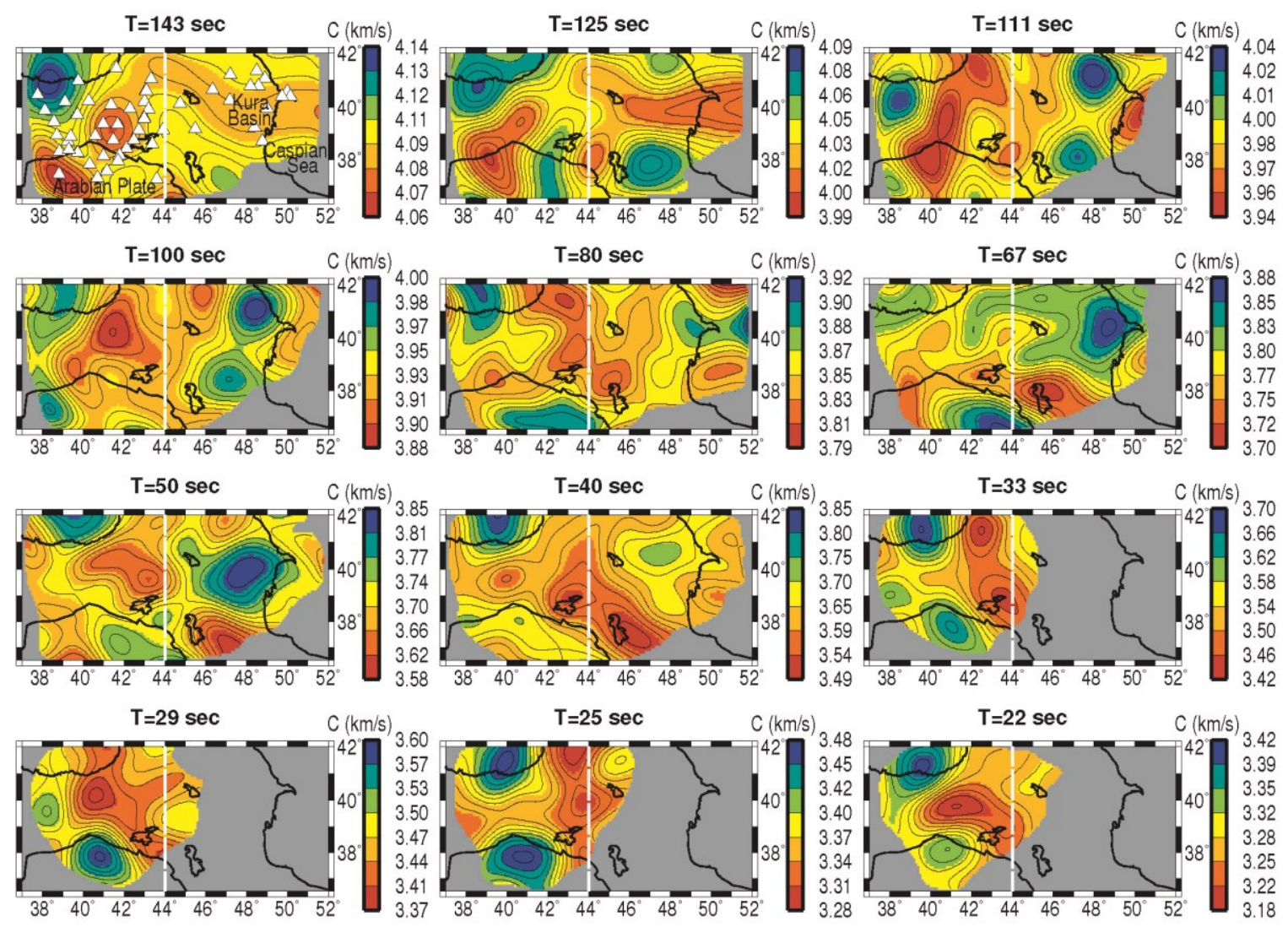

Figure 2.9. Maps of fundamental mode Rayleigh wave phase velocity for different periods. The maps are clipped using twice the standard error estimate of $0.07 \mathrm{~km} / \mathrm{s} \mathrm{of}$ phase velocity for the periods of $143-80 \mathrm{~s}$ and $0.05 \mathrm{~km} / \mathrm{s}$ for the periods of $67-22 \mathrm{~s}$. Dashed white line - the boundary between the regions where different numbers of frequencies were used in the $S$ wave velocity inversion. 


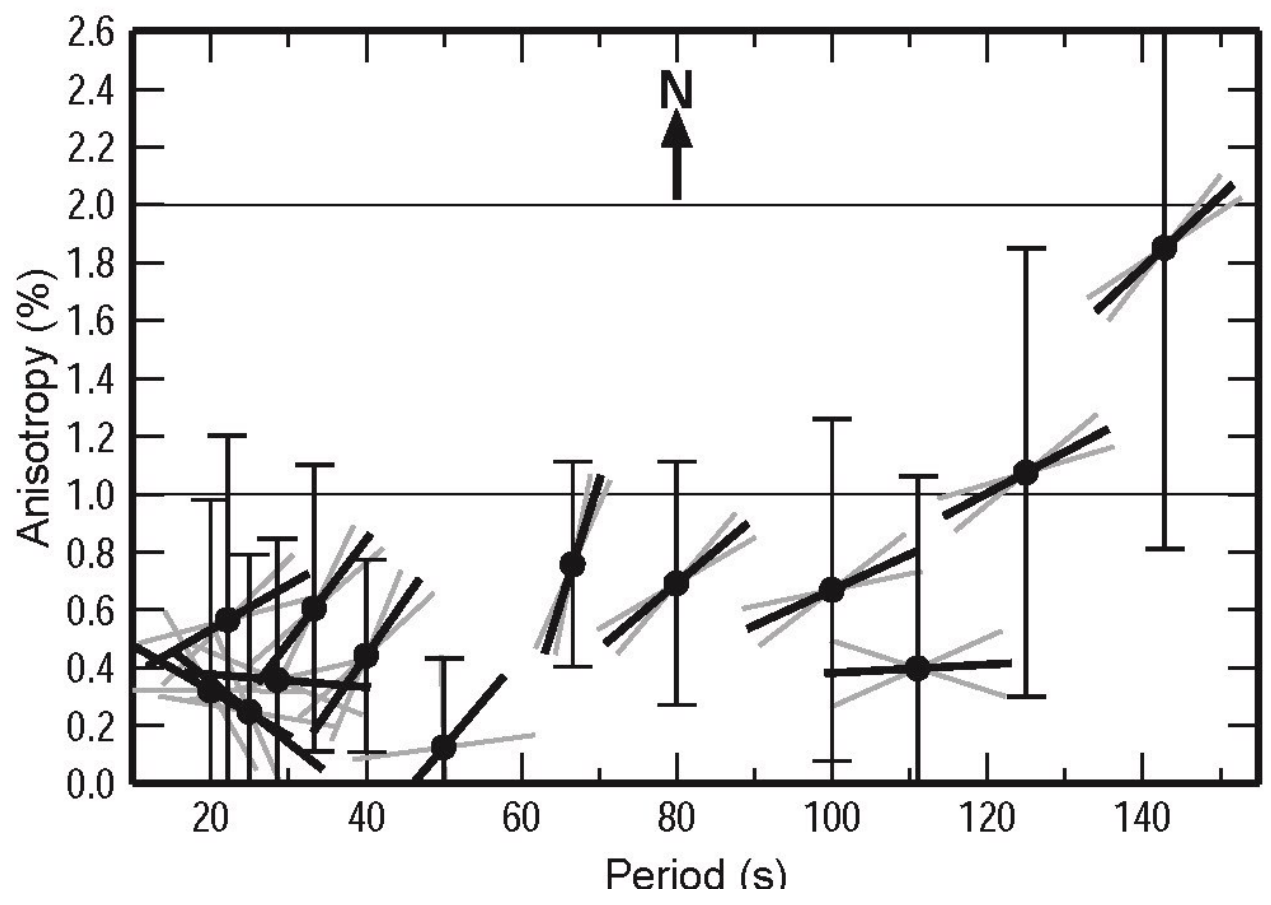

Figure 2.10. Average Rayleigh wave azimuthal anisotropy in the region. Black lines fast directions with vertical as north, vertical bars -1 standard deviation of the strength of anisotropy, and grey lines - standard errors in azimuth.

\subsubsection{3-D $S$ wave velocity model}

The problem of nonuniqueness of surface wave inversion can affect greatly the structure of an $S$ wave velocity model as different $S$ wave velocity profiles can produce dispersion curves with very close fits to the experimental one. However, I keep the thicknesses of most of the starting model layers constant and only adjust those layers, which are affected by the changes in the regional crustal thickness, thus greatly minimizing the number of possible solutions in the inversion. Nevertheless, such a fixed layer structure of our starting model does not completely eliminate all the problems related to the inversion method, and I had to adjust some inversion parameters such as 
damping, the number of iterations, etc., (see the appendix $2 \mathrm{~A} 1$ for examples) in order to remove the artifacts which contradicted the 2-D phase velocity model.

The pattern of lateral distribution of upper mantle $S$ wave velocity anomalies (Figures 2.11-2.13) in the region is very similar to that of the phase velocity model; most of the velocity anomalies preserved their spatial coordinates and only changed their shapes as the result of the inversion. The longer period high-velocity anomalies beneath the Pontides and Black Sea and beneath northern Iran are presented by slab-like bodies in the 3-D $S$ wave velocity model at depths below $140 \mathrm{~km}$. The high-velocity body beneath the Pontides and Black Sea is clearly visible in the teleseismic $P$ wave tomography models of Lei and Zhao [2007] (below $\sim 150 \mathrm{~km}$ depth) and Zor [2008] (below $200 \mathrm{~km}$ depth). Furthermore, the teleseismic $P$ wave tomography model of Biryol et al. [2011] images both deep positive velocity anomalies $\sim 200 \mathrm{~km}$ beneath the Pontides and northern Iran. Therefore, these two deep positive $S$ wave velocity anomalies, which are observed in our model, agree well laterally with the body wave tomography results. This fact supports the robustness of our model at depth below $150 \mathrm{~km}$ as teleseismic body wave tomography results usually have very good lateral resolution. The discrepancies in depths ranges of the observed anomalies between our results and the body wave tomography models can be explained by differences in sensitivity of propagation velocity of shear and compression waves to the physical properties of the medium as well as a better vertical resolution of surface wave tomography. 

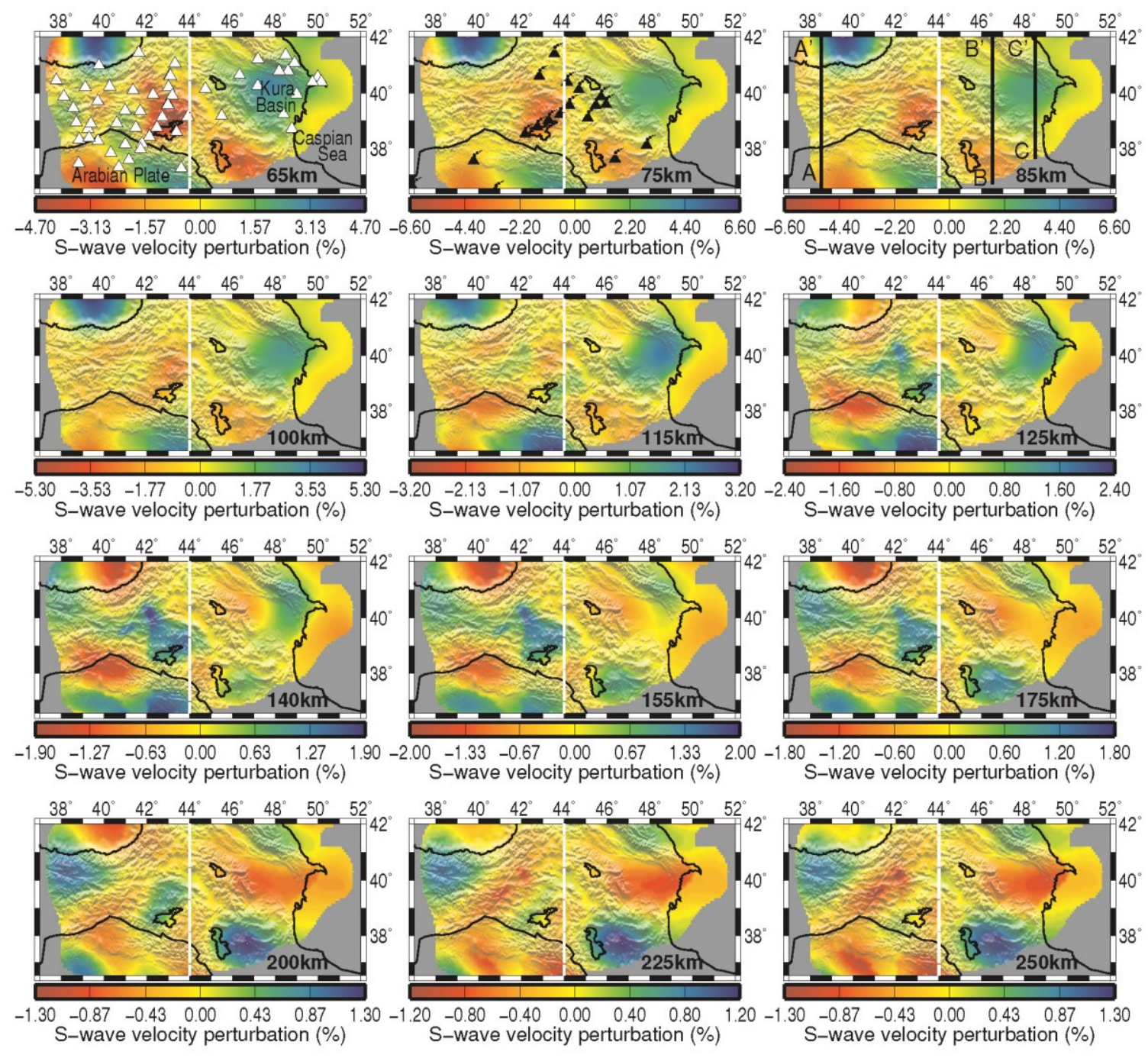

Figure 2.11. Maps of shear wave velocity perturbations that are calculated relative to the average shear wave velocity at the depth. The maps are clipped at the twice the standard deviation of $0.062 \mathrm{~km} / \mathrm{s}$ of phase velocity at the period of $50 \mathrm{~s}$. White triangles - seismic stations, volcano symbols - Holocene Volcanoes, north south solid black lines - locations of the vertical cross sections, and dashed white line - the boundary between the regions where different numbers of frequencies were used in the inversion. 


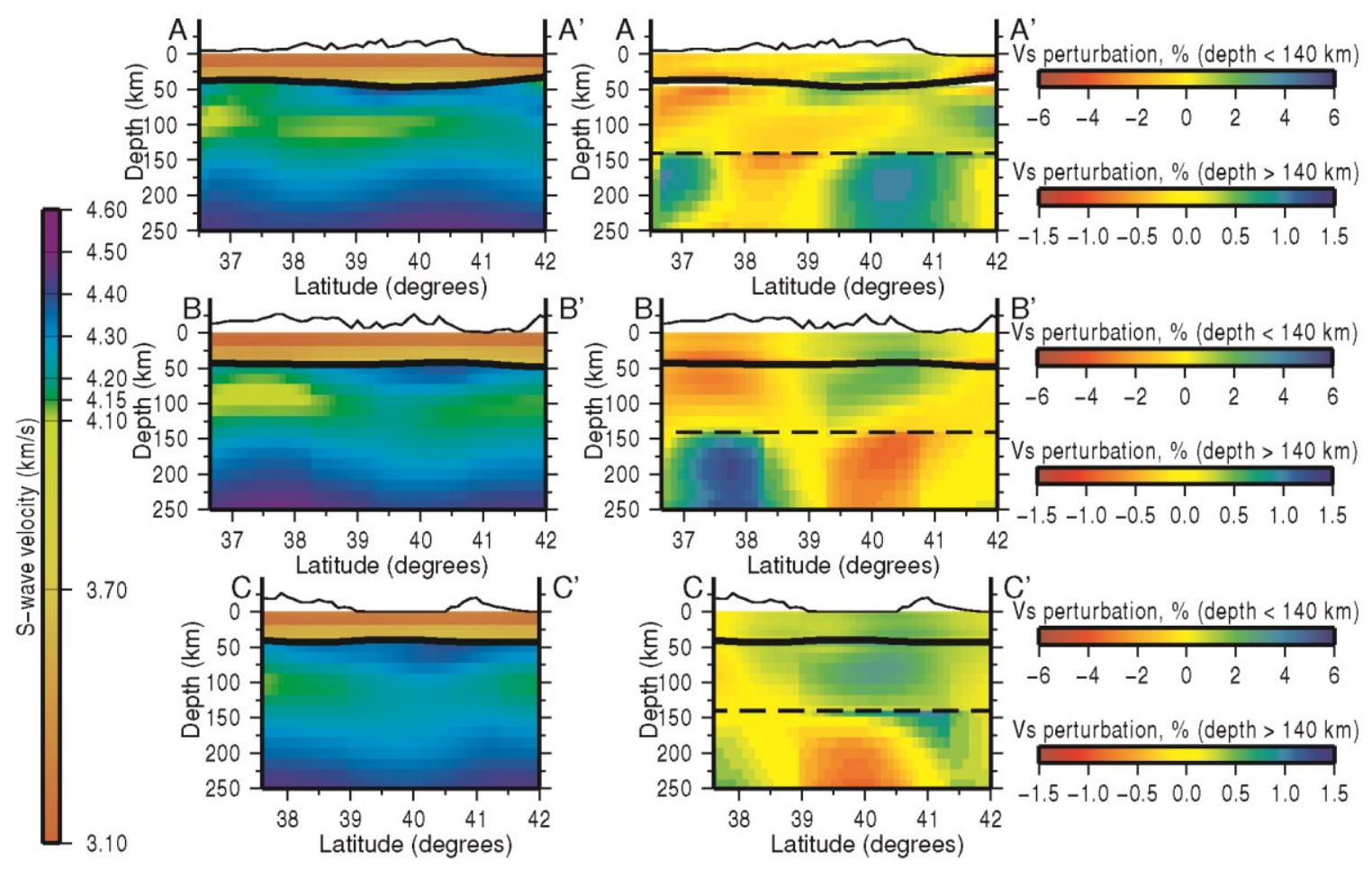

Figure 2.12. Vertical N-S cross sections showing (left) shear wave velocities, and (right) their perturbations relative to the average shear wave velocity at the depth. Positive topography is overestimated by a factor of 10 .

Another high $S$ wave velocity body appears in the middle of our study region at a depth range of $120-210 \mathrm{~km}$. These high $S$ wave velocities are right below the shallow low-velocity body ( $<100 \mathrm{~km}$ depth) and, thus, could be an inversion artifact. I have explored this possibility by experimenting with a large number of damping parameters; however, this anomaly always persists. This high-velocity structure is laterally disconnected from the high $S$ wave velocity bodies below Pontides and northwestern most Iran, the top of the structure is shallower, and the body does not extend as deep as they do. These factors are very important for the tectonic interpretation of this velocity structure. 

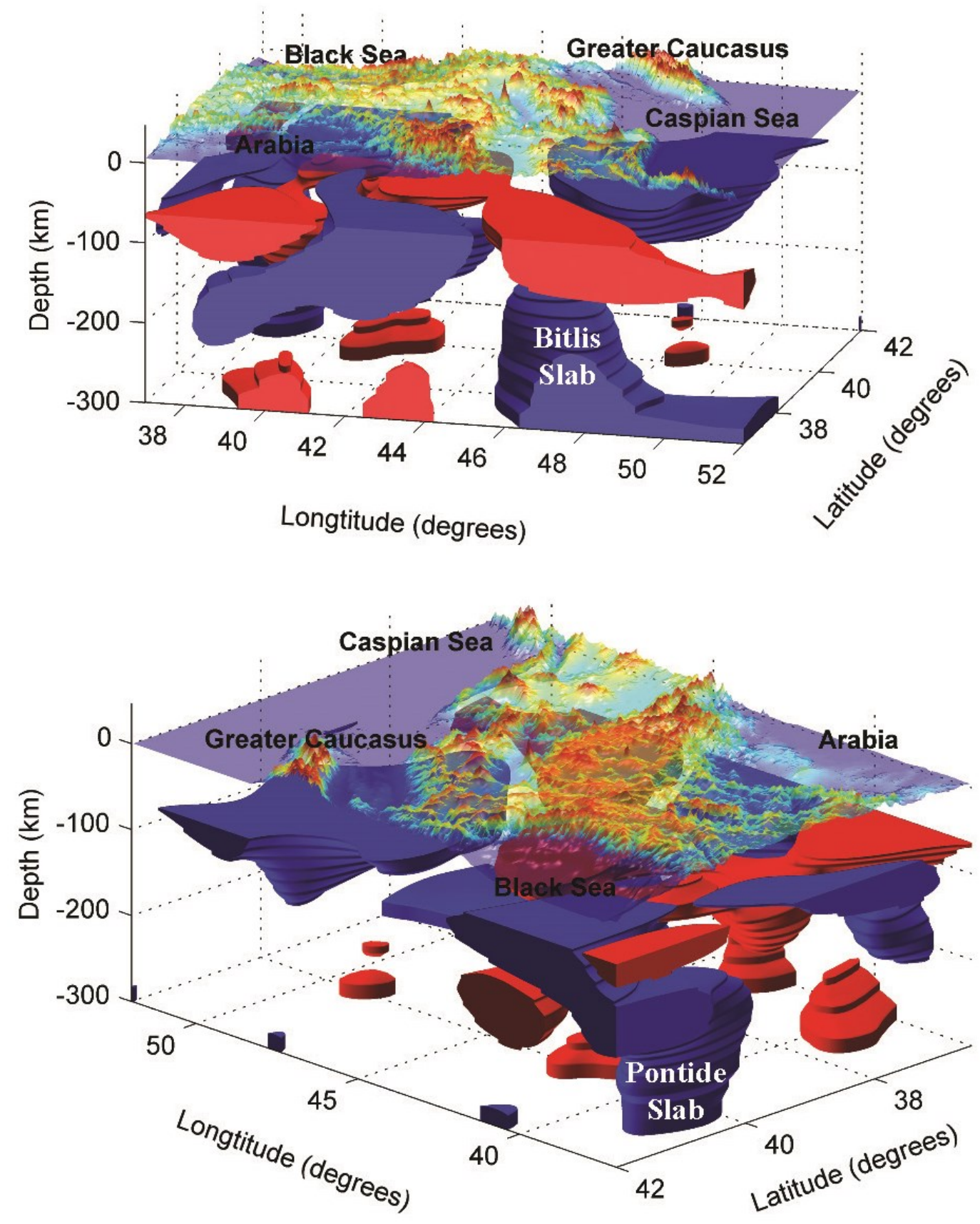

Figure 2.13. Three-dimentional views of iso surfaces drawn around $+0.5 \%$ (blue) and $0.8 \%$ (red) of $S$ wave velocity perturbation relative to the average velocity at the depth. 
The low phase velocity anomaly observed in Eastern Anatolia phase velocity maps at nearly all periods, extends from just below the Moho to depths of $150 \mathrm{~km}$. However, the North Iranian low-velocity layer is thinner and lies in the depth range of 30 $\mathrm{km}$ bellow the crust to $140 \mathrm{~km}$. The $80-50 \mathrm{~s}$ period high phase velocity anomaly below the northeastern part of Arabia is related to the positive $S$ wave velocity anomaly, which reaches the maximum depth of $180 \mathrm{~km}$. The $50-33 \mathrm{~s}$ high phase velocity Black Sea anomaly was caused by the $S$ wave velocity structure above the depth of $125 \mathrm{~km}$. Our model of the shallow ( $<150 \mathrm{~km}$ depth) upper mantle $S$ wave velocity structure of the region is very similar to the results of Pn tomography of Al-Lazki et al. [2003], which show the existence of high-velocity anomalies in the Black Sea and north-east Arabia and a low-velocity zone in the East Anatolian Plateau.

I observe a high $S$ wave velocity anomaly beneath the eastern part of the Greater Caucasus and the Kura Basin from subcrustal depths down to $250 \mathrm{~km}$. This velocity body is the result of inversion of the structure appeared on the phase velocity maps of periods of 111-50 s. The high $S$ wave velocity body appears to be slightly smeared to the east at depths up to $75 \mathrm{~km}$ creating an elongated positive velocity anomaly below ApsheronBalhan Sill where the south Caspian block subducts northward beneath the lithosphere of the middle Caspian Basin [e.g., Jackson et al., 2002]. I do not have data from any stations located west of the Apsheron Peninsula, which are necessary for surface wave tomography inversions to validate the existence of the high-velocity anomaly beneath the Apsheron-Balhan Sill. Therefore, I can only speculate on the shape of the anomaly and whether it extends into the Caspian Sea. Nevertheless, our observations of this positive $S$ wave velocity anomaly in Azerbaijan are consistent with the body wave tomography 
results of Koulakov et al. [2012], which demonstrate a similar $S$ wave velocity structure in that area.

\subsection{Discussion}

\subsubsection{Tectonic interpretations}

Our 1-D phase velocity model of the region is generally slower than the phase velocity model for the eastern branch of the East African Rift and faster at the longer periods in comparison with the western branch of the East African Rift due to a greater extent of the mantle plume beneath that part of the rift (Figure 2.4) [Weeraratne et al., 2003]. Another region with a similar dispersion curve that I have found is from the Basin and Range province in the western United States (Figure 2.4) [Preistley and Brune, 1978], the region which is believed to be affected by the Yellowstone plume [e.g., Parsons et al., 1994]. Such low phase velocity structure of the study area cannot be solely explained by a greater crustal thickness in East Anatolian-Caucasus region, and the low phase velocities of the longer period surface waves indicate that the upper mantle in our study region is on average slower than that in some of the hottest mantle environments beneath the continents. Furthermore, I observe an ultralow-velocity upper mantle zone in the depth range between 70 and $150 \mathrm{~km}$ in the average 1-D $S$ wave velocity model of the study region. Although there are several factors that could decrease the upper mantle $S$ wave velocity such as temperature, grain size, hydration, and composition of olivine (e.g., Schutt and Lesher, 2006; Yang and Forsyth, 2006b; Schmandt and Humphreys, 2010) I 
believe that asthenosphere with significant amounts of partial melt is the major factor producing this ultralow-velocity zone resulting in very thin lithosphere in the region. Three key regional observations support our conclusion: blockage of Sn [e.g., Gök et al., 2003], existence of wide spread uppermost mantle derived volcanism [Pearce et al., 1990; Keskin, 2003, 2007], and the very shallow observed LAB (lithosphereasthenosphere boundary) in the region [Angus et al., 2007] in the eastern Anatolia. I suggest that the average depth of LAB in the study region is around $70 \mathrm{~km}$ based on the amount of $S$ wave velocity decrease between two consecutive layers in our 1-D model. However, our regional 3-D $S$ wave velocity model shows that the East Anatolian and north Iranian Plateaus are supported by hot asthenosphere with little to no mantle lid beneath the volcanic areas which is in a good agreement with the $S$ wave receiver function results of Angus et al. [2006]. The mantle lid does exist beneath nonvolcanic parts of the plateaus (Figure 2.9) where it reaches the maximum thickness of around 35 $\mathrm{km}$. The bottom of the anomalously slow asthenosphere never exceeds a depth of $200 \mathrm{~km}$ in our regional $S$ wave velocity model based on the depth of the maximum velocity increase between two consecutive layers. Therefore, it is unlikely that either a deep or shallow mantle plume exists in the study region.

In our opinion, the shallow high-velocity anomalies beneath the Black Sea $(<125$ $\mathrm{km}$ depth) and northeastern part of Arabian Plate $(<180 \mathrm{~km}$ depth) represent cold lithospheric roots. The absence of cold lithosphere in our model, in the northwestern part of the Arabian Plate agrees well with the presence of active volcanism in the area (Karaca Dag volcano). The eastern Greater Caucasus-Kura Basin high-velocity mantle zone (depths up to $250 \mathrm{~km}$ ) (Figures 2.9-2.11) and the deep seismic events associated with it 
suggest underthrusting or subduction of the Kura Basin lithosphere beneath the eastern part of the Greater Caucasus [e.g., Mellors et al., 2012] instead of it being a mere cold lithospheric root. Neotectonic reconstructions of relative plate motions [Jackson et al., 2002; Kovachev et al., 2009] show a general NW direction of the south Caspian block movement with respect to Eurasia and it is understood that there is a right lateral transform boundary between the south Caspian block and the Kura Basin [e.g., Jackson et al., 2002; Reilinger et al., 2006]. Although, our results do not necessarily contradict the existence of two separate high-velocity slabs in the eastern Greater Caucasus and northern Caspian Sea, it is plausible that the convergence along the southern margin of the eastern Greater Caucasus is a part of the same subduction system across the Apsheron Peninsula as the band of the deep hypocenters extend in a linear manner through the eastern Greater Caucasus and the Caspian Sea [e.g., Triep et al., 1995; Jackson et al., 2002; Kovachev et al., 2009]. However, the relationship between the Kura Basin lithosphere and that of the south Caspian block remains unclear based on our results due to the lack of broadband data north and east of the Greater Caucasus, and further geophysical and geological investigation is required in order to make definitive conclusions on this matter.

I interpret the deep (depth $>140 \mathrm{~km}$ ) high-velocity anomalies beneath the Pontides and the northern Iran to be the remnant slabs of the northern and southern branches of Neo-Tethys, respectively. The magnitudes of these velocity anomalies may be too small to represent actual pieces of the broken off cold oceanic lithosphere and might be thermal tracks generated as the slabs were sinking into the mantle transition zone. However, the two-plane wave method underestimates the actual velocity anomalies 
due to over damping in the inversion. The over damping is required to minimize numerical artifacts which increase when a two-plane wave representation of the wavefield is unable to successfully model complex finite frequency effects. Nevertheless, the positive $S$ wave velocity anomalies beneath the Pontides and northern Iran, which are observed in our 3-D model (Figure 2.13), can still serve as evidence for the existence of two sinking detached slabs: the northern and southern branches of Neo-Tethys.

The positive $S$ wave velocity anomaly located in the center of the study region, below the East Anatolian Accretionary Complex (EAAC) in the depth range of 120-210 $\mathrm{km}$ could represent a delaminated block of lithosphere. However, such large subduction accretion complexes as EAAC are devoid of lithospheric roots as they are formed and instead are supported by shallow-angle oceanic slabs [Keskin, 2007]; therefore, I do not interpret this velocity body as a block of delaminated lithosphere. Instead, I suggest that this high-velocity body is another piece of the broken off Bitlis slab, perhaps the westernmost or shallowest part of the slab.

\subsubsection{Late Cenozoic tectonic evolution of the region}

\subsubsection{Eastern Anatolia}

The deep slab-like high-velocity anomalies that are observed in our images of upper mantle $S$ wave velocities support the existence of a double subduction of the NeoTethys lithosphere prior to the collision of Arabia and Eurasia. The locations of these anomalies relative to the Pontides and Bitlis suture combined with distribution of 
asthenospheric material in the region support the geodynamic model proposed by Barazangi et al. [2006]. In that model, the asthenospheric upwelling and collision-related volcanism was caused by the detachment of the flat Bitlis slab beneath the Bitlis arc. Keskin [2007] rejected this model and defended the earlier proposed model of the Pontide slab rollback and detachment [Şengör et al., 2003; Keskin, 2003], arguing that the absence of any collision-related volcanism younger than $11 \mathrm{Ma}$ along the Bitlis suture suggests that the Bitlis slab break occurred much earlier than the Pontide slab breakoff. However, our tomographic images show no evidence of roll back of the Pontide slab; instead, I observe two slabs, or their thermal tracks, beneath the Pontides and Black Sea in the north and the Bitlis slab in the south. The depths of the main parts of these two cold tracks are approximately the same, which strongly suggests that the two slab detachment events occurred at approximately the same time. Both tracks are quite large and therefore they cannot represent a delaminated blocks from the relatively thin lithosphere of Pontide and Bitlis arcs. The major piece of the detached Bitlis slab is shifted east of the Bitlis suture by approximately $300 \mathrm{~km}$; this is probably due to the general westward plate motion of Arabia and Eurasia with respect to a hot spot reference frame [Gripp and Gordon, 2002]. Furthermore, I explain the absence of any young volcanism in the BitlisPoturge massif due to the slab breaking off to the north of the massif's surface boundary. Therefore, our tomographic images of the upper mantle in the East Anatolian-Caucasus region support the Bitlis slab rollback and break off as the mechanism responsible for the uplift of the East Anatolian Plateau and the widespread occurrence of collision-related volcanism in the region. 
Based on our upper mantle velocity models and geochemistry of the volcanic products [Pearce et al., 1990; Keskin, 2003, 2007], I provide the following description of the possible mantle geodynamic processes that led to the dramatic geological changes in the region. As the flat subduction of the southern branch of Neo-Tethys Ocean continued beneath the Bitlis arc during most of Oligocene, the Bitlis slab was dehydrating and therefore enriching the overlying lithosphere of the northern branch of Neo-Tethys with fluids without producing any melt (Figure 2.14). When the Bitlis slab started to roll back in the north in the early Miocene, it caused upwelling and decompression melting of the asthenosphere, which then thinned the lithosphere of the northern Neo-Tethys and resulted in widespread melting across the northern East Anatolian Accretionary Complex (EAAC) [Şengör et al., 2003] producing the sub aerial plateau uplift and the first collision-related volcanism in the region around $11 \mathrm{Ma}$ (Figure 2.14). These volcanic rocks are characterized by a subduction signature likely due to higher concentrations of Bitlis slab-derived fluids in the northern part of the asthenospheric wedge. As the wedge became wider, more of the hot ashenosoheric material came into contact with the weakened lithosphere and the widespread volcanism, with a more pronounced intraplate signature, was initiated by the Bitlis slab break off just north of the Bitlis arc in the middle Miocene. However, the Pontide slab did not experience rolling back on a similar scale to the Bitlis slab and probably detached south of the Pontides almost simultaneously with the Bitlis slab and gradually descended into the upper mantle at a nearly vertical angle beneath the Pontides without producing any related volcanism in the arc. 

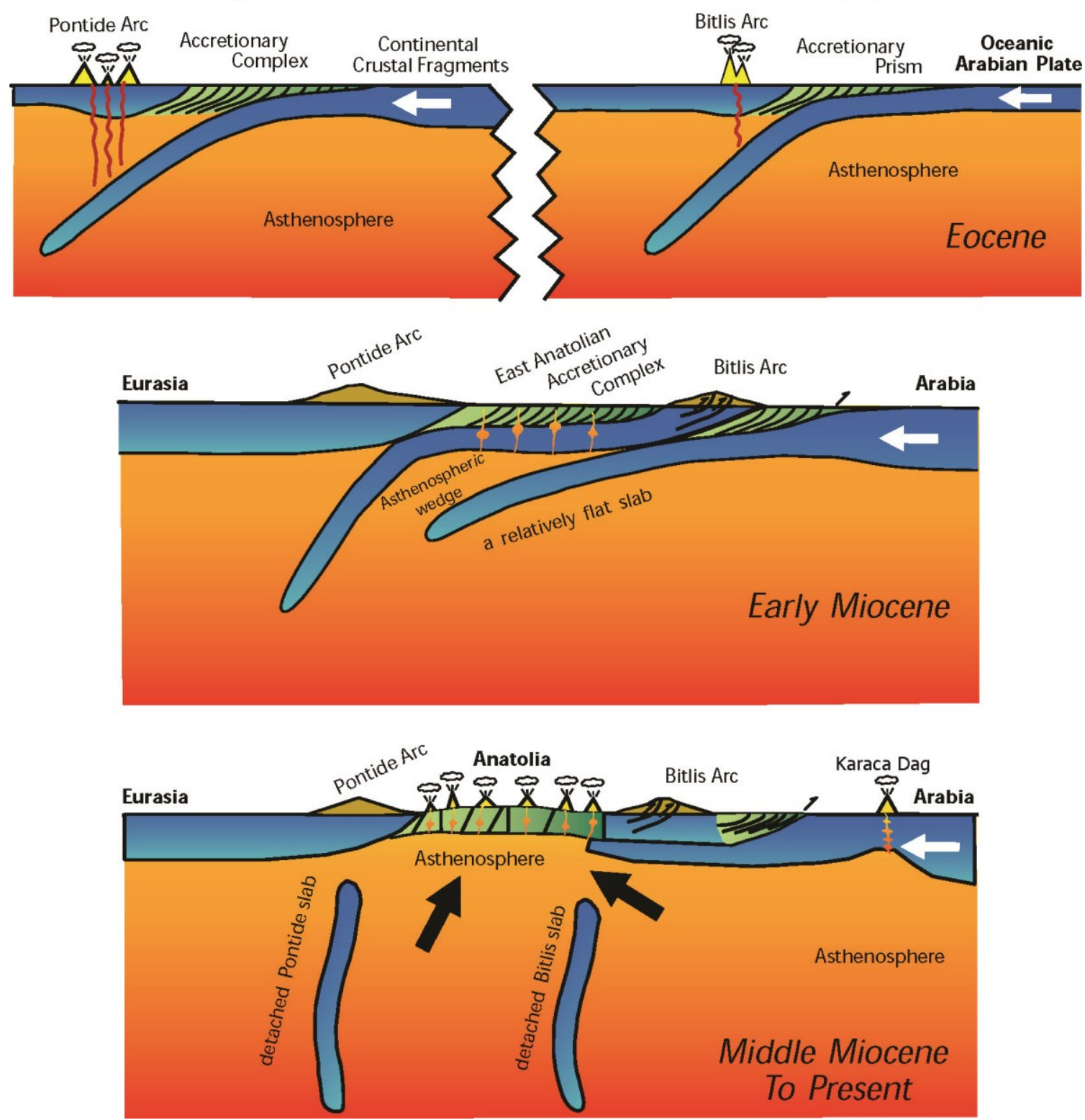

Figure 2.14. Schematic cross sections showing tectonic evolution of the Anatolian plateau in eastern Turkey from the Eocene to the present (adopted and edited from Barazangi et al. [2006]). The cross sections are approximately along the $42^{\circ} \mathrm{E}$ meridian. 


\subsubsection{Lesser and Greater Caucasus/Kura basin}

It has been traditionally understood that the acceleration in uplift during the early Pliocene in the central and eastern Greater Caucasus was caused by lateral translation of the compressive stress field produced by the converging Arabian Plate [e.g., Philip et al., 1989; Allen et al., 2003; Reilinger et al., 2006; Saintot et al., 2006]. An alternative explanation of the post-Miocene rapid exhumation of the Greater Caucasus involves the onset of a flat subduction of the back-arc basin, which existed between the Eurasia and the Pontide arcs [Avdeev and Niemi, 2011]. This would imply that today the Kura Basin is a forearc basin associated with a small-scale subduction zone that occurs along the eastern margin of the Greater Caucasus. Using this interpretation the regional highvelocity anomaly beneath the Eastern Greater Caucasus and Kura Basin in our models may be subducted back-arc basin lithosphere. Alternatively this high-velocity anomaly may be a lithospheric root that underlies the Kura Basin; however, observations of the earthquakes whose hypocenters lay deeper than $100 \mathrm{~km}$ just north of the eastern Greater Caucasus [e.g., Godzikovskaya and Reysner, 1989; Kovachev et al., 2009; Myers et al., 2011] are suggestive of ongoing subduction or underthrusting of the Kura Basin lithosphere beneath the Greater Caucasus.

\subsection{Conclusions}

Our surface wave tomographic model confirms the idea that the high plateaus of eastern Turkey and northern Iran are supported by hot asthenosphere instead of a thick 
crust and mantle lid combined with an Airy style isostatic response. The observed slablike high-velocity anomalies beneath Black Sea and northernmost Iran provide us with an additional evidence of the double subduction of the Neo-Tethys lithosphere occurring prior the initiation of the continent-continent collision of Arabia and Eurasia. The locations of these detached slab-like bodies suggest that the gradual rollback of the southern (Bitlis) slab and its consecutive break off are responsible for the widespread volcanism and uplift in the region. Furthermore, the fact that both bodies are at the same depth suggests that the two slabs broke off at about the same time. The high-velocity body that is imaged beneath the eastern Greater Caucasus and Kura Basin is consistent with ongoing subduction or underthrusting of the Kura Basin lithosphere under the Scythian platform.

\subsection{Acknowledgements}

I would like to thank Air Force Research Laboratory for funding of this project (contract FA8718-07-C-0007). I am also very grateful to Alan Wittington and Peter I. Nabelek for their helpful participation in discussions about geochemistry of volcanic rocks derived from mantle sources. I also would like to thank Paul Wessel, Walter H.F. Smith, and all the others for developing of the Generic Mapping Tools, which helped us to represent our work graphically. 


\subsection{References}

Al-Lazki, A., D. Seber, E. Sandvol, N. Türkelli, R. Mohamad, and M. Barazangi (2003), Tomographic Pn velocity and anisotropy structure beneath the Anatolian plateau (eastern Turkey) and the surrounding regions, Geophys. Res. Lett., 30(24), 8043, doi:10.1029/2003GL017391.

Allen, M. B., S. J. Vincent, G. I. Alsop, A. Ismail-zadeh, and R. Flecker (2003), Late Cenozoic deformation in the South Caspian region: Effects of a rigid basement block within a collision zone, Tectonophysics, 366(3-4), 223-239, doi:10.1016/S0040-1951(03)00098-2.

Angus, D. A., D. C. Wilson, E. Sandvol, and J. F. Ni (2006), Lithospheric structure of the Arabian and Eurasian collision zone in eastern Turkey from S-wave receiver functions, Geophys. J. Int., 166(3), 1335-1346, doi:10.1111/j.1365246X.2006.03070.x.

Avdeev, B., and N. A. Niemi (2011), Rapid Pliocene exhumation of the central Greater Caucasus constrained by low-temperature thermochronometry, Tectonics, 30 , TC2009, doi:10.1029/2010TC002808.

Barazangi, M., E. Sandvol, and D. Seber (2006), Structure and tectonic evolution of the Anatolian plateau in eastern Turkey, Geol. Soc. Am. Spec. Pap., 409, 463-473, doi: $10.1130 / 2006.2409(22)$.

Bassin, C., G. Laske, and G. Masters (2000), The current limits of resolution for surface wave tomography in North America, Eos Trans. AGU, 81, F987.

Biryol, B. C., S. L. Beck, G. Zandt, and A. A. Özacar (2011), Segmented African lithosphere beneath the Anatolian region inferred from teleseismic P-wave tomography, Geophys. J. Int., 184(3), 1037-1057, doi:10.1111/j.1365246X.2010.04910.x.

Dewey, J. F., M. R. Hempton, W. S. F. Kidd, F. Saroglu, and A. M. C. Şengör (1986), Shortening of continental lithosphere: The neotectonics of Eastern Anatolia-A young collision zone, Geol. Soc. Lond. Spec. Publ., 19(1), 1-36, doi:10.1144/gsl.sp.1986.019.01.01. 
Forsyth, D. W., S. C. Webb, L. M. Dorman, and Y. Shen (1998), Phase velocities of Rayleigh waves in the MELT experiment on the East Pacific Rise, Science, 280(5367), 1235-1238, doi:10.1126/science.280.5367.1235.

Forsyth, D. W., and A. Li (2005), Array analysis of two-dimensional variations in surface wave phase velocity and azimuthal anisotropy in the presence of multipathing interference, in Seismic Earth: Array Analysis of Broadband Seismograms, edited by A. Levander, and G. Nolet, pp. 81-97, AGU, Washington, D. C.

Godzikovskaya, A., and G. I. Reysner (1989), Endogenic position of deep earthquakes in the Caucasus, Geotectonics, 3, 205-213. Gök, R., E. Sandvol, N. Türkelli, D. Seber, and M. Barazangi (2003), Sn attenuation in the Anatolian and Iranian plateau and surrounding regions, Geophys. Res. Lett., 30(24), 8042, doi:10.1029/2003GL018020.

Gök, R., E. Sandvol, N. Türkelli, D. Seber, and M. Barazangi (2003), Sn attenuation in the Anatolian and Iranian plateau and surrounding regions, Geophys. Res. Lett., 30(24), 8042, doi:10.1029/2003GL018020.

Gök, R., et al. (2011), Lithospheric velocity structure of the Anatolian plateau-CaucasusCaspian region, J. Geophys. Res., 116, B05303, doi:10.1029/2009JB000837.

Gripp, A. E., and R. G. Gordon (2002), Young tracks of hotspots and current plate velocities, Geophys. J. Int., 150(2), 321-361, doi:10.1046/j.1365246X.2002.01627.x.

Jackson, J., K. Priestley, M. Allen, and M. Berberian (2002), Active tectonics of the South Caspian Basin, Geophys. J. Int., 148(2), 214-245, doi:10.1046/j.1365246X.2002.01005.x.

Kennett, B. L. N., E. R. Engdahl, and R. Buland (1995), Constraints on seismic velocities in the Earth from traveltimes, Geophys. J. Int., 122(1), 108-124, doi:10.1111/j.1365-246X.1995.tb03540.x.

Keskin, M. (2003), Magma generation by slab steepening and breakoff beneath a subduction-accretion complex: An alternative model for collision-related volcanism in Eastern Anatolia, Turkey, Geophys. Res. Lett., 30(24), 8046, doi:10.1029/2003GL018019. 
Keskin, M. (2007), Eastern Anatolia: A hotspot in a collision zone without a mantle plume, Geol. Soc. Am. Spec. Pap., 430, 693-722, doi:10.1130/2007.2430(32).

Koulakov, I., I. Zabelina, I. Amanatashvili, and V. Meskhia (2012), Nature of orogenesis and volcanism in the Caucasus region based on results of regional tomography, Solid Earth, 3(2), 327-337, doi:10.5194/se-3-327-2012.

Kovachev, S. A., V. G. Kaz'min, I. P. Kuzin, and L. I. Lobkovsky (2009), New data on mantle seismicity of the Caspian region and their geological interpretation, Geotectonics, 43(3), 208-220, doi:10.1134/s0016852109030030.

Lei, J., and D. Zhao (2007), Teleseismic evidence for a break-off subducting slab under Eastern Turkey, Earth Planet. Sci. Lett., 257(1-2), 14-28, doi:10.1016/j.eps1.2007.02.011.

Li, A. (2011), Shear wave model of southern Africa from regional Rayleigh wave tomography with 2-D sensitivity kernels, Geophys. J. Int., 185(2), 832-844, doi:10.1111/j.1365-246X.2011.04971.x.

Maggi, A., and K. Priestley (2005), Surface waveform tomography of the Turkish-Iranian plateau, Geophys. J. Int., 160(3), 1068-1080, doi:10.1111/j.1365246X.2005.02505.x.

Mellors, R. J., J. Jackson, S. Myers, R. Gök, K. Priestley, G. Yetirmishli, N. Türkelli, and T. Godoladze (2012), Deep earthquakes beneath the northern Caucasus: Evidence of active or recent Subduction in western Asia, Bull. Seismol. Soc. Am., 102(2), 862-866, doi:10.1785/0120110184.

Myers, S. C., G. Johannesson, and N. A. Simmons (2011), Global-scale P wave tomography optimized for prediction of teleseismic and regional travel times for Middle East events: 1. Data set development, J. Geophys. Res., 116, B04304, doi:10.1029/2010jb007967.

Parsons, T., G. A. Thompson, and N. H. Sleep (1994), Mantle plume influence on the Neogene uplift and extension of the U.S. western Cordillera?, Geology, 22(1), 83-86, doi:10.1130/0091-7613(1994)022<0083:mpiotn>2.3.co;2.

Pearce, J. A., J. F. Bender, S. E. De Long, W. S. F. Kidd, P. J. Low, Y. Güner, F. Saroglu, Y. Yilmaz, S. Moorbath, and J. G. Mitchell (1990), Genesis of collision 
volcanism in Eastern Anatolia, Turkey, J. Volcanol. Geotherm. Res., 44(1-2), 189-229.

Philip, H., A. Cisternas, A. Gvishiani, and A. Gorshkov (1989), The Caucasus: An actual example of the initial stages of continental collision, Tectonophysics, 161(1-2), $1-21$.

Priestley, K., and J. Brune (1978), Surface waves and the structure of the Great Basin of Nevada and western Utah, J. Geophys. Res., 83(B5), 2265-2272, doi:10.1029/JB083iB05p02265.

Reilinger, R., et al. (2006), GPS constraints on continental deformation in the AfricaArabia-Eurasia continental collision zone and implications for the dynamics of plate interactions, J. Geophys. Res., 111, B05411, doi:10.1029/2005JB004051.

Ritzwoller, M. H., N. M. Shapiro, M. P. Barmin, and A. L. Levshin (2002), Global surface wave diffraction tomography, J. Geophys. Res., 107(B12), 2335, doi:10.1029/2002JB001777.

Saintot, A., and J. Angelier (2002), Tectonic paleostress fields and structural evolution of the NW-Caucasus fold-and-thrust belt from Late Cretaceous to Quaternary, Tectonophysics, 357(1-4), 1-31, doi:10.1016/s0040-1951(02)00360-8.

Saintot, A., M. F. Brunet, F. Yakovlev, M. Sebrier, R. Stephenson, A. Ershov, F. ChalotPrat, and T. McCann (2006), The Mesozoic-Cenozoic tectonic evolution of the Greater Caucasus, Geol. Soc. Lond. Mem., 32(1), 277-289, doi:10.1144/gsl.mem.2006.032.01.16.

Saito, M. (1988), DISPER80: A subroutine package for the calculation of seismic normal-mode solutions, in Seismological Algorithms, edited by D. J. Doornbos, pp. 293-319, Elsevier, New York, N. Y.

Sandvol, E., N. Türkelli, and M. Barazangi (2003a), The Eastern Turkey Seismic Experiment: The study of a young continent-continent collision, Geophys. Res. Lett., 30(24), 8038, doi:10.1029/2003GL018912.

Sandvol, E., N. Türkelli, E. Zor, R. Gök, T. Bekler, C. Gurbuz, D. Seber, and M. Barazangi (2003b), Shear wave splitting in a young continent-continent collision: 
An example from Eastern Turkey, Geophys. Res. Lett., 30(24), 8041, doi:10.1029/2003GL017390.

Schmandt, B., and E. Humphreys (2010), Complex subduction and small-scale convection revealed by body-wave tomography of the western United States upper mantle, Earth Planet. Sci. Lett., 297(3-4), 435-445, doi:10.1016/j.eps1.2010.06.047.

Schutt, D. L., and C. E. Lesher (2006), Effects of melt depletion on the density and seismic velocity of garnet and spinel lherzolite, J. Geophys. Res., 111, B05401, doi:10.1029/2003jb002950.

Şengör, A. M. C., and W. S. F. Kidd (1979), Post-collisional tectonics of the TurkishIranian plateau and a comparison with Tibet, Tectonophysics, 55(3-4), 361-376.

Sengör, A. M. C., and Y. Yilmaz (1981), Tethyan evolution of Turkey: A plate tectonic approach, Tectonophysics, 75(3-4), 181-190. Şengör, A. M. C., S. Özeren, T. Genç, and E. Zor (2003), East Anatolian high plateau as a mantle-supported, north-south shortened domal structure, Geophys. Res. Lett., 30(24), 8045, doi:10.1029/2003GL017858.

Tarantola, A., and B. Valette (1982), Generalized nonlinear inverse problems solved using the least squares criterion, Rev. Geophys., 20(2), 219-232, doi:10.1029/RG020i002p00219.

Triep, E. G., G. A. Abers, A. L. Lerner-Lam, V. Mishatkin, N. Zakharchenko, and O. Starovoit (1995), Active thrust front of the Greater Caucasus: The April 29, 1991, Racha earthquake sequence and its tectonic implications, J. Geophys. Res., 100(B3), 4011-4033, doi:10.1029/94JB02597.

Türkelli, N., et al. (2003), Seismogenic zones in eastern Turkey, Geophys. Res. Lett., 30(24), 8039, doi:10.1029/2003GL018023.

Türkoğlu, E., M. Unsworth, İ. Çağlar, V. Tuncer, and Ü. Avşar (2008), Lithospheric structure of the Arabia-Eurasia collision zone in eastern Anatolia: Magnetotelluric evidence for widespread weakening by fluids?, Geology, 36(8), 619-622, doi:10.1130/g24683a.1. 
Ulomov, V. I., T. I. Danilova, N. S. Medvedeva, T. P. Polyakova, and L. S. Shumilina (2007), Assessment of seismic hazard in the North Caucasus, Izvestiya Phys Solid Earth, 43(7), 559-572, doi:10.1134/S1069351307070051.

Weeraratne, D. S., D. W. Forsyth, K. M. Fischer, and A. A. Nyblade (2003), Evidence for an upper mantle plume beneath the Tanzanian craton from Rayleigh wave tomography, J. Geophys. Res., 108(B9), 2427, doi:10.1029/2002JB002273.

Yang, Y., and D. W. Forsyth (2006a), Regional tomographic inversion of the amplitude and phase of Rayleigh waves with 2-D sensitivity kernels, Geophys. J. Int., 166(3), 1148-1160, doi:10.1111/j.1365-246X.2006.02972.x.

Yang, Y., and D. W. Forsyth (2006b), Rayleigh wave phase velocities, small-scale convection, and azimuthal anisotropy beneath southern California, J. Geophys. Res., 111, B07306, doi:10.1029/2005JB004180.

Yilmaz, Y. (1993), New evidence and model on the evolution of the southeast Anatolian orogen, Geol. Soc. Am. Bull., 105(2), 251-271, doi:10.1130/00167606(1993)105<0251:neamot>2.3.co;2.

Zhou, Y., F. A. Dahlen, and G. Nolet (2004), Three-dimensional sensitivity kernels for surface wave observables, Geophys. J. Int., 158(1), 142-168, doi:10.1111/j.1365246X.2004.02324.x.

Zor, E. (2008), Tomographic evidence of slab detachment beneath eastern Turkey and the Caucasus, Geophys. J. Int., 175(3), 1273-1282, doi:10.1111/j.1365246X.2008.03946.x.

Zor, E., E. Sandvol, C. Gürbüz, N. Türkelli, D. Seber, and M. Barazangi (2003), The crustal structure of the East Anatolian plateau (Turkey) from receiver functions, Geophys. Res. Lett., 30(24), 8044, doi:10.1029/2003GL018192. 


\subsection{Appendix 2A1: Non-uniqueness in inversion of Rayleigh wave phase velocities as a function of period to $S$ wave velocities as a function of depth}

The problem of non-unique solutions in surface wave tomography arises when the observed dispersion curve is used in the inversion to get $S$ wave velocity variation with depth. The solution of the inverse problem is non-unique and may result in many different $S$ wave velocity profiles, which can produce predicted dispersion curves that have good fits with the observed dispersion curve. I employ the DISPER80 algorithm of Saito [1988] in order to invert Rayleigh wave phase velocities as a function of period for $S$ wave velocities as a function of depth. Typically, the inversion converges to the solution in 10 iterations. Increasing of the number of iterations by a factor of ten does not affect the results dramatically. In order to reduce the number of free model parameters the algorithm keeps constant Vp/Vs ratio and densities at depths. Furthermore, the thicknesses of the inverted $S$ wave velocity structure are unchanged during the inversion. In spite of these preventive measures, the problem of non-uniqueness still prevails, as there are many possible $\mathrm{S}$ wave profile solutions with the same layer thicknesses, which can produce the predicted dispersion curves with good fits to the observed one. However, there are two important inversion parameters that can constrain the inverse solution: the input starting model and damping.

The $S$ wave velocity solutions greatly depend on the starting model: the closer the starting model to the real result, the more reliable the solution will be (providing the damping is reasonable). However, it is often very difficult to choose a good starting model that is very close to the real solution. In my 1-D inversion, I use the average earth 
$S$ wave model AK135 as the starting model. However, during the 3-D inversion, I use the 1-D solution with adjusted Moho discontinuity instead. The choice of the average regional 1-D $S$ wave solution in my opinion is better because the $\mathrm{S}$ wave velocities of this starting model are probably closer to those at most of the points in the study region then the velocity values of the average earth model. On the other hand, I do not vary the starting model in the region because the solutions will be biased.
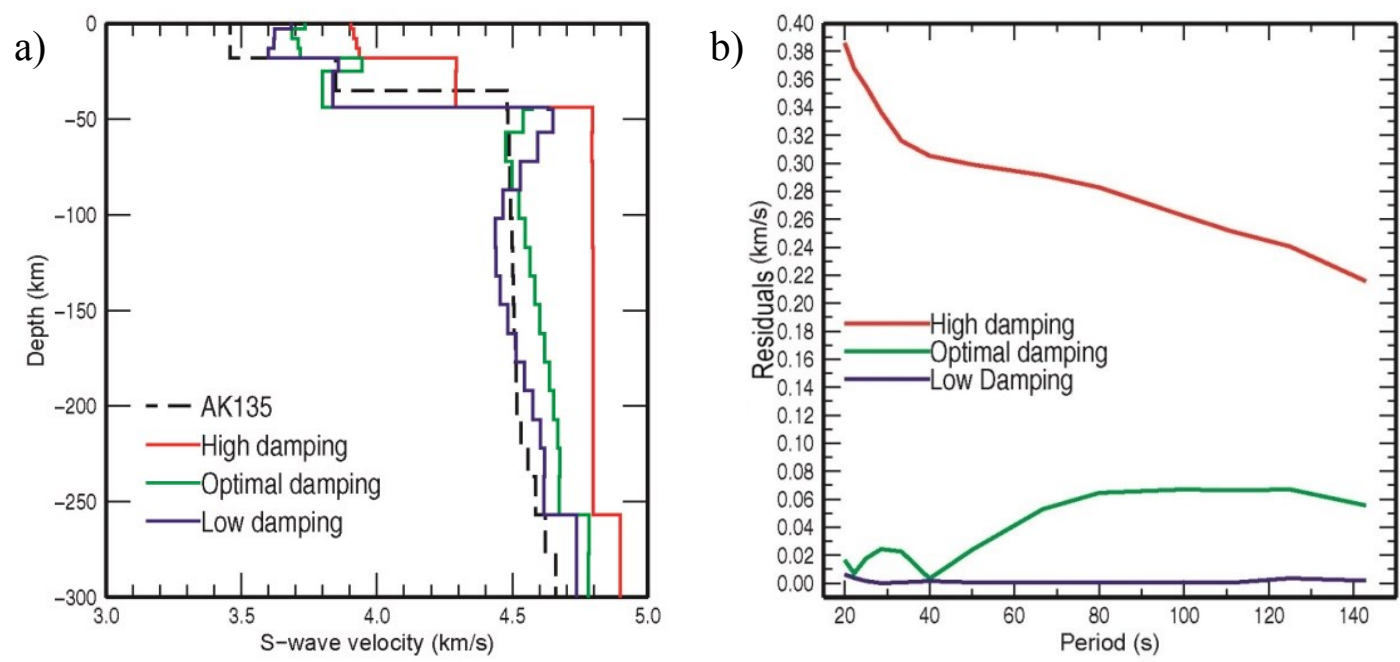

Figure 2A1. Non-uniqueness in the inversion of the theoretical Rayleigh wave phase velocity dispersion curve for AK135. a - 1-D $S$ wave velocity profiles derived using three scenarions of damping; $b$ - the absolute values of the residuals showing the fit of the predicted to the observed dispersion curves.

The only inversion parameter that I change is the damping, which serves as a smoothing factor of the $S$ wave velocities between the adjacent layers. The higher the damping, the less the variation in $S$ wave velocities between the adjacent layers. Figure 2A1a shows the effect of the damping on the solutions inverted from a theoretical dispersion curve of AK135. The starting $S$ wave velocity model is very different form the AK135 (it is very close to the red solution on the graph). This makes it very difficult to resolve the model correctly. My experiments show that a lower damping results in a 
better fit of the predicted dispersion curve to the observed one (Figure 2A1b). However, in this case a better fit does not mean a more correct solution i.e. the sudden velocity drop in the blue solution below the Moho depth, while the correct model should show only increase of velocity with depth.

When I calculated the uniform 1-D S wave velocity model, I verified my solutions with other models such as S wave receiver functions results [Angus et al., 2006] showing a shallow LAB. That is why I chose to use the optimal damping parameter as it gave me the result that did not contradict the other geophysical observations in the region (Figure 2A2).
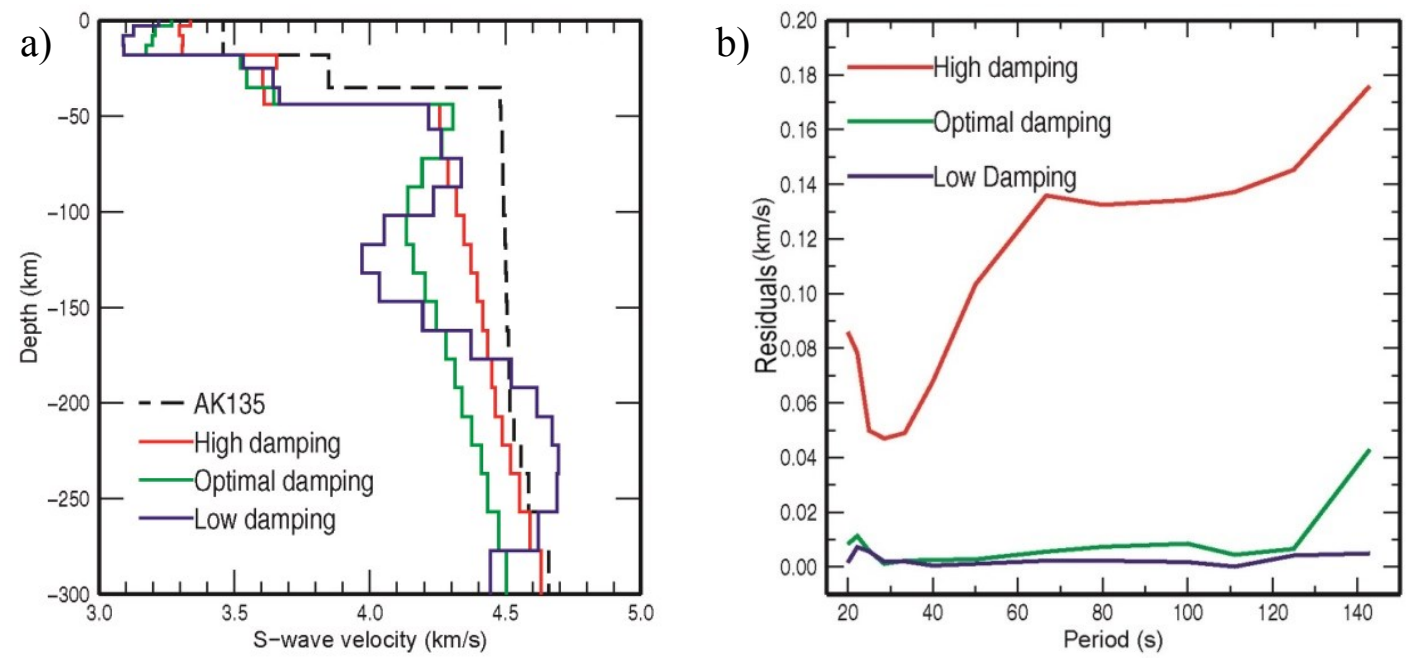

Figure 2A2. Non-uniqueness in the inversion of the regional phase velocity dispersion curve. a - 1-D $S$ wave velocity profiles derived using three scenarions of damping; $\mathrm{b}$ the absolute values of the residuals showing the fit of the predicted to the observed dispersion curves. 


\title{
Chapter 3
}

\section{SHEAR WAVE SPLITTING IN THE EASTERN ANATOLIAN-CAUCASUS REGION}

\begin{abstract}
The ongoing continent-continent collision of Arabia and Eurasia has mostly produced strike slip fault deformation within the Eastern Anatolian plateau and Lesser Caucasus during the Pliocene. In contrast, during the Pliocene the deformation style in the Greater Caucasus is dominated by folding and thrust faulting. Such distinct tectonic characteristics of these neighboring regions likely cannot be understood without knowing the regional upper mantle structure. I have performed $S$ wave splitting analysis on a small number of local $S$ waves and a larger number of teleseismic core phases (e.g. SKS and SKKS) from stations within the IRIS network, station KIV located in Russia, and the regional seismic networks of Turkey, Azerbaijan, and Georgia to determine shear wave splitting fast polarization directions and delay times in the region. This study presents the first such analysis for the data recorded by the stations located in Azerbaijan and two stations located in Georgia. The results of this research show that the fast polarization directions are quite uniformly parallel to NE-SW across the Eastern Anatolian Plateau and the central part of the Greater Caucasus. The observed delay times decrease northward towards the central Greater Caucasus. However, the fast polarization directions seem to gradually rotate clockwise along the eastward trend in the region until they become roughly parallel to EW directions of the absolute plate motions in the Lesser
\end{abstract}


Caucasus (Armenia). The situation becomes more complex north of the southern Lesser Caucasus, in the Kura Basin, the western part of the eastern Greater Caucasus, and the easternmost part of Talesh Mountains where the average fast polarization directions produced below the stations seem to either suddenly turn back or turn more clockwise and become NNE-SSW. The rest of the stations in the eastern Greater Caucasus have fast directions roughly orogeny-parallel and perpendicular to the direction of the inferred crustal shortening. The uniform fast directions across the Eastern Anatolian Plateau and the central Greater Caucasus are probably associated with the anisotropy located deeper in the mantle. Both of the regions have little or no lithospheric mantle and instead are supported by a low-density asthenosphere, which prevents the development of the basal drag that would otherwise produce a noticeable anisotropic pattern. The gradual rotation of the fast polarization orientations in the Eastern Anatolian Plateau could be the manifestation of the local mantle flow, which has been affected by the broken off and sinking Neo-Tethys slab. In my opinion, the fast polarization directions of the teleseismic core phases in the easternmost Greater Caucasus could be associated either with the simple shear deformation on a cold and wet or serpentinized mantle layer that resulted from subduction or underthrusting of the Kura basin lithosphere. In case of two-layer anisotropy, the anisotropy of the top layer below the eastern Greater Caucasus and Kura Basin, which is likely to originate from the lithospheric mantle, could be the result of the preserved LPO that preceded the hard collision stage in that region. The differences in the crustal deformation styles of the Eastern Anatolian Plateau and the Greater Caucasus are dominated in large part by the regional lithospheric structure and the upper mantle geodynamic processes that have occurred since the initiation of the continental collision. 
between the Eastern Anatolia - central Greater Caucasus and the eastern Greater Caucasus.

\subsection{Introduction}

The Eastern Anatolian-Caucasus region is located in the zone of active continental collision of Arabian plate with Eurasia (Figures 1.1 and 2.1). The northward motion of Arabian Plate produces shortening in the Caucasus region by means of thrust faulting and folding, which accommodate about $40 \%$ of convergence between Arabia and Eurasia [Allen et al., 2003]. The fold belt is characterized by south-verging thrust faults and seems to form as a result of underthrusting of the Transcaucasus (Lesser Caucasus, Kura Basin) lithosphere [e.g., Kovachev et al., 2009; .Mellors et al., 2012]. The Anatolian block is forced by this convergence to escape westward, towards the Hellenic subduction zone along North Anatolian and Eastern Anatolian faults with little ongoing internal compressional deformation [e.g., Barazangi et al., 2006]. The Eastern Anatolian Plateau is similarly characterized by strike-slip fault deformation and associated pull apart basins [e.g., Dewey et al., 1986; Pearce et al., 1990; Örgülü et al., 2003].

The average topographic elevation in the Eastern Anatolian Plateau is about $2 \mathrm{~km}$ above sea level and is not entirely supported by crustal thickening [e.g., Sengör et al., 2003; Barazangi et al., 2006; Gök et al., 2011]. The most significant geological feature found in the plateau is the widespread middle Miocene to present mantle-derived volcanism with products covering over a half of the region [e.g., Pearce et al., 1990; Keskin, 2003, 2007]. In fact, the mantle origin of these huge volumes of lava points out 
that the high topography of the Turkish and Iranian plateaus are supported by shallow buoyant asthenosphere, which is in a good agreement with the regional gravity models [Seber et al., 2001; Maggi and Priestley, 2005] and the regional studies of receiver functions [e.g., Zor et al., 2003; Angus et al., 2006] ,Sn attenuation [e.g., Gök et al., 2003; Al-Damegh et al., 2004], and Pn tomography [e.g., Al-Lazki et al., 2003; Amini et al., 2012] (Figures 1.4 and 1.5). Some of these studies as well as the regional models of body wave [Zor, 2008; Koulakov et al., 2012] and surface wave [e.g., Maggi and Priestly, 2005; Skobeltsyn et al., 2014] tomography also indicate the absence or thinning of the lithospheric mantle beneath the central part of the Greater Caucasus, which has been the fastest uplifting part of the mountain range since early Pliocene [ e.g., Avdeev and Niemi, 2011]. Furthermore, this most rapidly uplifting part of the Greater Caucasus is characterized by Neogene-Quaternary mantle-derived volcanism [e.g., Lebedev et al., 2011; Chernyshev et al., 2014], which is absent in the other parts of the mountain range (i.e. the western and eastern Greater Caucasus).

The Eastern Anatolian-Caucasus region is extremely seismically active [e.g., Türkelli et al., 2003; Örgülü et al., 2003; Jackson et al., 2002]. However, most of the seismicity in the areas underlain by the shallow asthenosphere is shallow and associated only with the crustal deformation [e.g., Türkelli et al., 2003]. Almost all of the deep subcrustal events in the region of study (Figures 1.6 and 2.2) are located in the eastern Greater Caucasus, under the mid-Caspian, and at the edges of the south Caspian under the Kura Basin [e.g., Ulomov et al., 2007; Triep et al., 1995; Godzikovskaya and Reysner, 1989; Myers et al., 2011]. The deepest of those events appear at depths bellow 150 and are concentrated in in the Dagestan portion of the eastern Greater Caucasus [e.g., Mellors 
et al., 2012]. It is probably not a coincidence that the region's deepest subcrustal seismic events are only found in the places with substantial amount of lithospheric mantle (Figure 2.9) [e.g., Skobeltsyn et al., 2014]. This deep mantle seismogenic zone represents the ongoing deep lithospheric deformations possibly caused by subduction or underthrusting of the Kura Basin lithosphere beneath the eastern part of Greater Caucasus forced by the continent collision of Arabia and Eurasia.

In this study, I employ various $S$ wave splitting techniques in order to investigate the regional upper mantle anisotropic patterns and their association with the recent plate motions and tectonic deformation. I compare the splitting parameters resulting from the analysis of teleseismic and local phases with the azimuthal anisotropy derived from the regional surface wave tomography study of Skobeltsyn et al. [2014] in order to constrain the change of anisotropic directions with depth. Furthermore, the objective of this study includes investigation of a possible existence of two-layer anisotropy in the study region by means of a new grid search method that takes into account both signal to noise and the frequency of the waveforms. This study is different from the previous studies as it represents the first application of the $S$ wave splitting techniques in the eastern Greater Caucasus with the objective to describe the uppermost mantle fabrics in that region and their relationship with the observed late Cenozoic crustal deformations. Furthermore, this study for the first time has found evidence of complexity that is azimuthal dependence, of splitting parameters in a region where there is a remarkably uniform fast direction. 


\subsection{Data}

We collected the seismic records using 26 permanent broadband stations that have operated in Azerbaijan, Turkey, Georgia and Russia. The data were recorded at 20 to 50 samples per second by 13 permanent stations of Bogazici University and Kandilli Observatory and the Earthquake Research Institute (KOERI) and 13 permanent stations of the National Seismic Network of Azerbaijan during January, 2006 - July, 2008 as well as 2 Georgian stations and the KIV station (Russia). I windowed PKS, SKS and SKKS phases including at least 8 seconds of noise before their arrivals for the SNR (signal-tonoise ratio) estimate in the $S$ wave splitting analysis. We selected 52 split or null events with good SNR (>3) (Figure 3.1). The $S$ wave splitting results of Sandvol et al. [2003b], which I used to augment the results of this study, were obtained from temporary PASSCAL (Program for Array Seismic Studies of the Continental Lithosphere) stations, which were deployed to continuously record the data at 40 samples per second during Eastern Turkey Seismic Experiment (ETSE) conducted from late October, 1999 to August, 2001 [Sandvol et al., 2003a]. I was able to select only one deep split local event from the dataset, which was close enough (delta $<$ depth) to one of the stations (QUB) located in the eastern Greater Caucasus (Azerbaijan), in order to perform the $S$ wave splitting analysis of the direct $S$ arrival. The depth of this event was $62 \mathrm{~km}$. The data for the investigation of the Rayleigh wave azimuthal anisotropy was borrowed from the surface wave study of Skobeltsyn et al., [2014] 


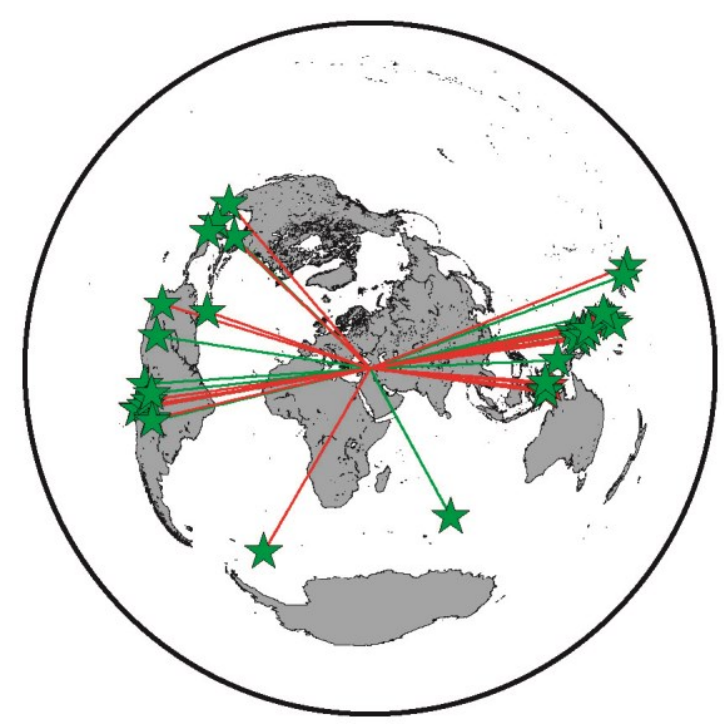

Figure 3.1. World map showing the epicenters of selected teleseismic earthquakes. Green stars - events that split, and red stars - events that did not split.

\subsection{Methods}

The role of the olivine LPO (lattice-preferred orientation) in the upper mantle is considered the most significant in the observed upper mantle anisotropy [e.g., Long, 2013]. Generally, the olivine LPO tends to have a systematic relationship with respect to the direction of maximum finite strain [e.g., Karato, 2008; Long, 2013]. However, detailed studies of olivine LPO have showed that this relationship depends strongly on factors which involve water content [Jung et al., 2006], presence of partial melt [e.g., Kaminski, 2006], pressure and temperature [e.g., Mainprice 2005; Karato, 2008].

Furthermore, presence of hydrous minerals in the upper mantle such as serpentine, which possesses a stronger intrinsic anisotropy than olivine, can have a significant effect on the anisotropic measurements [Mainprice and Ildefonse, 2009; Long, 2013]. 
Measuring shear wave splitting can provide an estimate of the bulk average seismic anisotropy of the upper mantle beneath a seismic station that does not trade off with lateral velocity heterogeneity. Shear wave splitting can be characterized by two parameters: the lag time between the slow and fast polarizations and the polarization direction of the fast phase. Shear wave splitting can be observed both the teleseismic core phases (i.e. PKS, SKS, SKKS) and local direct $S$ wave arrivals. In order to calculate the optimal $S$ wave splitting parameters ( $\phi$ and $\delta t$ ) for the Eastern Anatolian-Caucasus region, I apply the method of Silver and Chan [1991] to determine the shear wave splitting parameters for SKS and SKKS phases. This method has been used in many regional $S$ wave splitting studies of the core phases [e.g., Sandvol et al., 2003b] and utilizes a grid search over all possible combinations of splitting parameters, $\phi$ and $\delta t$ in order to minimize the energy of the corrected tangential component [Silver and Chan, 1991]. In addition to this method, I apply the method of Wolfe and Silver, [1998], which applies the aforementioned technique and then stacks corrected tangential energy surfaces of all the teleseismic core phases instead of that for a single event to determine the average splitting parameters for the station. In order to calculate the optimal splitting parameters for direct $S$ wave arrivals of deep subcrustal local events, I use an approach, which utilizes minimization of the second eigenvalue in the covariance matrix formed by the horizontal components [Bowman and Ando, 1987]. The deep local events have to be close enough to the stations, which means that the epicentral distances should not exceed the depths of the events in order to prevent the incidence angles to be greater than the critical angle (i.e. $35^{\circ}$ ). Incidence angles larger than this will tend to create nonlinear particle motions that mimic shear splitting from mode conversions at the free surface. 
I performed a quality control of the splitting results after the initial inversion by analyzing the plots of particle motions, corrected tangential energy, as well as the original and corrected tangential components (Figure 3.2) in order to ensure the reliability of the measurements. The events that had inconsistent results such as nonlinear corrected $S$ wave particle motion, absence of global minimum in the tangential energy, and unacceptable amplitudes of the corrected tangential components, were removed from the dataset. Then, I re-window the phase and rerun the inversion again in order to produce more reliable outcome.

If the station splitting parameters depend on the back azimuth of the events, there is a chance that the medium beneath the station consists of two or more anisotropic layers [e.g., Silver and Savage, 1994]. In order to determine the splitting parameters for the case of two anisotropic layers, I used a grid search over all possible splitting parameters, which corresponded to the assigned polarizations and lag times of the layers. These parameters were assigned in the following order: the anisotropic directions for the two layers ranged from 0 to $180^{\circ}$ with a step of $10^{\circ}$, while the lag times changed from 0.4 to $1.5 \mathrm{~s}$. The back azimuth of the incoming synthetic $\mathrm{S}$ waves varied from 0 to $90^{\circ}$ with a step of $2^{\circ}$ due to the symmetry for two layer anisotropic solutions. Therefore, the number of combinations of the assigned layer parameters and the back azimuth values was 2391264. However, the optimal lag times and fast polarization directions strongly depends on the period of the analyzed $S$ waves and the noise level [e.g., Wirth and Long, 2010]. Therefore, it is essential to account for the noise levels and the signal periods in the real data in the process of generating synthetic split $S$ waves. As expected, the errors in solutions of synthetic data grow with the increased level of noise and the $S$ wave 
period (Figure 3.3). The signal to noise ratio (SNR) of the real seismograms was determined using the relationship between the maximum energy values of the corrected tangential and radial components; this definition works because the corrected tangential component is essentially defined as the background noise [e.g., Silver and Chan, 1991]. The periods of the analyzed SKS were determined manually. I chose to use single SKS phases in the real data for the grid search analysis because other phases such as SKKS have different periods and I had to assign only one period for the corresponding synthetic seismogram. Based on the analysis of the real data, I selected the periods of 4, 6, and 10 s. and the noise amplitude levels of 10,20 , and $30 \%$. Therefore, the total number of combinations in the grid of solutions reached 21521376.
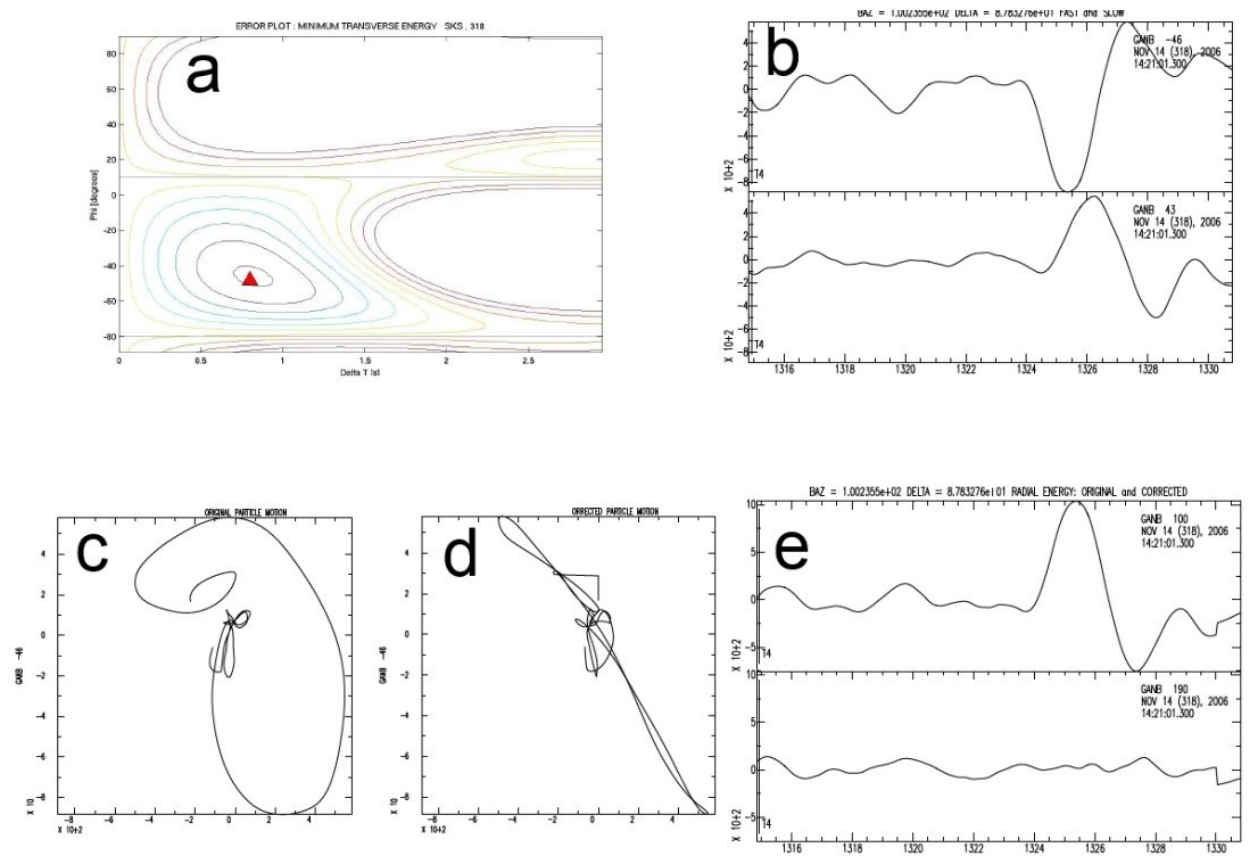

Figure 3.2. Illustration of the visual data quality control. a - corrected tangential energy plot, b - the fast (top) and slow (bottom) components, c - uncorrected elliptical $S$ wave particle motion, $\mathrm{d}$ - corrected linear particle motion, $\mathrm{e}$ - original (top) and corrected (bottom) tangential component. 

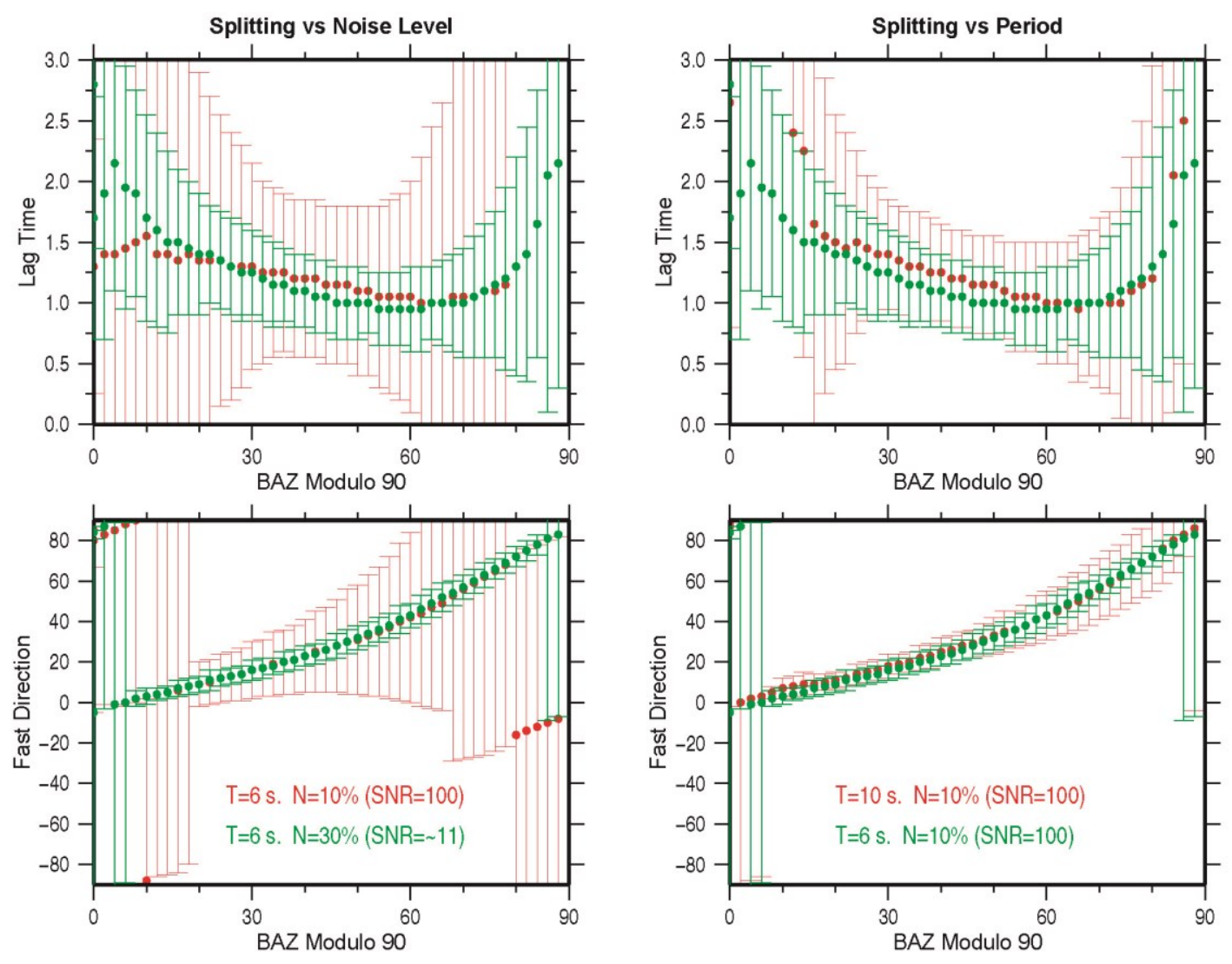

Figure 3.3. Dependence of synthetic splitting observations from two-layer anisotropic structure on the characteristic period $(\mathrm{T})$ and noise level $(\mathrm{N})$. The two layer model parameters are: bottom layer: fast direction, $-30^{\circ}$, lag time, $1.2 \mathrm{~s}$; top layer: fast direction, $45^{\circ}$, lag time, $1.0 \mathrm{~s}$. Vertical bars show twice the standard deviation.

In order to create the grid of pairs of solutions of the optimal fast polarizations and lag times, I, first, created a synthetic wavelet of a single period sine wave on both the east and north components of the seismogram. Then, this synthetic $S$ wave was split according to the back azimuth and the anisotropic model parameters of the two layers. Finally, I added filtered white noise to the seismogram. I used the same filter for the white noise that I applied in the real data processing. The period of the sine wave and the noise levels in the synthetic seismograms corresponded to those described earlier in order to simulate the real data. Finally, I performed the splitting analysis of the resulting 
synthetic seismograms using the method of Silver and Chan [1991] in order to form a large grid of solution pairs. This large number of solutions can be thought of as the parameter space for our inversion. A small subset of this parameter space can be seen in Figure 3.3.

The aim of the grid search was to find the optimal fast polarizations and lag times for both layers, which correspond to the minimum differences between the observed splitting parameters for real data and the synthetic splitting parameters. First, the grid search algorithm finds the closest period, noise level, and back azimuth for each event at the station. Then it calculates a weighted difference between the observed and synthetic solutions for all of the suitable combinations of two layer splitting parameters. Finally, it computes a weighted sum of all the differences between the observed and synthetic solutions; the minimum sum corresponds to the optimal splitting parameters for the two layers. In order for the grid search to properly constrain the splitting parameters of the two layers, it is essential that each station had good azimuthal coverage of the real solutions. Furthermore, the real solutions have to be reliable and large enough in number. However, it is very difficult to evaluate the case of two-layer anisotropy if the difference between the fast polarization directions of the layers approaches $90^{\circ}$ as the resolution drops dramatically with longer periods, which is typical for the teleseismic core phases. Therefore, it is difficult to reliably constrain the splitting parameters for the two-layer anisotropy case and often the results of the grid search are inconclusive. However, I have successfully tested the validity of the grid search approach on solutions derived independently from synthetic seismograms generated using a ray tracing technique of $A b t$ and Fisher [2008] through a two-layer test anisotropic structure. During this test, the 
splitting parameters were calculated from synthetic local $S$ phases with radial initial polarizations (i.e. $S V$ polarization), the characteristic period of $8 \mathrm{~s}$, and noise level of $10 \%$ $(\mathrm{SNR}=100)$ (Figure 3.4). The effect of the azimuthal coverage and the number of splitting observations is clearly visible; the case with 9 splitting observations and a 90 -degree azimuthal coverage produced the best results, while the case with only 2 split events and a 10-degree azimuthal coverage demonstrated a 30-degree clockwise rotation of the fast directions due to the insufficient azimuthal coverage in the lag times.
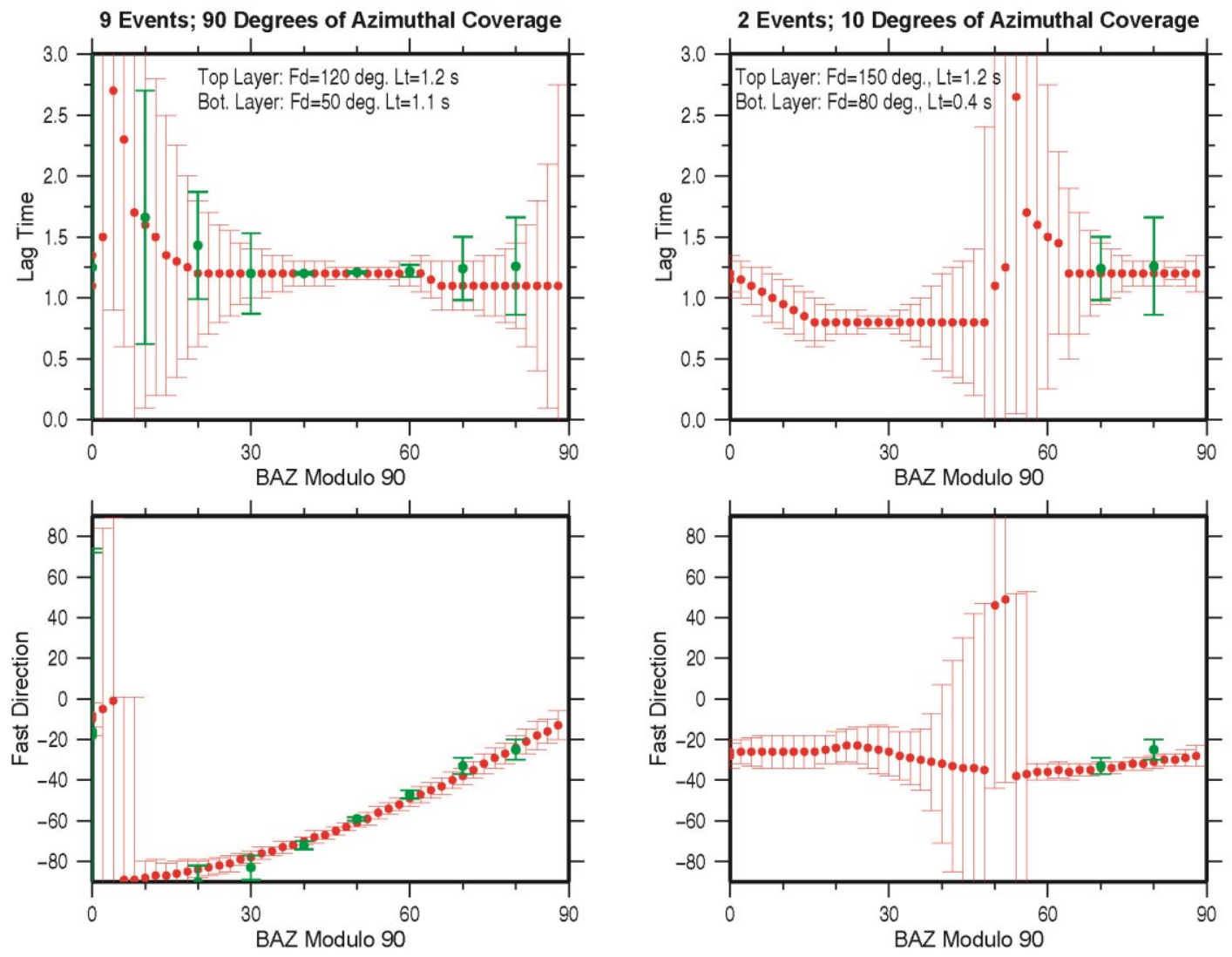

Figure 3.4. The fit of the $S$ wave splitting synthetic results derived using method of $A b t$ and Fisher [2008] (green) to the synthetic results generated by the grid search approach (red). The original model parameters for the bottom layer: anisotropic direction, $50^{\circ}$, lag time $\sim 1.26 \mathrm{~s}$; the top layer: anisotropic direction, $120^{\circ}$, lag time, $\sim 1.2 \mathrm{~s}$. The best fitting layer parameters are described within the figure; $\mathrm{Fd}$ - anisotropic fast direction, $\mathrm{Lt}$ - lag time. Vertical bars show twice the standard deviation. 
I used the two-plane wave tomography method of Yang and Forsyth [2006a, 2006b] to address the problem of the change of upper mantle azimuthal anisotropy with depth. The Rayleigh wave tomography has the best resolution in the upper $250 \mathrm{~km}$ of the Earth interior and allows to calculate the azimuthal anisotropy in the region for different frequencies, which are most sensitive to different depth intervals [Yang and Forsyth, 2006a, 2006b].

\subsection{Results}

The average $S$ wave splitting parameters of most of the stations were estimated based on 2 - 5 selected events with SNR $>3$. Generally, the average $S$ wave splitting parameters of the teleseismic phases derived from the stations without (Figure 3.5) and with staking (Figure 3.6) of the tangential energy, are very similar, and show only minor discrepancies in the fast polarization directions. The mismatch of the lag times is more significant. The fast polarization directions calculated for the stations located in Eastern Anatolia are consistent with the ETSE results of Sandvol et al. [2003b] and generally show a uniform NE-SW orientation of the polarizations of the fast $S$ waves components. Other stations located in the Pontides and the central Greater Caucasus area show similar fast polarization directions as those in the Eastern Anatolian Plateau. However, the two stations located in the central part of the Greater Caucasus demonstrate on average shorter lag times in comparison with the lags from the stations in Pontides and Eastern Anatolian Plateau. The orientations of the fast polarizations in the aforementioned areas deviate strongly from the absolute plate motions with a hot spot reference [Reilinger et 
al., 2006]. As we continue eastward across the region the fast directions derived from the stations located in the Lesser Caucasus seem to rotate clockwise and become roughly parallel to EW. The Lesser Caucasus fast polarization directions are more consistent with the absolute plate motion vectors than the fast directions in the Eastern Anatolia and the central Greater Caucasus.

The stations located north of the eastern Lesser Caucasus, in the Kura Basin, the western part of the eastern Greater Caucasus, and the easternmost part of Talesh Mountains demonstrate an abrupt change in the average fast polarization directions to NNE-SSW. On the other hand, the rest of the stations, which are located in the eastern Greater Caucasus show the fast polarization directions, which are roughly parallel to the

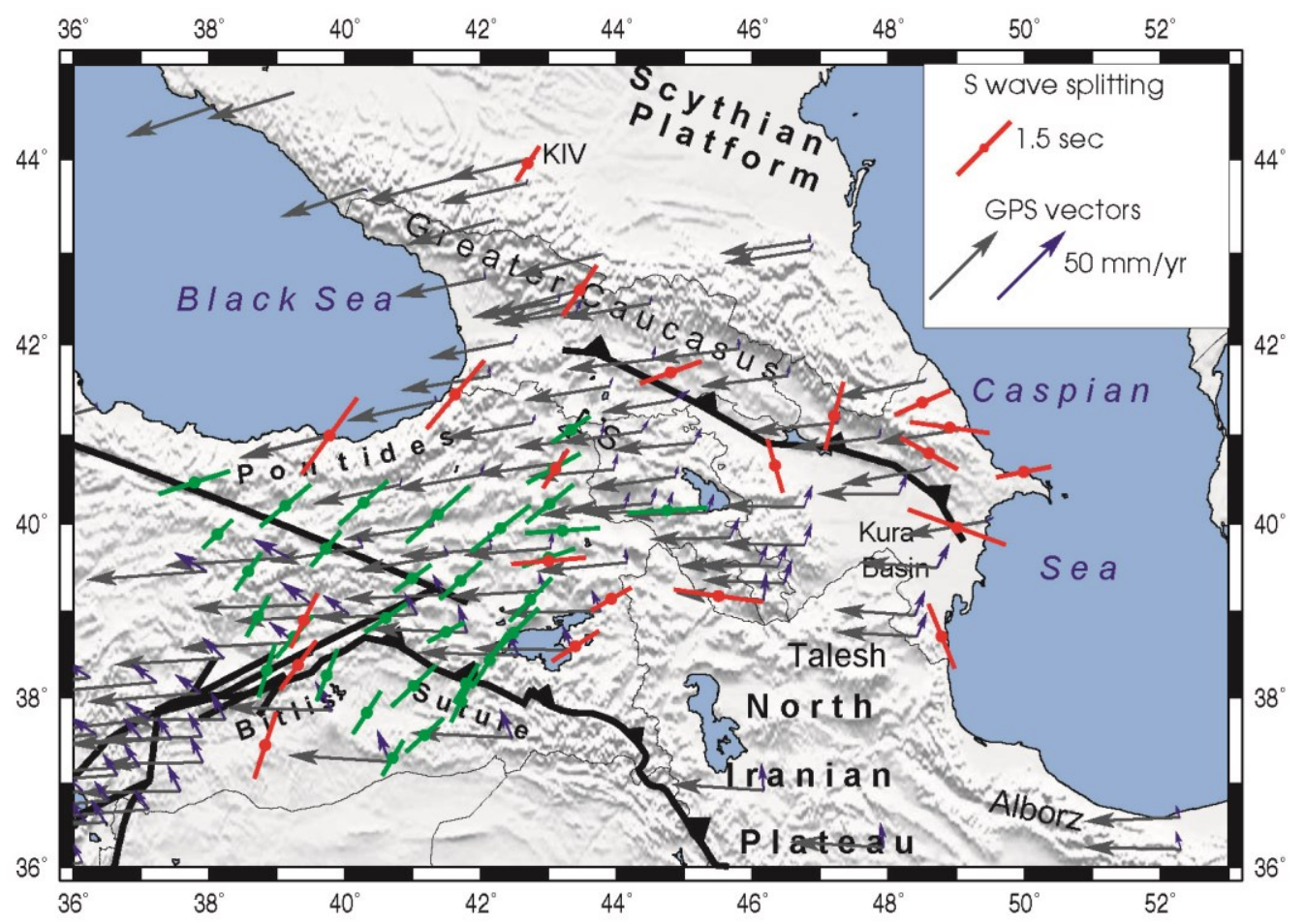

Figure 3.5. Teleseismic $S$ wave splitting results of the method of Silver and Chan [1991]. Green splitting parameters - results from Sandvol et al. [2003b], red splitting parameters the results of the present study, grey arrows - GPS vectors with a hot spot reference, blue arrows - GPS vectors relative to stable Eurasia [Reilinger et al., 2006] 
Greater Caucasus fold belt and perpendicular to the plate motion vectors with respect to stable Eurasia [Reilinger et al., 2006]. The splitting parameters of the only available local sub-crustal event, which had the epicentral distance to the station (QUB) less than the hypocenter depth $(62 \mathrm{~km})$ show that the shallow anisotropy is also parallel to the mountain range and perpendicular to the direction of shortening.

The two-layer splitting station results were selected based on the requirement the station has to have more than two good splitting results with acceptable azimuthal coverage $\left(>10^{\circ}\right)$. These criteria were derived from my grid search experiments that show

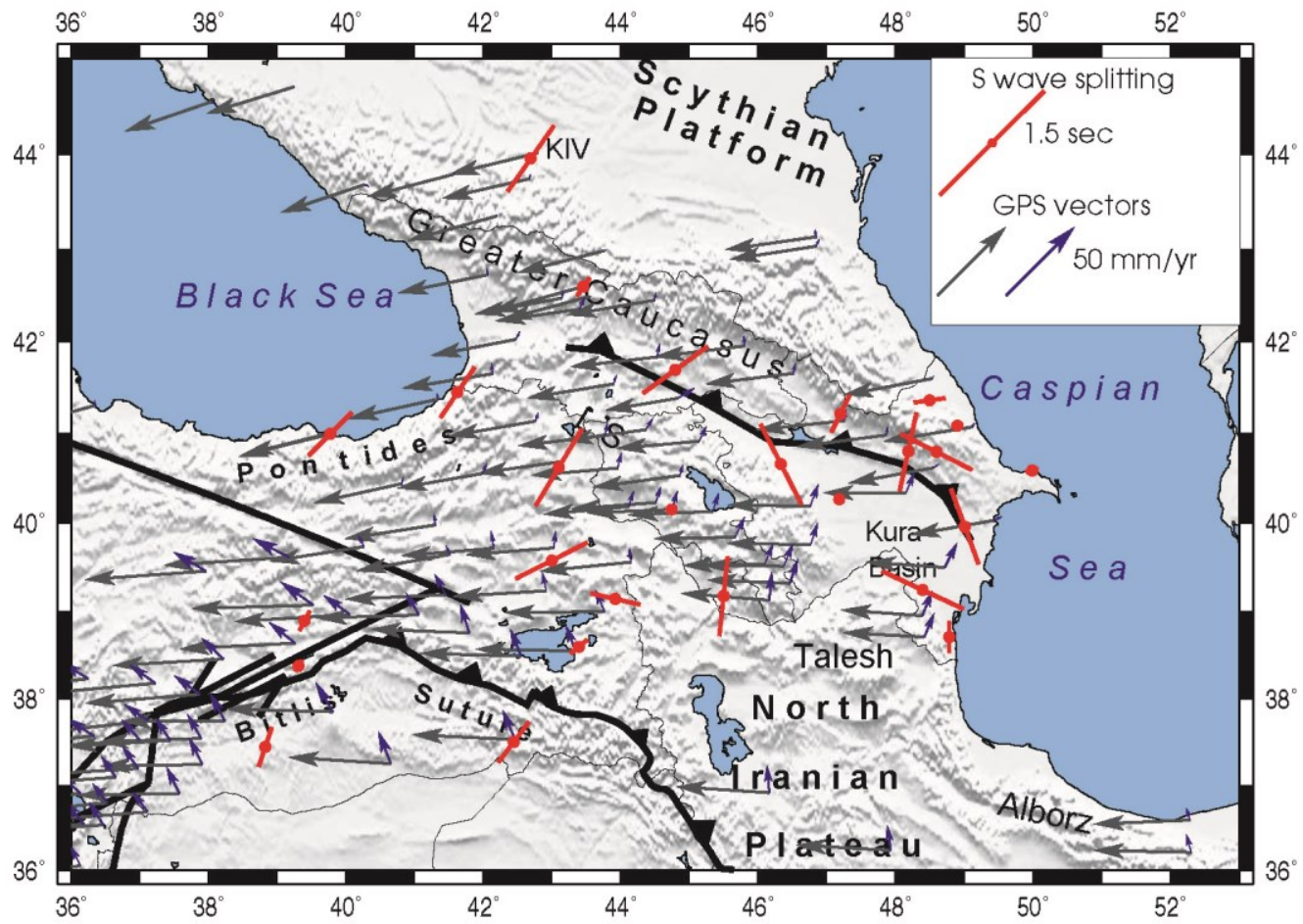

Figure 3.6. Teleseismic $S$ wave splitting results of the method of Wolfe and Silver [1998]. Red splitting parameters the results of the present study, grey arrows - GPS vectors with a hot spot reference, blue arrows - GPS vectors relative to stable Eurasia [Reilinger et al., 2006]. 
that two events with the back azimuth difference of $10^{\circ}$ are insufficient to reasonably determine the splitting parameters of a two-layer anisotropic structure: the fast polarization directions, however, were more reliably recovered than the lag times as they preserved the angle between the fast directions of the layers (Figure 3.4, left graphs). Figure 3.7 shows the fit of the $S$ wave splitting results for station GAN derived by the method of Silver and Chan [1991] to synthetic results. The grid search results (Figure 3.8) for most of the stations show that the bottom layer has generally NE-SW fast polarization directions across the Caucasus region while the top layer is roughly perpendicular to the direction of shortening in the region (i.e. the relative plate motions with respect to stable Eurasia). However, the results of two Caucasus stations, QUB and SEK approach a single layer of anisotropy.

The fast polarization direction derived from the analysis of the local deep direct $S$ arrival to the station QUB (Figure 3.9) deviates by $38^{\circ}$ from the fast direction of the of the top layer at the station, which was determined by the grid search. However, it is in a good agreement with the fast polarization directions of the top layer determined for the two closest stations in the east, SIZ and PQL. Therefore, it is likely that the uppermost mantle in the eastern Greater Caucasus has fast directions parallel to the axis of the mountain range and perpendicular to the direction of shortening [Allmendinger et al., 2007] in this region. 

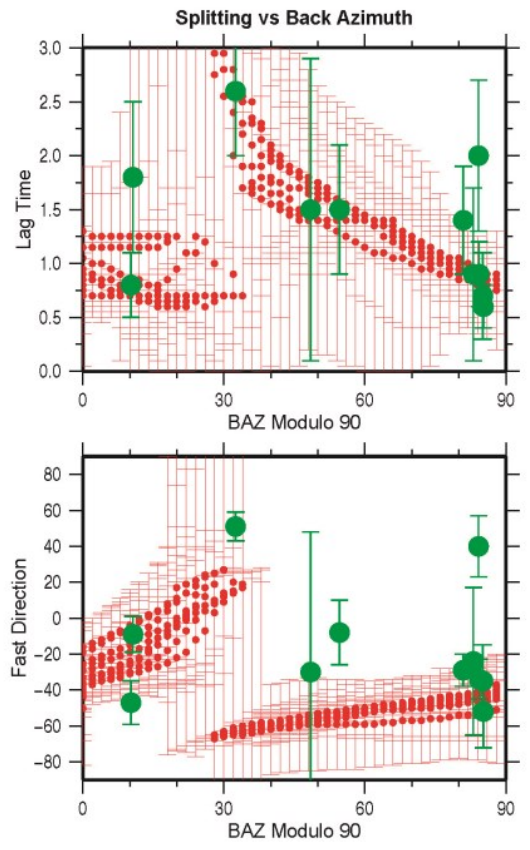

Figure 3.7. The fit of the $S$ wave splitting results for station GAN (green) to the synthetic results (red) corresponding to the two layer model: bottom layer: fast direction, $60^{\circ}$, lag time, $0.7 \mathrm{~s}$; top layer: fast direction, $130^{\circ}$, lag time, $1.4 \mathrm{~s}$. Vertical bars show twice the standard deviation.

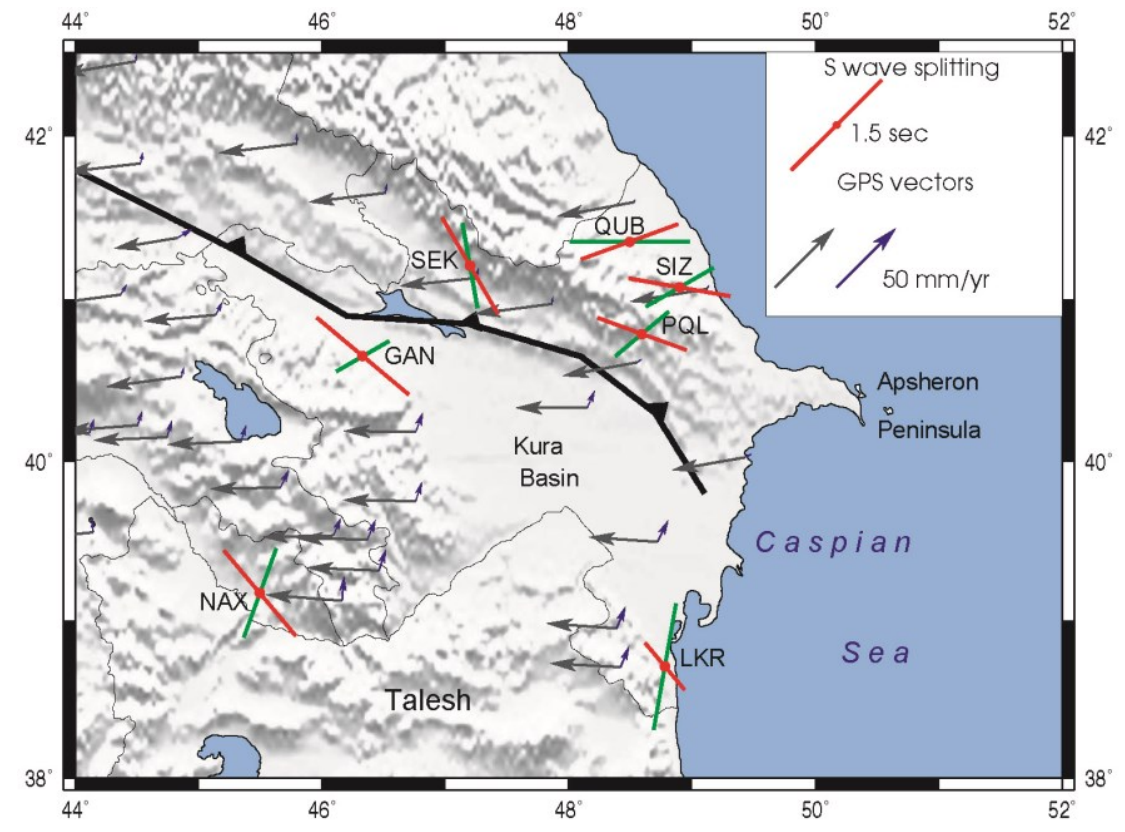

Figure 3.8. Two layer splitting results. Green splitting parameters - the bottom layer, red splitting parameters - the top layer, grey arrows - GPS vectors with a hot spot reference, blue arrows - GPS vectors relative to stable Eurasia [Reilinger et al., 2006]. 


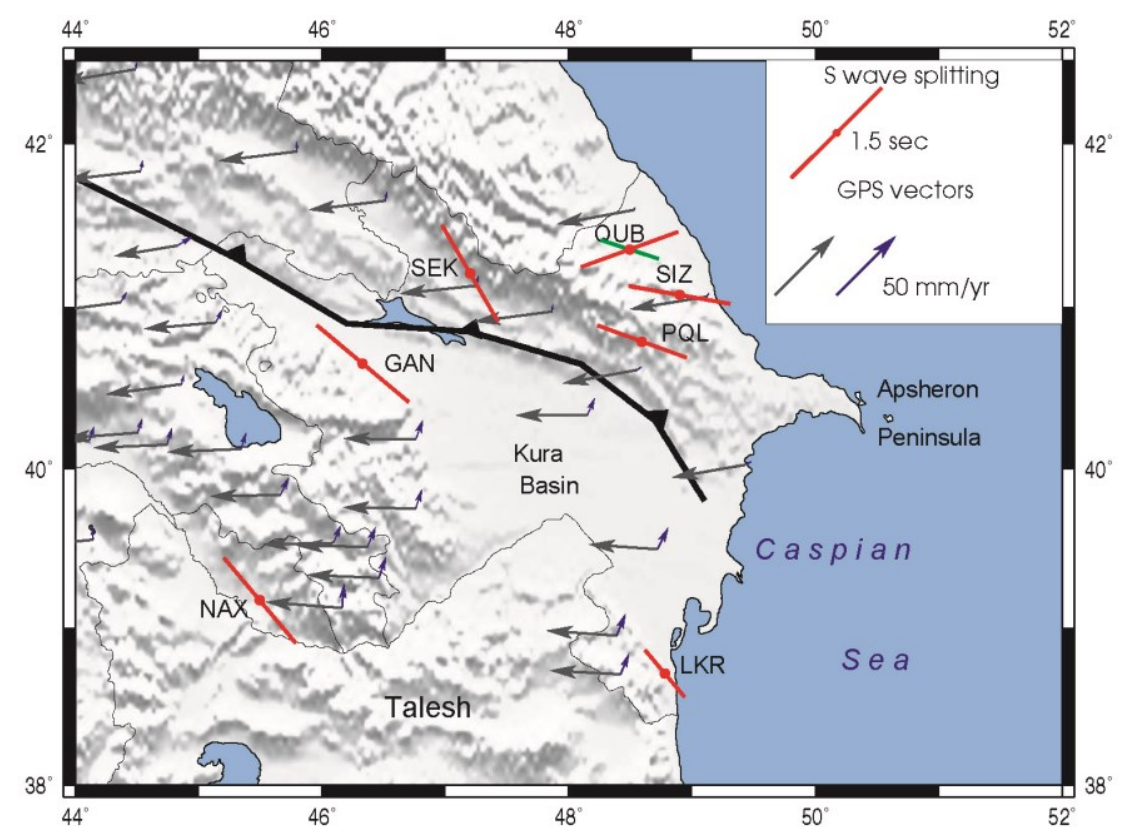

Figure 3.9. Local $S$ wave splitting parameters (green) in comparison with the top layer anisotropy (red). Grey arrows - GPS vectors with a hot spot reference, blue arrows GPS vectors relative to stable Eurasia [Reilinger et al., 2006].

\subsection{Disscution}

The $S$ wave splitting results of this study combined with the results of Sandvol et al. [2003b] show that the fast polarization directions imply a uniform NE-SW upper mantle anisotropy in the regions, which have thin to absent mantle lid and supported by anomalously hot and ductile asthenosphere: the Eastern Anatolian Plateau and the central Greater Caucasus [e.g., Skobeltsyn et al., 2014; Koulakov et al., 2012]. Sandvol et al. [2003b] suggested that the fast polarization directions in the Eastern Anatolia are associated with deeper mantle anisotropy as these directions did not change across the Arabian Plate boundary and significantly deviated from the absolute plate motion vectors. A similar suggestion can be made about the central Greater Caucasus based on the results 
of this study (Figure 3.1). A comparison of the $S$ wave splitting results with the Rayleigh wave phase velocity azimuthal anisotropy in the Eastern Anatolian Plateau (Figure 3.10) reveals a good agreement between the directions of the fast polarizations and the azimuthal anisotropy. The increase of the Rayleigh wave anisotropy percent with the increased period and therefore depth further support the suggestion of the deep mantle source of anisotropy in Eastern Anatolia. The absence of shallow mantle anisotropy could be explained by inability of the plate motions in the region to create a thick layer of LPO in the shallow, ductile asthenosphere, which could produce a time lag long enough to be detected within the resolution of the splitting analysis of the long period teleseismic phases. Another possible reason why the fast polarizations in the Eastern Anatolian Plateau and eastern Greater Caucasus are related to deep mantle flow is that the shallow flow could be vertical and therefore not detectable by traditional $S$ wave splitting techniques.

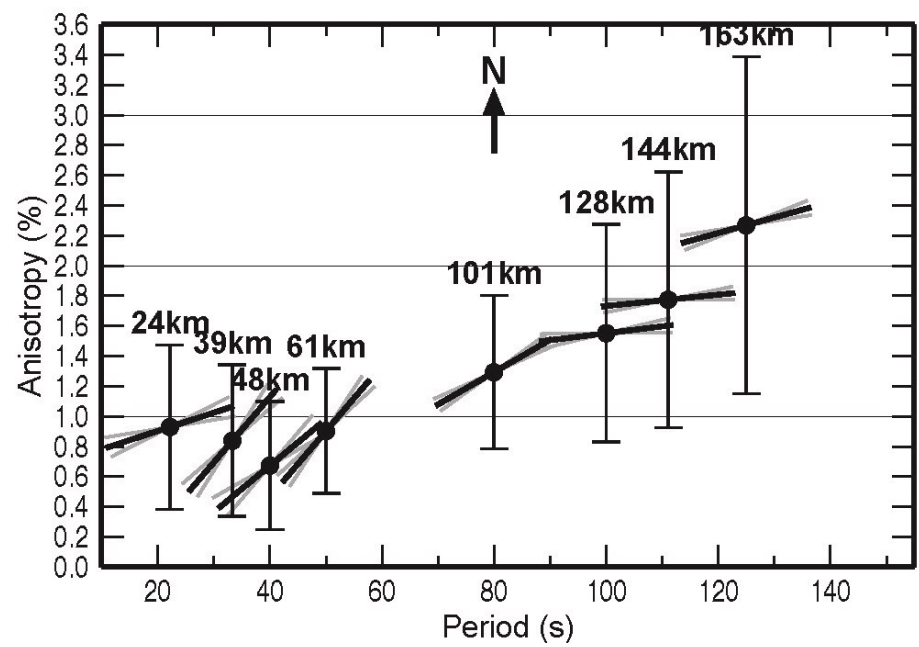

Figure 3.10. Average Rayleigh wave azimuthal anisotropy in the Eastern Anatolian Plateau. Black lines are the fast directions with vertical as north, vertical bars -1 standard deviation of the strength of anisotropy, and grey lines - standard errors in azimuth, the numbers above the error bars are the approximate peak sensitivity depths. 


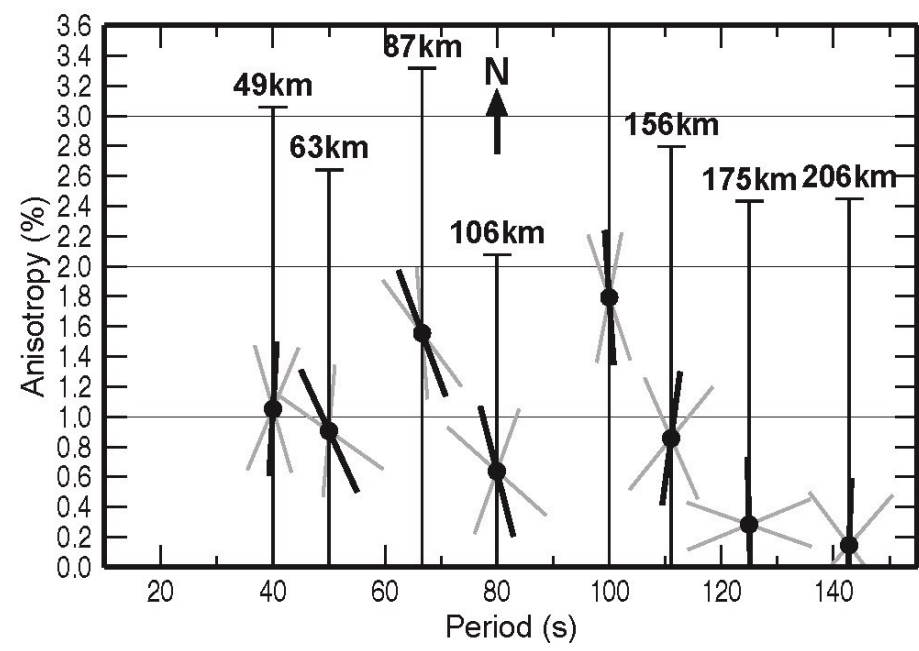

Figure 3.11. Average Rayleigh wave azimuthal anisotropy in Azerbaijan. Black lines are the fast directions with vertical as north, vertical bars -1 standard deviation of the strength of anisotropy, and grey lines - standard errors in azimuth, the numbers above the error bars are the approximate peak sensitivity depths.

In spite of the absence of most of the lithospheric mantle, the southern Lesser Caucasus seems to show the fast polarizations that agree well with the absolute plate motions. It actually looks like the fast directions are rotated clockwise with respect to those to the west of this area. A possible explanation of this rotation could be the effect of the sinking slab below the northern Iran [Skobeltsyn et al., 2014] on the regional mantle flow.

Unlike the regions described in the previous paragraphs, the Kura Basin and the eastern Greater Caucasus have a thick lithospheric structure. Furthermore, the northeastern Greater Caucasus is characterized by deep mantle seismicity [e.g. Mellors et al., 2012]. Kovachev at al. [2009] studied the mantle seismicity using an array of ocean bottom seismometers (OBS) deployed near the Dagestan coast of the Middle Caspian basin. As the signal to noise ratio significantly improves for seismograms recorded by OBS instruments in comparison with those recorded by inland-based seismometers, the 
ability to detect smaller and deeper events greatly increases. The authors were able to determine the hypocenters of over 550 micro earthquakes with local magnitudes ranging from 0.5 to 2.5 and weak earthquakes with local magnitudes 3.0-5.0. Approximately 110 of these events occurred at depths 50-200 km with most of the events located in the boundary zone between the eastern Greater Caucasus and the Scythian Platform near the city of Grozny. Interestingly, the field of the focal depths of these deep events is dipping northward gently, which implies that this deep seismogenic zone may be related to underthrusting of the Transcaucasus (i.e. the Lesser Caucasus, Kura Basin) continental lithosphere [Kovachev at al., 2009]. Moreover, Kovachev at al. [2009] argued that no oceanic subduction preceded the continental subduction in the eastern Greater Caucasus due to the absence of evidence supporting the prior existence of oceanic crust in the Transcaucaus [Kazmin and Tikhonova, 2006]. However, Mellors et al. [2012] suggested that the deep seismicity is caused by the northward subduction of a relict oceanic crust sinking below Eurasia. An alternative hypothesis of the deep mantle seismogenic zone in the Greater Caucasus is reactivation of Paleozoic or Early Mesozoic deep faults in the boundary zone between the Greater Caucasus and the Scythian Plate [Kovachev at al. 2009].

The two-layer grid search results and the splitting analysis of the local deep event show that the shallow mantle anisotropy in the eastern Greater Caucasus is roughly parallel to the range axis and perpendicular to the shortening in that region determined by Allmendinger et al. [2007]. Therefore, this anisotropic pattern is interpreted as the result of the LPO aligned parallel to the direction of the maximum finite extensional strain that has been produced by horizontal shortening of the lithosphere (i.e. pure shear 
deformation) in the eastern Greater Caucasus caused by the compressive regime due to subduction of the Kura Basin lithosphere beneath the Scythian Platform. The results of Rayleigh wave phase velocity azimuthal anisotropy for the eastern Caucasus region (i.e. eastern Greater Caucasus, Kura Basin, and northeastern Lesser Caucasus) show null percent of anisotropy due to high errors probably caused by higher noise levels in the data from Azerbaijan (Figure 3.11). Thus, I cannot make a definite conclusion from the comparison of my S wave splitting in the eastern Caucasus region with the surface wave azimuthal anisotropy. However, if there is a two layer anisotropic structure in the eastern Caucasus, it is possible that this would contribute to the observed large errors of surface wave azimuthal anisotropy.

It is common to observe B-type of olivine LPO at in the vicinity of the trench of a subductions zone because of relatively low temperature, high stress and water rich mantle wedge [e.g., Jung et al., 2006; Karato, 2008]. As a result, the B-type olivine LPO produces the fast polarization splitting directions, which are parallel to the trench and perpendicular to the maximum finite strain of the mantle wedge, which is characterized by a deformation style approximated by simple shear [e.g. Jung et al., 2006]. On the other hand, a serpentinized mantle layer that is deformed by simple shear can produce trench parallel fast polarization directions similar to those of B-type olivine LPO [e.g., Long, 2013]. Unlike the central Greater Caucasus there is no evidence for recent volcanism in the eastern part of the mountain belt, which suggest that there is no melt generation in the uppermost mantle below it. In case of the shallow angle subduction of either oceanic or continental lithosphere beneath the eastern Greater Caucasus, a possible dehydration of that lithosphere would not lower the olivine solidus line to the 
temperatures observed at shallow depths. Therefore, presence of B-type olivine LPO or serpentinized mantle layer is possible below the orogen. The present study orogenparallel $S$ wave fast polarization directions could be explained by a possible development

of B-type LPO as the result of the shallow angle underthrusting or subduction of the Kura Basin Lithosphere underneath the eastern Greater Caucasus. However, the consistency of the fast polarization directions in the top layer in the Kura Basin, eastern portions of the Lesser and Greater Caucasus, and Talesh can also suggest that the regional uppermost fabrics could have been preserved since before the initiation of the hard stage of the collision in this region.

\subsection{Conclusions}

The observed splitting parameters in the Eastern Anatolia and the central part of the Greater Caucasus suggest many similarities between the upper mantle fabrics of these regions, particularly the deep source of the observed anisotropy. Results from stations located in the Kura Basin and the eastern Greater Caucasus show azimuthal dependence of splitting parameters and suggest a two-layer anisotropic structure in the region. The anisotropic directions of the bottom layer are roughly NE-SW, which is similar to $S$ wave splitting observations in the Eastern Anatolian Plateau and central Greater Caucasus. The anisotropic directions of the top layer are nearly parallel to the strike of the Greater Caucasus mountain belt and therefore perpendicular to the crustal shortening in that region. These observations coupled with the deep seismicity of the eastern Greater Caucasus suggest a northward underthrusting or subduction of the Kura Basin 
Lithosphere beneath the Scythian Platform. The Kura Basin therefore could be considered as the trench in this subduction zone. The orogen-parallel anisotropic directions in the eastern part of the Greater Caucasus could be also related to B-type of olivine mantle fabrics or a relatively thin serpentine mantle layer. However, the uppermost mantle fabrics might represent an ancient preserved LPO, which is not related to the deep seismogenic zone caused by deformations in the eastern Greater Caucasus.

\subsection{References}

Abt, D. L., and K. M. Fischer (2008), Resolving three-dimensional anisotropic structure with shear wave splitting tomography, Geophysical Journal International, 173(3), 859-886, doi: 10.1111/j.1365-246X.2008.03757.x.

Al-Damegh, K., E. Sandvol, A. Al-Lazki, and M. Barazangi (2004), Regional seismic wave propagation ( $\mathrm{Lg}$ and $\mathrm{Sn}$ ) and Pn attenuation in the Arabian Plate and surrounding regions, Geophysical Journal International, 157(2), 775-795, doi: 10.1111/j.1365-246X.2004.02246.x.

Al-Lazki, A., D. Seber, E. Sandvol, N. Türkelli, R. Mohamad, and M. Barazangi (2003), Tomographic Pn velocity and anisotropy structure beneath the Anatolian plateau (eastern Turkey) and the surrounding regions, Geophysical Research Letters, 30(24), doi: 10.1029/2003GL017391.

Allen, M. B., S. J. Vincent, G. I. Alsop, A. Ismail-zadeh, and R. Flecker (2003), Late Cenozoic deformation in the South Caspian region: effects of a rigid basement block within a collision zone, Tectonophysics, 366(3-4), 223-239, doi: 10.1016/s0040-1951(03)00098-2.

Allmendinger, R. W., R. Reilinger, and J. Loveless (2007), Strain and rotation rate from GPS in Tibet, Anatolia, and the Altiplano, Tectonics, 26(3), TC3013, doi: 10.1029/2006TC002030.

Amini, S., Z. H. Shomali, H. Koyi, and R. G. Roberts (2012), Tomographic upper-mantle velocity structure beneath the Iranian Plateau, Tectonophysics, 554-557(0), 42-49, doi: dx.doi.org/10.1016/j.tecto.2012.06.009. 
Angus, D. A., D. C. Wilson, E. Sandvol, and J. F. Ni (2006), Lithospheric structure of the Arabian and Eurasian collision zone in eastern Turkey from S-wave receiver functions, Geophysical Journal International, 166(3), 1335-1346, doi: 10.1111/j.1365-246X.2006.03070.x.

Avdeev, B., and N. A. Niemi (2011), Rapid Pliocene exhumation of the central Greater Caucasus constrained by low-temperature thermochronometry, Tectonics, 30(2), TC2009, doi: 10.1029/2010TC002808.

Barazangi, M., E. Sandvol, and D. Seber (2006), Structure and tectonic evolution of the Anatolian plateau in eastern Turkey, Geological Society of America Special Papers, 409, 463-473, doi: 10.1130/2006.2409(22).

Bowman, J. R., and M. Ando (1987), Shear-wave splitting in the upper-mantle wedge above the Tonga subduction zone, Geophysical Journal of the Royal Astronomical Society, 88(1), 25-41, doi: 10.1111/j.1365-246X.1987.tb01367.x.

Chernyshev, I. V., S. N. Bubnov, V. A. Lebedev, Y. V. Gol'tsman, E. D. Bairova, and A. I. Yakushev (2014), Two stages of explosive volcanism of the Elbrus area: Geochronology, petrochemical and isotopic-geochemical characteristics of volcanic rocks, and their role in the neogene-quaternary evolution of the Greater Caucasus, Stratigr. Geol. Correl., 22(1), 96-121, doi: $10.1134 / \mathrm{S} 086959381401002 \mathrm{X}$.

Dewey, J. F., M. R. Hempton, W. S. F. Kidd, F. Saroglu, and A. M. C. Şengör (1986), Shortening of continental lithosphere: the neotectonics of Eastern Anatolia - a young collision zone, Geological Society, London, Special Publications, 19(1), 136, doi: 10.1144/gsl.sp.1986.019.01.01.

Godzikovskaya, A., and G. I. Reysner (1989), Endogenic position of deep earthquakes in the Caucasus, Geotectonics 3, 205-213

Gök, R., E. Sandvol, N. Türkelli, D. Seber, and M. Barazangi (2003), Sn attenuation in the Anatolian and Iranian plateau and surrounding regions, Geophysical Research Letters, 30(24), TUR 5-1 - TUR 5-4, doi: 10.1029/2003GL017391.

Gök, R., R. J. Mellors, E. Sandvol, M. Pasyanos, T. Hauk, R. Takedatsu, G. Yetirmishli, U. Teoman, N. Türkelli, T. Godoladze, and Z. Javakishvirli (2011), Lithospheric velocity structure of the Anatolian plateau-Caucasus-Caspian region, Journal of Geophysical Research: Solid Earth, 116(B5), B05303, doi: 10.1029/2009JB000837. 
Jackson, J., K. Priestley, M. Allen, and M. Berberian (2002), Active tectonics of the South Caspian basin, Geophysical Journal International, 148(2), 214-245, doi: 10.1046/j.1365-246X.2002.01588.x.

Kaminski, E. (2006), Interpretation of seismic anisotropy in terms of mantle flow when melt is present, Geophysical Research Letters, 33(2), L02304, doi: 10.1029/2005GL024454.

Karato, S.-i., H. Jung, I. Katayama, and P. Skemer (2008), Geodynamic Significance of Seismic Anisotropy of the Upper Mantle: New Insights from Laboratory Studies, Annual Review of Earth and Planetary Sciences, 36(1), 59-95, doi: doi:10.1146/annurev.earth.36.031207.124120.

Kaz'min, V. G., and N. F. Tikhonova (2006), Late Cretaceous-Eocene marginal seas in the Black Sea-Caspian region: Paleotectonic reconstructions, Geotectonics, 40(3), 169-182, doi: $10.1134 / \mathrm{S} 0016852106030022$.

Keskin, M. (2003), Magma generation by slab steepening and breakoff beneath a subduction-accretion complex: An alternative model for collision-related volcanism in Eastern Anatolia, Turkey, Geophysical Research Letters, 30(24), doi: $10.1029 / 2003$ gl018019.

Keskin, M. (2007), Eastern Anatolia: A hotspot in a collision zone without a mantle plume, Geological Society of America Special Papers, 430, 693-722, doi: $10.1130 / 2007.2430(32)$.

Koulakov, I., I. Zabelina, I. Amanatashvili, and V. Meskhia (2012), Nature of orogenesis and volcanism in the Caucasus region based on results of regional tomography, Solid Earth, 3(2), 327-337, doi: 10.5194/se-3-327-2012.

Kovachev, S. A., V. G. Kaz'min, I. P. Kuzin, and L. I. Lobkovsky (2009), New data on mantle seismicity of the Caspian region and their geological interpretation, Geotectonics, 43(3), 208-220, doi: 10.1134/s0016852109030030.

Lebedev, V. A., I. V. Chernyshev, and E. V. Sharkov (2011), Geochronological scale and evolution of late Cenozoic magmatism within the Caucasian segment of the alpine belt, Doklady Earth Sciences, 441(2), 1656-1660, doi: $10.1134 / \mathrm{S} 1028334 \mathrm{X} 11120051$.

Long, M. D. (2013), CONSTRAINTS ON SUBDUCTION GEODYNAMICS FROM SEISMIC ANISOTROPY, Reviews of Geophysics, 51(1), 76-112, doi: 10.1002/rog.20008. 
Maggi, A., and K. Priestley (2005), Surface waveform tomography of the Turkish-Iranian plateau, Geophysical Journal International, 160(3), 1068-1080, doi: 10.1111/j.1365-246X.2005.02505.x.

Mainprice, D., and B. Ildefonse (2009), Seismic Anisotropy of Subduction Zone Minerals-Contribution of Hydrous Phases, in Subduction Zone Geodynamics, edited by S. Lallemand and F. Funiciello, pp. 63-84, Springer Berlin Heidelberg.

Mainprice, D., A. Tommasi, H. Couvy, P. Cordier, and D. J. Frost (2005), Pressure sensitivity of olivine slip systems and seismic anisotropy of Earth's upper mantle, Nature, 433(7027), 731-733

Mellors, R. J., J. Jackson, S. Myers, R. Gök, K. Priestley, G. Yetirmishli, N. Türkelli, and T. Godoladze (2012), Deep Earthquakes beneath the Northern Caucasus: Evidence of Active or Recent Subduction in Western Asia, Bulletin of the Seismological Society of America, 102(2), 862-866, doi: 10.1785/0120110184.

Myers, S. C., G. Johannesson, and N. A. Simmons (2011), Global-scale P wave tomography optimized for prediction of teleseismic and regional travel times for Middle East events: 1. Data set development, Journal of Geophysical Research: Solid Earth, 116(B4), B04304, doi: 10.1029/2010jb007967.

Örgülü, G., M. Aktar, N. Türkelli, E. Sandvol, and M. Barazangi (2003), Contribution to the seismotectonics of Eastern Turkey from moderate and small size events, Geophysical Research Letters, 30(24), 8040, doi: 10.1029/2003GL018258.

Pearce, J. A., J. F. Bender, S. E. De Long, W. S. F. Kidd, P. J. Low, Y. Güner, F. Saroglu, Y. Yilmaz, S. Moorbath, and J. G. Mitchell (1990), Genesis of collision volcanism in Eastern Anatolia, Turkey, Journal of Volcanology and Geothermal Research, 44(1-2), 189-229

Reilinger, R., S. McClusky, P. Vernant, S. Lawrence, S. Ergintav, R. Cakmak, H. Ozener, F. Kadirov, I. Guliev, R. Stepanyan, M. Nadariya, G. Hahubia, S. Mahmoud, K. Sakr, A. ArRajehi, D. Paradissis, A. Al-Aydrus, M. Prilepin, T. Guseva, E. Evren, A. Dmitrotsa, S. V. Filikov, F. Gomez, R. Al-Ghazzi, and G. Karam (2006), GPS constraints on continental deformation in the Africa-Arabia-Eurasia continental collision zone and implications for the dynamics of plate interactions, Journal of Geophysical Research: Solid Earth, 111(B5), B05411, doi: 10.1029/2005JB004051.

Sandvol, E., N. Türkelli, and M. Barazangi (2003a), The Eastern Turkey Seismic Experiment: The study of a young continent-continent collision, Geophysical Research Letters, 30(24), 8038, doi: 10.1029/2003GL018912. 
Sandvol, E., N. Türkelli, E. Zor, R. Gök, T. Bekler, C. Gurbuz, D. Seber, and M. Barazangi (2003b), Shear wave splitting in a young continent-continent collision: An example from Eastern Turkey, Geophysical Research Letters, 30(24), 8041, doi: 10.1029/2003GL017390.

Seber, D., E. Sandvol, C. Sandvol, C. Brindisi, and M. Barazangi (2001), Crustal model for the Middle East and North Africa region: implications for the isostatic compensation mechanism, Geophysical Journal International, 147(3), 630-638, doi: 10.1046/j.0956-540x.2001.01572.x.

Şengör, A. M. C., S. Özeren, T. Genç, and E. Zor (2003), East Anatolian high plateau as a mantle-supported, north-south shortened domal structure, Geophysical Research Letters, 30(24), 8045, doi: 10.1029/2003GL017858.

Silver, P. G., and W. W. Chan (1991), Shear wave splitting and subcontinental mantle deformation, Journal of Geophysical Research: Solid Earth, 96(B10), 1642916454, doi: 10.1029/91JB00899.

Silver, P. G., and M. K. Savage (1994), The interpretation of shear-wave splitting parameters in the presence of two anisotropic layers, Geophysical Journal International, 119(3), 949-963

Silver, P. G., and M. D. Long (2011), The non-commutivity of shear wave splitting operators at low frequencies and implications for anisotropy tomography, Geophysical Journal International, 184(3), 1415-1427, doi: 10.1111/j.1365246X.2010.04927.x.

Skobeltsyn, G., R. Mellors, R. Gök, N. Türkelli, G. Yetirmishli, and E. Sandvol (2014), Upper mantle $\mathrm{S}$ wave velocity structure of the East Anatolian-Caucasus region, Tectonics, 33(3), 2013TC003334, doi: 10.1002/2013TC003334.

Triep, E. G., G. A. Abers, A. L. Lerner-Lam, V. Mishatkin, N. Zakharchenko, and O. Starovoit (1995), Active thrust front of the Greater Caucasus: The April 29, 1991, Racha earthquake sequence and its tectonic implications, J. Geophys. Res., 100(B3), 4011-4033, doi: 10.1029/94jb02597.

Türkelli, N., E. Sandvol, E. Zor, R. Gök, T. Bekler, A. Al-Lazki, H. Karabulut, S. Kuleli, T. Eken, C. Gurbuz, S. Bayraktutan, D. Seber, and M. Barazangi (2003), Seismogenic zones in Eastern Turkey, Geophysical Research Letters, 30(24), 8039, doi: 10.1029/2003GL018023. 
Ulomov, V. I., T. I. Danilova, N. S. Medvedeva, T. P. Polyakova, and L. S. Shumilina (2007), Assessment of seismic hazard in the North Caucasus, Izv., Phys. Solid Earth, 43(7), 559-572, doi: 10.1134/s1069351307070051.

Wirth, E., and M. D. Long (2010), Frequency-dependent shear wave splitting beneath the Japan and Izu-Bonin subduction zones, Physics of the Earth and Planetary Interiors, 181(3-4), 141-154, doi: 10.1016/j.pepi.2010.05.006.

Wolfe, C. J., and P. G. Silver (1998), Seismic anisotropy of oceanic upper mantle: Shear wave splitting methodologies and observations, Journal of Geophysical Research: Solid Earth, 103(B1), 749-771, doi: 10.1029/97JB02023.

Yang, Y., and D. W. Forsyth (2006a), Regional tomographic inversion of the amplitude and phase of Rayleigh waves with 2-D sensitivity kernels, Geophysical Journal International, 166(3), 1148-1160, doi: 10.1111/j.1365-246X.2006.02972.x.

Yang, Y., and D. W. Forsyth (2006b), Rayleigh wave phase velocities, small-scale convection, and azimuthal anisotropy beneath southern California, Journal of Geophysical Research, 111(B7), doi: 10.1029/2005jb004180.

Zor, E. (2008), Tomographic evidence of slab detachment beneath eastern Turkey and the Caucasus, Geophysical Journal International, 175(3), 1273-1282, doi: 10.1111/j.1365-246X.2008.03946.x.

Zor, E., E. Sandvol, C. Gürbüz, N. Türkelli, D. Seber, and M. Barazangi (2003), The crustal structure of the East Anatolian plateau (Turkey) from receiver functions, Geophys. Res. Lett., 30(24), 8044, doi: 10.1029/2003gl018192. 


\section{Chapter 4}

\section{CONCLUSIONS}

I have applied two-plane Rayleigh wave tomography [Yang and Forsyth, 2006a, 2006b], shear wave splitting techniques of Silver and Chan [1991] and Wolfe and Silver [1998] as well as developed a two-layer shear wave splitting grid search algorithm in order to study the upper mantle shear wave velocity structure of the Eastern AnatolianCaucasus region located in the zone of ongoing continental collision between the Arabian and Eurasian Plates. The application of the two-plane Rayleigh wave tomography resulted in the regional anisotropic phase velocity structure as a function of frequency. Furthermore, I inverted these frequency dependent phase velocities using the method of Saito [1988] to obtain the three-dimensional shear wave velocity structure of the region down to depths of $250 \mathrm{~km}$, which improves the depth resolution over those of the preexisting regional body wave and surface wave velocity models. In addition to the surface wave study, I present the first shear wave splitting results for the stations located in the Caucasus Region (Azerbaijan and Georgia) along with results from some permanent Turkish stations in this dissertation. The shear wave splitting analysis of teleseismic and local shear wave phases allowed me to infer about the upper mantle strain fabrics and their relationship to the crustal deformation regimes in the study region. The results of the present dissertation research have some important implications on the regional tectonic setting and the late Cenozoic evolution of this part of the collision zone, which are summarized in the following sections of this chapter. 


\subsection{Eastern Anatolian, north Iranian Plateaus, and Lesser Caucasus}

The results of the surface wave tomography study confirm the previous conclusions suggesting that the region has a very thin to absent lithospheric mantle underlain by asthenosphere with significant amounts of partial melt [e.g., Gök et al., 2003; Al-Damegh et al., 2004; Al-Lazki et al., 2003, 2004; Angus et al., 2006; Amini et al., 2012]. According to my model of the three-dimensional shear wave velocity structure (e.g., Figure 2.11), the depth extent of the asthenospheric layer, measured from the greatest negative and positive velocity gradients with depth, is from $70 \mathrm{~km}$ to less than $200 \mathrm{~km}$ in the region. However, the Pontides and northeastern part of Arabia possess lithospheric roots reaching depths up to 125 and $200 \mathrm{~km}$ respectively that is in agreement with body wave tomography results [Biryol et al,. 2011]. The model also shows two deep relatively high velocity bodies in the region: one beneath the Pontides and the Black Sea (also observed in teleseismic P wave tomographic models of Biryol et al, [2011] and Lei and Zhao [2007]) the other beneath the northern Iranian Plateu. I interpret this high velocity structures as the remnants of the northern and southern branches of Neo-Tethys. The depths of the top parts of these slabs are approximately the same, which suggests that the break off events occurred at approximately the same time.

The locations of the detached oceanic slabs relative to the Pontides and Bitlis suture combined with the distribution of asthenospheric material in the region suggests that two slabs, one in the north the second in the south, broke off nearly simultaneously (Figure 2.14). This is partly consistent with the model of Barzangi et al., 2006 who suggested that the asthenospheric upwelling and collision-related volcanism was caused by the 
detachment and sinking of the flat Bitlis slab beneath the Eastern Anatolian Plateau (Figure 4.1 a). The differences between my model and that proposed by Barazangi et al. [2006] are that I suggest that the asthenospheric upwelling was first caused by the steepening of the Bitlis slab and then its detachment when the slab had a near vertical orientation (Figure 4.1 b). Furthermore, the model of Barazangi et al. [2006] suggested that the Pontide slab had completely sunk by the time of the Bitlis slab detachment which contradicts my tomographic observations and the $\mathrm{P}$ wave tomography results [Biryol et al, 2011; Lei and Zhao, 2007].
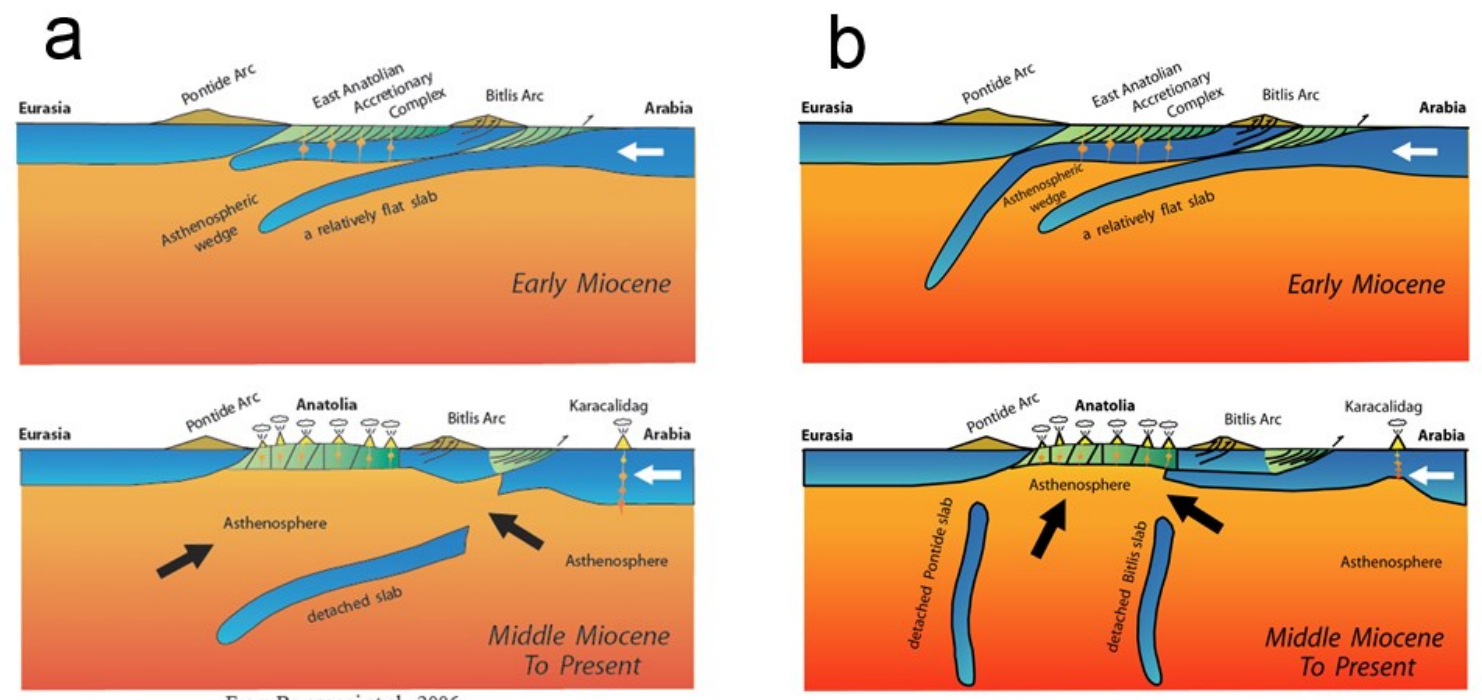

Figure 4.1. The differences between the geodynamic model proposed by Barazangi et al. [2006] (a) and the model proposed in the present dissertation (b).

My shear wave splitting results combined with the results of Sandvol et al. [2003] show the uniform NE-SW fast polarization directions in the Eastern Anatolian Plateau and across the Arabian Plate boundary, which implies a uniform upper mantle strain fabrics in the region that is not associated with the present plate motions. The comparison of the splitting results with the Rayleigh wave phase velocity azimuthal anisotropy in the 
East Anatolian Plateau (Figure 3.10) revealed a good agreement between the azimuthal anisotropy and fast polarization directions. The increase of the magnitude of the Rayleigh wave anisotropy with the increase of the period length of the dominant wave further supports a deep mantle source of anisotropy in the region suggested by Sandvol et al. [2003]. The rotations of the fast polarization directions at the stations located in the eastern part of the Lesser Caucasus relative to those in the Eastern Anatolia suggest a different local upper mantle flow, which could be affected by the sinking Bitlis slab (e.g. Figures 2.11 and 2.12).

\subsection{The Greater Caucasus region}

My regional three-dimensional shear wave velocity model demonstrates a relatively thick, up to $200 \mathrm{~km}$ lithospheric structure beneath the Kura Basin and the eastern Greater Caucasus (e.g., Figures 2.11 and 2.12) and the absence of such in the western part of the Lesser Caucasus. The distinct characteristics of the upper mantle structures in the regions of the Greater Caucasus and Eastern Anatolia are also supported by the Rayleigh wave dispersion curves (Figures 2.6 and 2.7), which show a significant increase of the longer period phase velocities in the eastern Greater Caucasus and Kura Basin with respect to those in the Eastern Anatolian Plateau. The three-dimensional shear wave velocity model shows that the lithospheric structure beneath the eastern Greater Caucasus appears to be dipping northward (e.g., Figure 2.12). This observation supports the hypothesis of the underthrusting or subduction of the Kura Basin lithosphere under the Scythian Platform in addition to the existence of the north dipping deep mantle 
seismicity zone in the eastern Greater Caucasus [e.g., Kovachev at al., 2009; Mellors et al., 2012].

The shear wave splitting analysis conducted for the stations in the central Greater Caucasus shows the fast polarization directions that are similar to those in the Eastern Anatolia suggesting that both regions that are devoid of much of their lithospheric roots have similar deep mantle strain fabrics. However, the fast polarization directions in the eastern Greater Caucasus and Kura basin are quite different from those in the rest of the study region and are more or less parallel to the mountain range. The station GAN located in the Kura Basin had azimuthally dependent shear wave splitting parameters (Figure 3.7), which suggests the presence of two distinct anistropic layers. This observation served as the motivation for developing the two-layer shear wave splitting grid search algorithm. The grid search splitting analysis of the teleseismic shear wave phases shows that the eastern Greater Caucasus and Kura Basin indeed have a two-layer anisotropic structure with the fast polarization directions in the bottom layer (Figure 3.8) similar to the uniform fast direction polarization in the Eastern Anatolia and the central Greater Caucasus. The fast polarization directions in the top layer are roughly parallel to the axis of the Greater Caucasus mountain range. If the northward subduction of the Kura Basin lithosphere beneath the Scythian Platform indeed takes the place in the region, the orogen-parallel fast polarization directions in the top anisotropic layer can be related to the olivine LPO developed as the result of the compressional stress associated with the subduction. In the eastern Greater Caucasus, the upper mantle fabrics could be also associated with a B-type LPO or a thin serpentinized layer resulted from the simple shear deformation caused by the shallow angle subduction of the Kura Basin lithosphere. On 
the other hand, these relatively uniform fast directions in the Kura block could represent remnant lithospheric fabrics that preceded the hard collision stage in this region.

\subsection{Possible future work}

The results of the present dissertation research leave some questions related to the late Cenozoic evolution of the Eastern Anatolian-Caucasus region unanswered. There are still areas within the region of study such as northern Iran and the central Greater Caucasus where the seismic data coverage is sparse or absent. This could be resolved through a better international scientific collaboration in sharing the data and installation of new permanent and temporary instruments to increase the data density. Furthermore, additional seismic techniques should be applied in the region in order to better understand the regional upper mantle velocity structure and tectonic settings. For example, a joint model of Love wave and Rayleigh wave phase velocities allows inferring the radial anisotropy and could provide an insight on the vertical component of the mantle flow in the region. Moreover, understanding of the focal mechanisms of the deep seismicity in the eastern Greater Caucasus can play an important role in characterization of this part of the plate boundary. On the other hand, the seismology alone provides in most cases only a present time snapshot of the velocity structure of the earth interior and cannot completely describe how that velocity structure was generated. The history of the development of the Arabian Eurasian collisional zone can only be studied through a thorough investigation of the geological data collected in this region. We need more dating and geochemical analysis of the regional volcanic rocks in order to better 
understand the lateral migration of the volcanic centers since the initiation of the continental collision. This would help to develop a better time constrain on the steepening of the northern branch of the Neo-Tethys lithosphere. For the same reason, it is necessary to study whether there are lateral variations in the rates of uplift within the Eastern Anatolian Plateau. This could be achieved, for example, by low-temperature thermochronometry and by sedimentology analysis of the deposits found in the pull-apart basins. Furthermore, the volcanic products that can rich $1 \mathrm{~km}$ in thickness cover half of the territory of the Eastern Anatolian Plateau thus hiding vital pieces of geological information on the composition of the eastern Anatolian crust. Therefore, a comprehensive drilling study could provide us with some of that missing information by delivering drill core samples from the crucial areas. Finally, geodynamic modeling can prove itself useful in estimating of the rates of uplift, asthenospheric upwelling, slab steepening, and detachment.

\subsection{References}

Al-Damegh, K., E. Sandvol, A. Al-Lazki, and M. Barazangi (2004), Regional seismic wave propagation ( $\mathrm{Lg}$ and $\mathrm{Sn})$ and Pn attenuation in the Arabian Plate and surrounding regions, Geophysical Journal International, 157(2), 775-795, doi: 10.1111/j.1365-246X.2004.02246.x.

Al-Lazki, A., D. Seber, E. Sandvol, N. Türkelli, R. Mohamad, and M. Barazangi (2003), Tomographic Pn velocity and anisotropy structure beneath the Anatolian plateau (eastern Turkey) and the surrounding regions, Geophys. Res. Lett., 30(24), 8043, doi:10.1029/2003GL017391.

Al-Lazki, A. I., E. Sandvol, D. Seber, M. Barazangi, N. Turkelli, and R. Mohamad (2004), Pn tomographic imaging of mantle lid velocity and anisotropy at the 
junction of the Arabian, Eurasian and African plates, Geophysical Journal International, 158(3), 1024-1040, doi: 10.1111/j.1365-246X.2004.02355.x

Amini, S., Z. H. Shomali, H. Koyi, and R. G. Roberts (2012), Tomographic upper-mantle velocity structure beneath the Iranian Plateau, Tectonophysics, 554-557(0), 42-49, doi: dx.doi.org/10.1016/j.tecto.2012.06.009.

Barazangi, M., E. Sandvol, and D. Seber (2006), Structure and tectonic evolution of the Anatolian plateau in eastern Turkey, Geol. Soc. Am. Spec. Pap., 409, 463-473, doi:10.1130/2006.2409(22).

Biryol, B. C., S. L. Beck, G. Zandt, and A. A. Özacar (2011), Segmented African lithosphere beneath the Anatolian region inferred from teleseismic P-wave tomography, Geophys. J. Int., 184(3), 1037-1057, doi:10.1111/j.1365246X.2010.04910.x.

Gök, R., E. Sandvol, N. Türkelli, D. Seber, and M. Barazangi (2003), Sn attenuation in the Anatolian and Iranian plateau and surrounding regions, Geophysical Research Letters, 30(24), TUR 5-1 - TUR 5-4, doi: 10.1029/2003GL017391.

Kovachev, S. A., V. G. Kaz'min, I. P. Kuzin, and L. I. Lobkovsky (2009), New data on mantle seismicity of the Caspian region and their geological interpretation, Geotectonics, 43(3), 208-220, doi: 10.1134/s0016852109030030.

Lei, J., and D. Zhao (2007), Teleseismic evidence for a break-off subducting slab under Eastern Turkey, Earth Planet. Sci. Lett., 257(1-2), 14-28, doi:10.1016/j.eps1.2007.02.011.

Mellors, R. J., J. Jackson, S. Myers, R. Gök, K. Priestley, G. Yetirmishli, N. Türkelli, and T. Godoladze (2012), Deep Earthquakes beneath the Northern Caucasus: Evidence of Active or Recent Subduction in Western Asia, Bulletin of the Seismological Society of America, 102(2), 862-866, doi: 10.1785/0120110184.

Saito, M. (1988), DISPER80: A subroutine package for the calculation of seismic normal-mode solutions, in Seismological Algorithms, edited by D. J. Doornbos, pp. 293-319, Elsevier, New York, N. Y.

Sandvol, E., N. Türkelli, E. Zor, R. Gök, T. Bekler, C. Gurbuz, D. Seber, and M. Barazangi (2003), Shear wave splitting in a young continent-continent collision: An example from Eastern Turkey, Geophysical Research Letters, 30(24), 8041, doi: 10.1029/2003GL017390. 
Silver, P. G., and W. W. Chan (1991), Shear wave splitting and subcontinental mantle deformation, Journal of Geophysical Research: Solid Earth, 96(B10), 1642916454, doi: 10.1029/91JB00899.

Wolfe, C. J., and P. G. Silver (1998), Seismic anisotropy of oceanic upper mantle: Shear wave splitting methodologies and observations, Journal of Geophysical Research: Solid Earth, 103(B1), 749-771, doi: 10.1029/97JB02023.

Yang, Y., and D. W. Forsyth (2006a), Regional tomographic inversion of the amplitude and phase of Rayleigh waves with 2-D sensitivity kernels, Geophys. J. Int., 166(3), 1148-1160, doi:10.1111/j.1365-246X.2006.02972.x.

Yang, Y., and D. W. Forsyth (2006b), Rayleigh wave phase velocities, small-scale convection, and azimuthal anisotropy beneath southern California, J. Geophys. Res., 111, B07306, doi:10.1029/2005JB004180. 


\section{VITA}

Gleb Skobeltsyn was born in Novosibirsk, USSR. He received BS and MS in Geology with an emphasis on Regional Geology from the Department of Geology and Geophysics of Novosibirsk State University in 2002 and 2004, respectively. He focused his undergraduate research on geological mapping of an area located in the Altai Mountains. During his masters research he performed geomorphological mapping and neotectonic analysis in the area adjacent to the epicenter location of the 2003 Altai earthquake $(\mathrm{Mw}=7.3)$. He began his doctoral study at the Department of Geological Sciences of University of Missouri-Columbia in 2007. His research interests include geology, geophysics, seismology, and petroleum geology. 